\title{
Program-assisted analysis of the transverse pressure capacity of block stoppings for mine ventilation control
}

Timothy J. Batchler

West Virginia University

Follow this and additional works at: https://researchrepository.wvu.edu/etd

\section{Recommended Citation}

Batchler, Timothy J., "Program-assisted analysis of the transverse pressure capacity of block stoppings for mine ventilation control" (2008). Graduate Theses, Dissertations, and Problem Reports. 1969.

https://researchrepository.wvu.edu/etd/1969

This Thesis is protected by copyright and/or related rights. It has been brought to you by the The Research Repository @ WVU with permission from the rights-holder(s). You are free to use this Thesis in any way that is permitted by the copyright and related rights legislation that applies to your use. For other uses you must obtain permission from the rights-holder(s) directly, unless additional rights are indicated by a Creative Commons license in the record and/ or on the work itself. This Thesis has been accepted for inclusion in WVU Graduate Theses, Dissertations, and Problem Reports collection by an authorized administrator of The Research Repository @ WVU. For more information, please contact researchrepository@mail.wvu.edu. 


\title{
Program-Assisted Analysis of the Transverse Pressure Capacity of Block Stoppings for Mine Ventilation Control
}

\author{
Timothy J. Batchler
}

\author{
Thesis submitted to the \\ College of Engineering and Mineral Resources \\ at West Virginia University \\ in partial fulfillment of the requirements \\ for the degree of
}

\author{
Master of Science \\ in \\ Mining Engineering
}

Syd S. Peng, Ph.D., Chair

Yi Luo, Ph.D.

Thomas M. Barczak, Ph.D.

Department of Mining Engineering

\author{
Morgantown, West Virginia \\ 2008
}

Keywords: Transverse pressure, Mine ventilation stoppings

Copyright 2008 Timothy J. Batchler 


\begin{abstract}
Program-Assisted Analysis of the Transverse Pressure Capacity of Block Stoppings for Mine Ventilation Control

Timothy J. Batchler

Previously a new test procedure, based on rigid arching, had been developed to determine the true transverse pressure capacity of mine ventilation block stoppings. Using this test procedure, a parametric study of the design parameters was tested to determine the arching capability in block stoppings. Theoretical assessments of arching and design equations were developed creating design guidelines based on the physical properties of the block stoppings. Based on these design guidelines, a computer program was developed to simulate the transverse pressure capacity of mine ventilation block stoppings. Inputs from users will generate a set of representative scenarios simulating a particular system. Users can incorporate block characteristics, mine opening dimensions, mine roof/floor boundary conditions addition of deformable materials and other parameters relevant to the design capabilities of the block stoppings. This program will provide a comparison summary of transverse pressure capacity of various block types under arch loading conditions.
\end{abstract}




\section{Dedication}

This thesis is dedicated to my daughter Marion and my wife Johnna who have supported me all the way since the beginning of my studies and has been a great source of motivation and inspiration. 


\section{Acknowledgements}

From the formative stages of this thesis, to the final draft, I owe an immense debt of gratitude to my supervisor, Dr. Thomas M. Barczak. His sound advice and careful guidance were invaluable.

For their efforts and assistance, a special thanks as well to the Dr. Syd Y. Peng who showed me a lot about the inner workings of ground control. Dr. Yi Luo who went out of his way to help me learn at WVU. Also to Dave Dwyer, Dave Gearhart, Ted Klemetti, Michal Murphy, and many others who helped me in this process. 


\section{Table of contents}

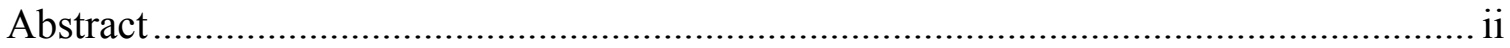

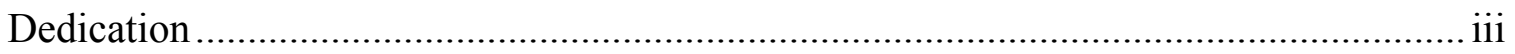

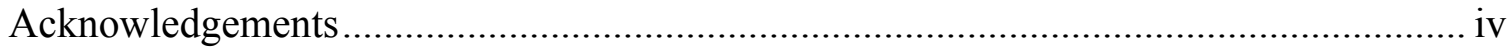

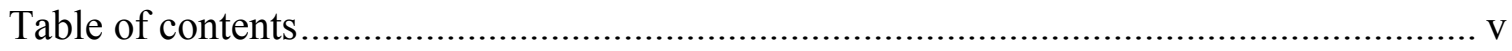

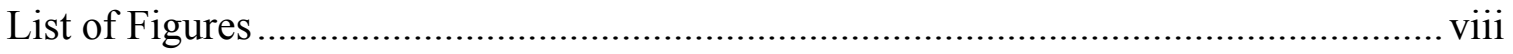

List of Tables ...................................................................................................... Xii

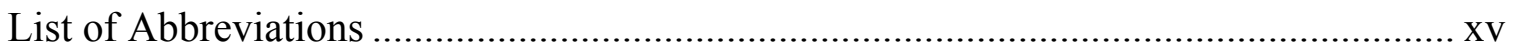

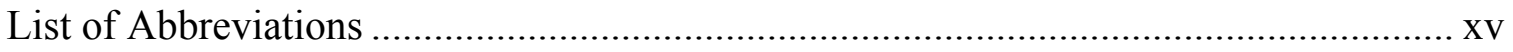

CHAPTER 1 - INTRODUCTION …................................................................... 1

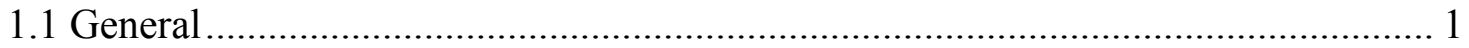

1.2 Thesis Statement .......................................................................................... 2

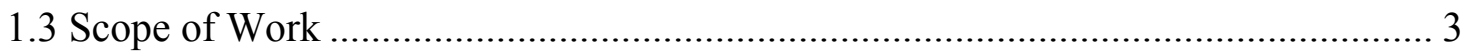

CHAPTER 2 - BACKGROUND INFORMATION .................................................... 5

2.1 REVIEW OF LITERATURE ................................................................ 5

2.2 RIGID ARCH LOADING MECHANISM....................................................... 10

2.2.1 Physical description of arching ............................................................ 10

2.2.2 Transverse pressure design equation for rigid arching ............................ 10

2.3 FACTORS THAT AFFECT THE TRANSVERSE PRESSURE OF MINE

VENTILATION STOPPINGS _.................................................................... 14

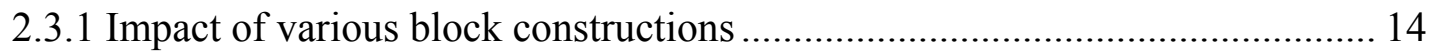

2.3.1.1 Wall Thickness ..................................................................... 15

2.3.1.2 Wall Height .......................................................................... 16 
2.3.2 Impact of lateral wall displacement............................................................. 17

2.3.3 Impact of ground pressures from roof to floor convergence............................. 19

2.3.4 Impact of deformable materials to absorb ground deformation ....................... 22

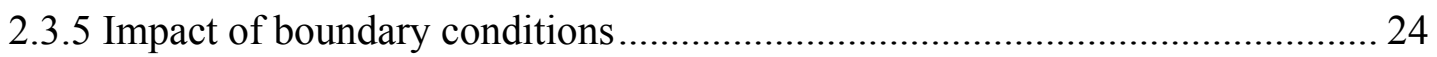

2.4 SIMULATING ARCHING THROUGH BIAXIAL LOADING IN THE MINE

ROOF SIMULATOR

2.4.1 Description of Mine Roof Simulator........................................................... 26

2.4.2 Simulation of rigid arching through biaxial loading ...................................... 27

2.4.3 Simulation of arching with deformable materials ........................................... 28

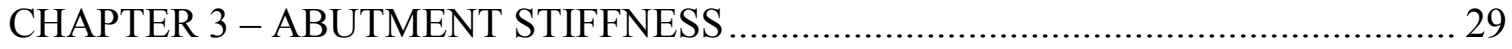

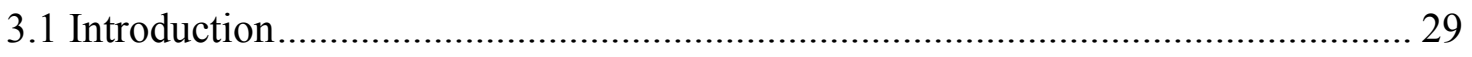

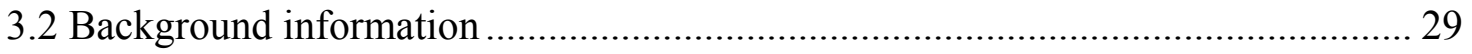

3.3 Impact of deformable materials on transverse pressure .......................................... 30

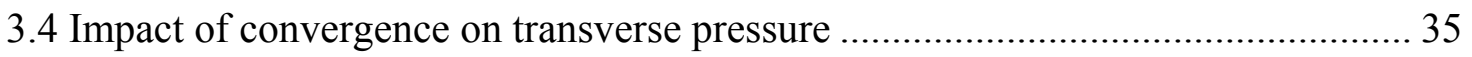

CHAPTER 4 - DEVELOPENT OF A COMPUTER PROGRAM FOR ASSESSMENT

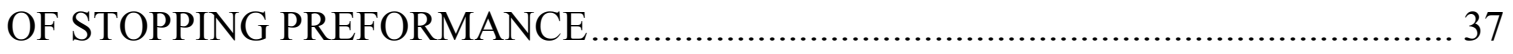

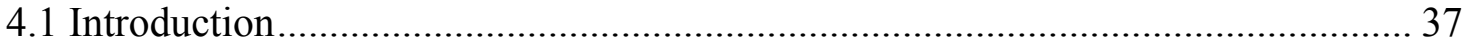

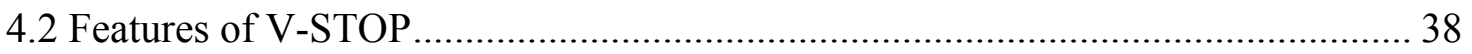

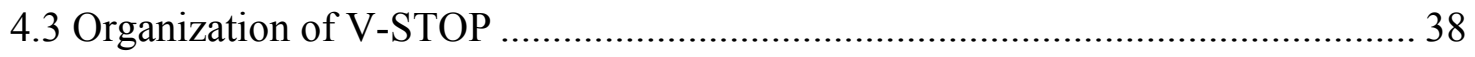

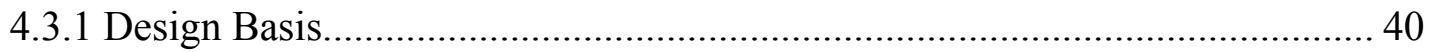

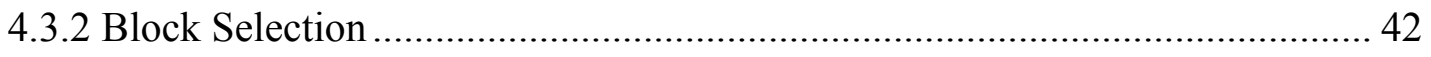

4.3.3 Solution Phase of V-STOP ........................................................................... 46 


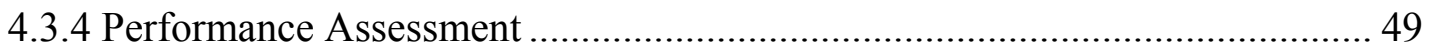

4.3.5 Construction Details.................................................................................. 51

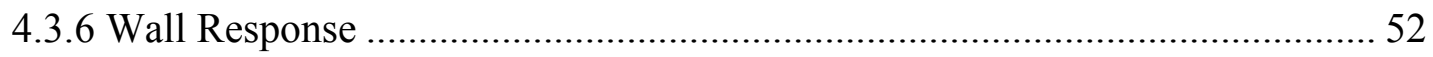

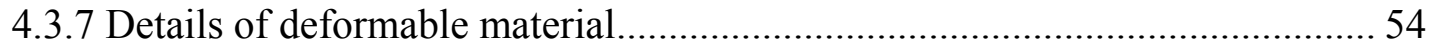

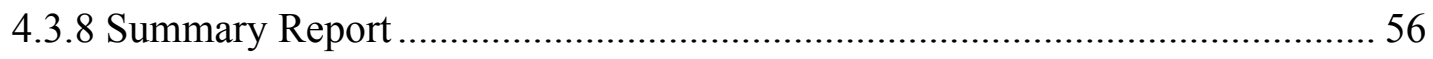

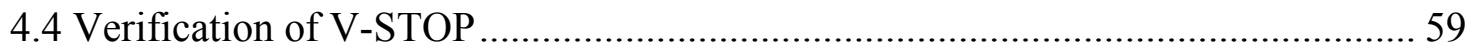

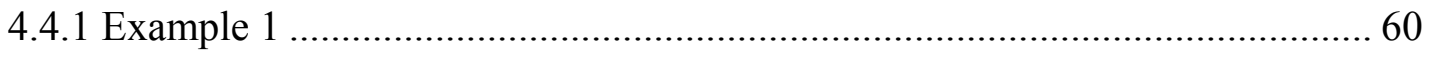

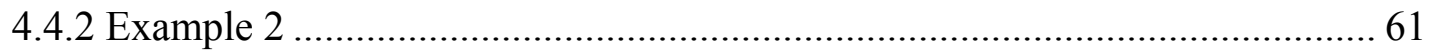

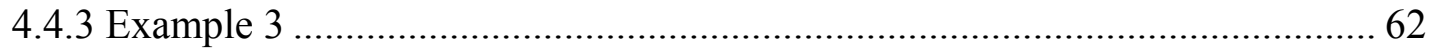

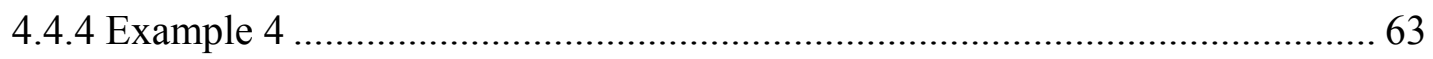

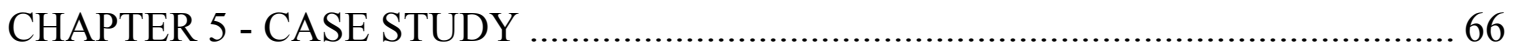

CHAPTER 6 - SUMMARY AND CONCLUSION .............................................. 75

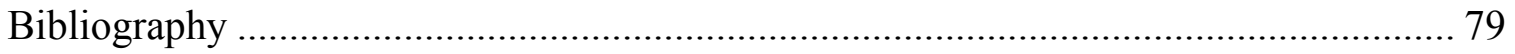

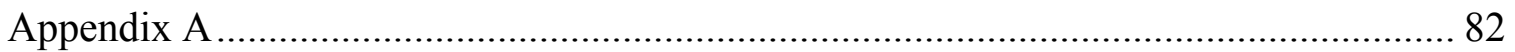

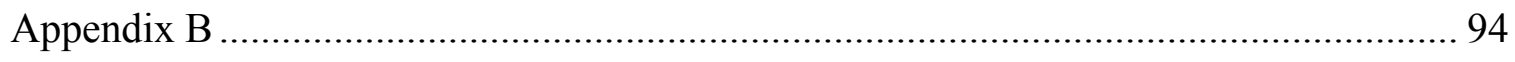

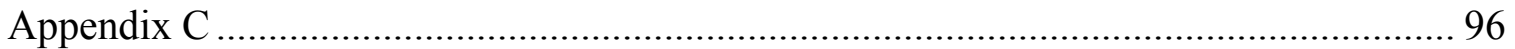

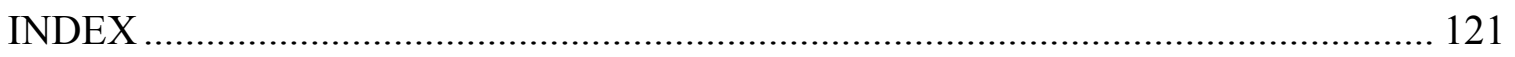




\section{List of Figures}

Figure 1. Free-body diagram related with predictive models shown in tables 1 and $2 \ldots . .7$

Figure 2. Three hinged arch illustration and free body diagram of half-wall................ 11

Figure 3. Examination of the thrust force developed in rigid arch load conditions......... 12

Figure 4. Impact of wall thickness on transverse pressure capacity ............................. 15

Figure 5. Impact of wall height on the transverse pressure capacity ........................... 16

Figure 6. Half-wall statics showing the width of the arching thrust varies as a function of

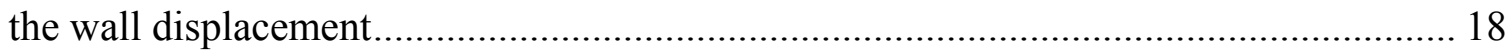

Figure 7. Impact of lateral displacement on transverse pressure capacity..................... 19

Figure 8. Combining arching with axial loading caused by ground pressures

(convergence) moves the resultant arch thrust more towards the centerline of the wall.. 20

Figure 9. Effects of preload (convergence) on the transverse pressure capacity of the wall

Figure 10. The impact on reducing the modulus of elasticity on the transverse pressure

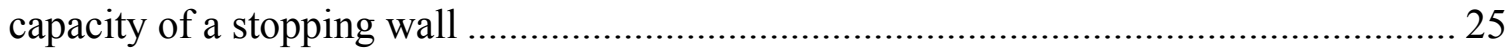

Figure 11. Photo of NIOSH's Mine Roof Simulator................................................. 26

Figure 12. Simulating rigid arching in the NIOSH Mine Roof Simulator....................... 27

Figure 13. Half-wall moment equilibrium equation showing the half-wall geometry .... 28

Figure 14. Deformable material placed at the roof interface in the MRS testing program

Figure 15. Diagram showing that increased lateral displacement of the stopping reduces

the arch thrust which reduces the transverse pressure capacity of the stopping. 
Figure 16. Transverse pressure capacity is reduced as the lateral displacement of the wall increases. 33

Figure 17. Lateral displacement decreases as the modulus of elasticity of the deformable material of the wall increases, causing an increase in system modulus. 34

Figure 18. Transverse pressure capacity is increase as the system stiffness of the material of the wall increases due to the use of a higher modulus strain-softening. 35

Figure 20. Design Basis window for V-STOP showing the design criteria for the stopping and properties of the mine boundary conditions. 40

Figure 21. Block Selection window for V-STOP allows the user to add/modify blocks for analysis.

Figure 22. Block window for V-STOP allow user to select from block categories and add deformable materials. 43

Figure 23. Wedges placed on high pressure side (A) and low pressure side (B).......... 46

Figure 24. Flowchart of V-STOP calculations for transverse load capacity solution. .... 48 Figure 25. Performance Assessment window for V-STOP simulates peak transverse pressure capacity for selected block. 49

Figure 26. Construction Details window for V-STOP for selected block.................... 51

Figure 27. Wall Response window displaying the height variable for V-STOP........... 52

Figure 28. Wall Response window displaying the thickness variable for V-STOP ....... 53

Figure 29. Wall Response window displaying the surface contact in V-STOP ............. 53

Figure 30. Transverse pressure vs. preload comparison with 2-in foam layer. .............. 54

Figure 31. Transverse pressure vs. convergence comparison with 2-in foam layer....... 55 
Figure 32. Summary window displaying the Comparison of selected ventilation blocks.

Figure 33. Summary window displaying the Plot of selected ventilation blocks. 57

Figure 34. Summary window displaying the Chart of selected ventilation blocks 58

Figure 35. Comparison of CMU half-wall rigid-arch test in MRS to V-STOP simulation.

Figure 36. Comparison of Cellular half-wall rigid-arch test in MRS to V-STOP

simulation.

Figure 37. Comparison using deformable material (foam) on a CMU half-wall arch test

to V-STOP simulation.

Figure 38 Comparison using deformable material (wood) on a CMU half-wall arch test to V-STOP simulation.

Figure 39. Design criteria, construction dimensions, and boundary conditions entered into V-STOP. 66

Figure 40. Standard CMU block parameters used for an example mine ventilation stopping

Figure 41. The green highlighted area on the graph shows that the standard CMU wall is able to withstand the 0.5 inch convergence design criteria. 68

Figure 42. The red highlighted are demonstrates that the standard CMU wall can withstand the 5 psi design criteria after initial preloading. 68

Figure 43. CMU block rotated to a thickness of 7.5-in to meet design criteria of 5-psi. 69

Figure 44. Foam block stopping wall able to withstand 0.5 -in of convergence. 70

Figure 45. Foam block stopping wall unable to meet design criteria of 5-psi. 70 
Figure 46. Plot of various stoppings wall for comparison.

Figure 47. Convergence plot of a 2.1-in polystyrene foam layer added to standard CMU stopping wall to increase the stopping wall ability to withstand 2-in of convergence. .... 73 Figure 48. The transverse pressure capacity reaction of a standard CMU stopping to a polystyrene foam layer.

Figure 49. A 60-in wood layer added to a standard CMU stopping to reach the design criteria of 2-in of convergence. (A -Transverse load vs Convergence : B - Transverse load vs Preload)..... Error! Bookmark not defined.

Figure 50. MTS Rock Mechanics load frame. 114 


\section{List of Tables}

Table 1. Predictive models to define the transverse pressure capacity.......................... 8

Table 2. Prediction of the transverse pressure capacity of stoppings ............................. 9

Table 3. Material properties of deformable material .................................................. 31

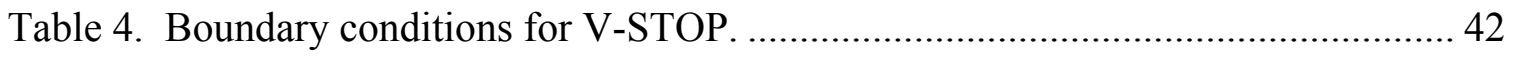

Table 5. Multivariable regression analysis for determining thrust position factor for

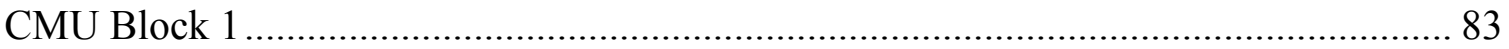

Table 6. Multivariable regression analysis for determining lateral displacement for CMU

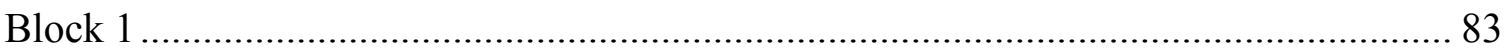

Table 7. Multivariable regression analysis for determining thrust position factor for

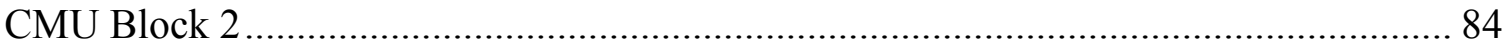

Table 8. Multivariable regression analysis for determining lateral displacement for CMU

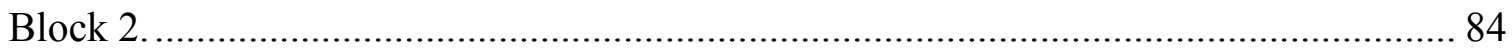

Table 9. Multivariable regression analysis for determining thrust position factor for

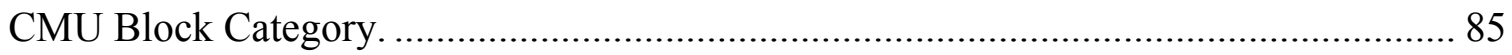

Table 10. Multivariable regression analysis for determining lateral displacement for

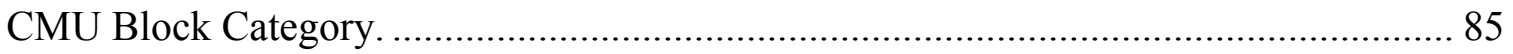

Table 11. Multivariable regression analysis for determining thrust position factor for

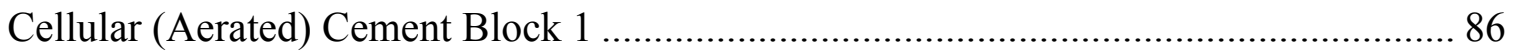

Table 12. Multivariable regression analysis for determining lateral displacement for

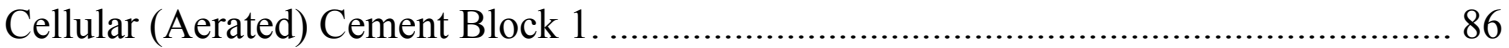

Table 13. Multivariable regression analysis for determining thrust position factor for

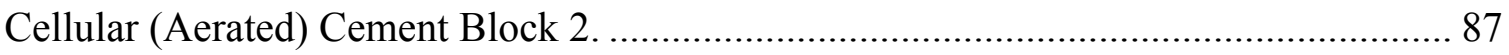


Table 14. Multivariable regression analysis for determining lateral displacement for

Cellular (Aerated) Cement Block 2.

Table 15. Multivariable regression analysis for determining thrust position factor for

Cellular (Aerated) Cement Block 3.

Table 16. Multivariable regression analysis for determining lateral displacement for

Cellular (Aerated) Cement Block 3.

Table 17. Multivariable regression analysis for determining thrust position factor for

Cellular (Aerated) Cement Block Category.

Table 18. Multivariable regression analysis for determining lateral displacement for

Cellular (Aerated) Cement Block Category.

Table 19. Multivariable regression analysis for determining thrust position factor for

Hollow Block 1 and Hollow Block Category.

Table 20. Multivariable regression analysis for determining lateral displacement for

Hollow Block 1 and Hollow Block Category....

Table 21. Multivariable regression analysis for determining thrust position factor for

Extruded Block 1 and Extruded Block Category.....

Table 22. Multivariable regression analysis for determining lateral displacement for

Extruded Block 1 and Extruded Block Category

Table 23. Multivariable regression analysis for determining thrust position factor for

Foam Block 1 and Foam Block Category.

Table 24. Multivariable regression analysis for determining lateral displacement for

Foam Block 1 and Foam Block Category. 
Table 25. Multivariable regression analysis for determining thrust position factor for Other Block Category.

Table 26. Multivariable regression analysis for determining lateral displacement for Other Block Category. 93 


\section{List of Abbreviations}

psf - pounds per square foot

psi - pounds per square inch

lbs - pounds

kips - measure of force equating to 1,000 pounds

in - inch

$\mathrm{ft}-$ feet

mils - thousands of an inch

pct - percent

sq $\mathrm{ft}$ - square feet

cu ft - cubic feet

in $^{2}-$ square inches

$\mathrm{ft}^{2}-$ square feet

$\mathrm{lbs} / \mathrm{ft}^{3}$ - pounds per cubic feet 


\section{CHAPTER 1 - INTRODUCTION}

\subsection{General}

Mine ventilation is responsible for the circulation of air, in both amount and direction, throughout the mine. Air must be brought and removed from the working areas and the volume and quality of air must be adequate to insure proper working conditions for the workers. Control devices maintain this airflow throughout the ventilation system.

A ventilation stopping is one example of an airflow control device. It is typically a dry-stacked concrete block wall erected between intake and return airways to direct ventilation air throughout the working sections of underground coal mines. Stoppings are designed primarily to withstand air pressure differentials (transverse pressure) generated by mine fans or extraneous events, such as roof falls and gas ignitions. Excessive pressures can cause failures of the ventilation stoppings that can disrupt the entire mine ventilation system.

Previous research has shown that many factors determine the transverse pressure capacity of a ventilation stopping wall and design guidelines were then developed to predict the transverse pressure capacity based on mine dimensions and block characteristics. Stoppings are typically constructed of concrete or cinder blocks; however there is now a new generation of lightweight blocks available. The introduction of this new generation of blocks creates a large range of transverse pressure capacities for stoppings. As the modulus of elasticity of the block increases, the ability of the stopping to resist transverse pressure also increases. By design, stoppings are very stiff structures that can absorb very little deformation prior to compressive loading failures. In order to 
prevent premature failure from convergence, deformable materials can be incorporated into the stopping construction. Although deformable materials can be effective in enhancing the yield capability of the wall and extending the service life of the stopping in response to the closure of the mine opening, they can significantly reduce the capacity of a stopping to resist transverse pressure. Similarly, the abutment stiffness of the roof/floor can have a major impact on the transverse pressure capacity. When the modulus of elasticity for the roof/floor is reduced, the transverse pressure capacity of the stopping is also likely to be reduced.

New guidelines were designed to incorporate the impact of the deformable material component into the transverse pressure capacity of mine ventilation stoppings. Based on new/revised design guidelines, a computer program was developed to analyze the transverse pressure capacity of mine ventilation block stoppings. This software will assist the user in making engineering decisions regarding the selection and orientation of block materials for stopping construction to meet specific design criteria. The software will include a database of several currently used block characteristics and loading profiles obtained through performance testing of these stoppings at the National Institute for Occupational Safety and Health (NIOSH) Mine Roof Simulator Facility. This software can provide an engineering foundation to ensure that inadequate stopping designs as well as ultra conservative stopping applications are avoided. Safety will be improved by properly matching the ventilation stopping performance to the mine conditions.

\subsection{Thesis Statement}

The first objective of this thesis is to develop additional design guidelines for incorporating deformable materials and variable boundary conditions into ventilation 
stopping construction. The second is to create a computer program analyze the transverse pressure capacity of mine ventilation block stoppings under such loading conditions. Users can incorporate block characteristics, mine opening dimensions, mine roof/floor boundary conditions, deformable materials, and additional parameters to evaluate the design capabilities of the block stoppings. This program also provides a summary to compare the performance at various transverse pressure conditions.

\subsection{Scope of Work}

This thesis will quantify the impact of various deformable materials in block stopping constructions under transverse pressure conditions. Adding a deformable material to a stopping construction can prevent premature failure due to convergence, but will degrade the transverse capacity of the stopping under arch loading conditions. Safety will be improved by properly matching the stopping performance to mine conditions.

Creating a computer program will assist in making engineering decisions regarding the selection of mine ventilation stoppings. The software will analyze transverse pressure capacity so users can see firsthand the impact that block selection or deformable materials can have on the stopping wall capacity. Calculating the transverse pressure capacity is complex and involves many variables (block type, and material properties, including modulus of elasticity and compressive strength, mine height and width, boundary stiffness, wall thickness, deformable materials, etc.). A user-friendly interface program will prompt the user to select variables and for analysis of the transverse pressure of a stopping wall. The use of lighter weight blocks are used to reduce material handling injuries associated with stopping construction. This program 
incorporates this factor. Comparisons show the performance of different stopping designs and allow the user to select the best design for their mine conditions. 


\section{CHAPTER 2 - BACKGROUND INFORMATION}

\subsection{REVIEW OF LITERATURE}

For more than 6,000 years, forms of masonry have been used in some of the world's most significant architectural achievements. The Great Wall of China, Egyptian Pyramids, and the Colosseum in Rome are all prime examples of man made structures that used masonry in their construction. The name "masonry" means the building of structures from individual units laid in and bound together by mortar, and the term "masonry" can also refer to the units themselves. The first concrete blocks were molded in the early 1880s and since that time the industry have made great strides in the volume of units produced, in the variety of the blocks available and in the quality of the products. Today, more than two-thirds of the volume of all masonry walls being constructed is made up of concrete block of one kind or another. (Smith, 1979) Mine ventilation stoppings are typically dry-stacked concrete block walls and although not usually mortared, they can fit into a classification with masonry blocks.

According to McDowell (1956), the arching behavior of masonry walls was first considered by the Armor Research Foundation in 1951, in connection with work sponsored by the Air Force and technically monitored by the Special Studies Office of the Installation Division, Air Materiel Command. McDowell proposed a theory to explain and predict the relative great strength of masonry walls constructed between essentially rigid supports. Under certain conditions, masonry wall have been known to withstand much larger lateral loads than would be predicted on a basis of conventional bending analyses. McDowell suggest that the arching theory proposed in his paper assumes the resistance of the wall to lateral loads is due entirely to forces set up in the plane of the 
panel (wall) as the result of the tendency of the masonry material to be crushed at mid span and at the end of the supports. McDowell concluded that the arching theory represents an extreme idealization of the behavior of end-restrained masonry beam, both with respect of the geometry and of the motion and the stress-strain properties of the material.

Anderson (1984) presented a theory for predicting the behavior of one-way spanning unreinforced masonry subjected to transverse lateral pressure in which arching action may develop within the wall thickness. Anderson compared the behavior of the wall prior to cracking and post-cracking and demonstrated the effects of movements trains, abutment stiffness, and material properties of the strength. Anderson conducted a series of tests which determined that masonry walls are acceptable of carrying arching action within their thickness and have a resistance for transverse lateral pressure significantly in excess of their strength as flexural panels. He concluded that arching action should only be used in design when the stiffness of the abutments is known and can be relied on, where realistic estimates of dimensional changes can be made, where alterations to the wall that might affect the arching action are unlikely, and where the material properties and good workmanship are guaranteed.

Dysdale (1994) also address the impact of flexural behavior of unreinforced walls and describes why it is instructive to study the wall's behavior when subjected to increasing wind pressure (transverse pressure). He describes that the failure mechanism can be quite complex and depends upon the type of support provided at the top and bottom edges and the magnitude of axial forces form the self-weight and any superimposed loads. Initially, any tensile stresses that tend to develop from bending of 
the wall will be suppressed by the compressive stress due to the weight of the wall. Dysdale also considers the effect of superimposed load from a roof or floor. Additional axial load delays cracking at the base and elsewhere due to a pre-compressing effect, but after cracking of the base the counteracting moment due eccentricity of the base reaction further increases the lateral load that must be applied to cause cracking near mid-height.

In Barczak (2005) dissertation, a parametric analysis of the arching condition for a ventilation stopping was examined to develop a theoretical relationship for predicting the transverse pressure capacity. This analysis used a newly developed lab testing protocol to simulate arching of stopping wall by biaxial loading. The study indicated that block characteristics (block thickness, wall height, etc) and arching mechanics have a significant impact on transverse pressure capacity of the ventilation stopping (Figure 1). Using this analysis several different models were developed to predict transverse pressure. The two models in Table 1 utilized either the measured arch thrust or the measured lateral displacement to predict the laboratory arch test results.

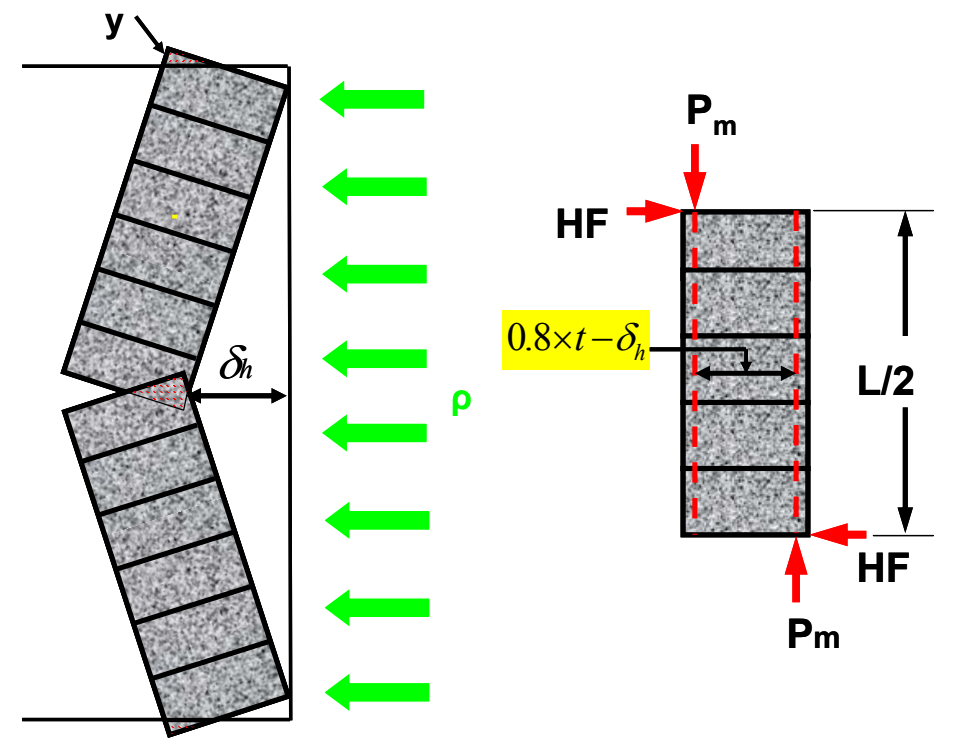

Figure 1. Free-body diagram related with predictive models shown in tables 1 and 2 (after Barczak 2005). 
Table 1. Predictive models to define the transverse pressure capacity.

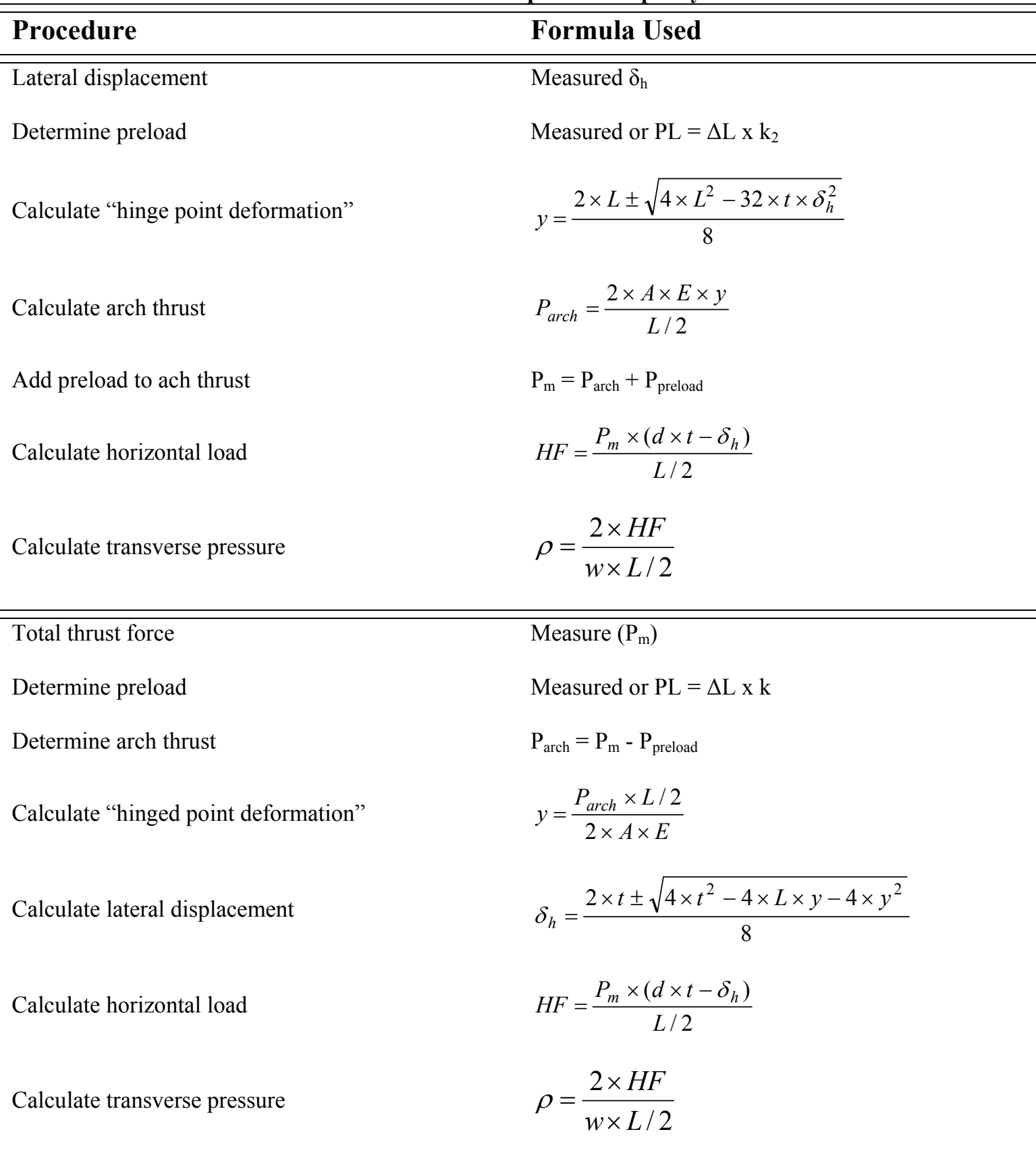

Where

$$
\begin{aligned}
& P L=\text { Preload, psi } \\
& L=\text { height of section of wall that arches, in } \\
& k=\text { stiffness constant of wall, lbs/in } \\
& y=\text { deformation in each of two crush zones on half-wall section, in } \\
& t=\text { wall thickness, in }
\end{aligned}
$$


$\delta_{\mathrm{h}}=$ lateral displacement of wall at mid span, in

$\mathrm{P}_{\mathrm{arch}}=$ arch thrust, lbs

$\mathrm{A}=$ axial loading area of the wall, in $^{2}$

$\mathrm{E}=$ elastic modulus, psi

$\mathrm{P}_{\mathrm{m}}=$ total thrust load, lbs

$\mathrm{P}_{\text {preload }}=$ thrust generated from preload, lbs

$\mathrm{d}=$ position factor for resultant arching thrust,

$\mathrm{HF}=$ Horizontal force, $\mathrm{psi}$

$\mathrm{w}=$ wall width, in

$\rho=$ transverse pressure, $p s i$

Further refinement of the methods would allow these measurements (lateral displacement and arch load) to be estimated and then used these refined models to predict transverse pressure capacity. The new methods are based on block characteristics and preload pressure (convergence) and a multivariable regression analysis of the test data.

Table 2 shows an example of Hybrid Theoretical Lateral Displacement Model.

Table 2. Prediction of the transverse pressure capacity of stoppings

\begin{tabular}{ll}
\hline \hline Procedure & Formula Used \\
\hline Determine lateral displacement & $\begin{array}{l}\text { Multivariable regression analysis relating } \\
\text { displacement to } \mathrm{E}^{*}(\mathrm{t} / \mathrm{L})^{2} \text { and preload }\end{array}$ \\
Determine preload & Measured or $\mathrm{PL}=\Delta \mathrm{L} \times \mathrm{k}_{2}$ \\
Calculate "hinge point deformation" & $y=\frac{2 \times L \pm \sqrt{4 \times L^{2}-32 \times t \times \delta_{h}^{2}}}{8}$ \\
Calculate arch thrust & $P_{\text {arch }}=\frac{2 \times A \times E \times y}{L / 2}$ \\
Add preload to arch thrust & $\mathrm{P}_{\mathrm{m}}=\mathrm{P}_{\text {arch }}+\mathrm{PL}$ \\
Calculate horizontal load & $H F=\frac{P_{m} \times\left(d \times t-\delta_{h}\right)}{L / 2}$ \\
Calculate transverse pressure & $\rho=\frac{2 \times H F}{w \times L / 2}$ \\
\hline
\end{tabular}




\subsection{RIGID ARCH LOADING MECHANISM}

\subsubsection{Physical description of arching}

Barczak (2006) describes rigid arching loading as the mechanism that occurs when the curvature of the stopping, specifically the extension of the tension face of the stopping, as it bends under the application of transverse pressure is prevented by the rigid contacts of the mine roof and floor. This arching of the wall produces a thrust force that acts at the mine roof and floor interface, and produces compressive forces within the wall that can dramatically increase the transverse pressure capacity of the wall compared to a freestanding condition. In the unloaded or minimally transverse pressure condition, the ends of the wall are in full contact with the mine roof and floor and the individual horizontal joints between the courses of block are in full contact with each other. As the transverse pressure increases, the wall will begin to flex or bend. Associated with the bending will be the opening of the block joints along the mid height span of the wall (location of the maximum positive movement), and the opening of the interfaces between the blocks and the mine roof and floor (location of the maximum negative movement). This resistance of the walls to transverse forces as a result of the masonry material to be crushed at mid-span and the end supports creates a three-hinged arch and is referred to as rigid arch loading.

\subsubsection{Transverse pressure design equation for rigid arching}

A three-hinged arch is formed where the external moment caused by the transverse pressure ( $\mathrm{w} \times \rho \times \mathrm{L} 2 / 8$ term in equation 1 ) is resisted by the internal force couple ( $\mathrm{P} \times \mathrm{r}$ ), where " $\mathrm{r}$ " is defined as the width of the arch and "P" is the thrust force 
generated by the arching. This condition is illustrated in the free-body diagram in Figure 2 and expressed mathematically by equation 2 . This equation can then be solved for the transverse pressure $(\rho)$ as shown in equation 3.

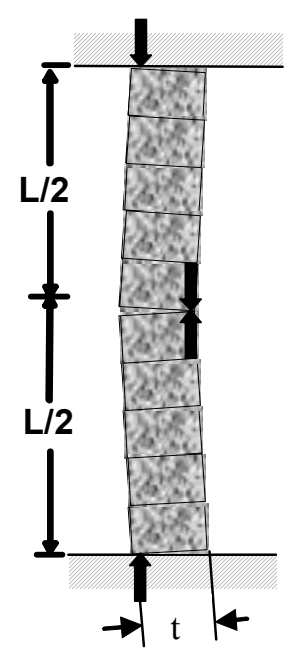

Full-wall

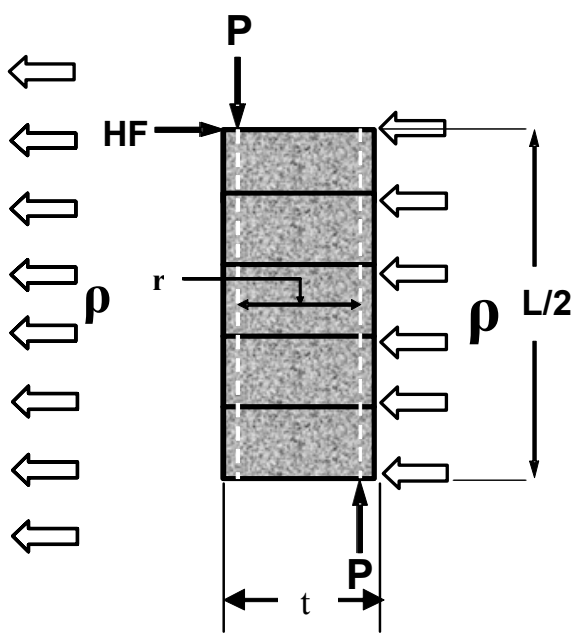

Half-wall

Figure 2. Three hinged arch illustration and free body diagram of half-wall (after Barczak 2005).

$$
\begin{aligned}
& \int_{0}^{\mathrm{L} / 2} \mathrm{~W} \times \mathrm{y} \times \rho \times \mathrm{dy}=\mathrm{w} \times \frac{\mathrm{y}^{2}}{2} \times\left.\rho\right|_{0} ^{\mathrm{L} / 2}=\frac{\mathrm{w} \times \mathrm{L}^{2}}{8} \times \rho \\
& \frac{w \times \rho \times L^{2}}{8}=P \times r \\
& \rho=\frac{8 \times P \times r}{w \times L^{2}}
\end{aligned}
$$

If it is assumed that the arching thrust (P) is controlled by the compressive strength of the block material and the "crush zone" is acting over an area of the block equal to $2 / 10$ the thickness of the wall (see Figure 3), then an expression for "P" can be derived as given in equation 4. As shown in Figure 3, this assumption also results in the 
width of the pressure arch (r) being equal to $0.8 \mathrm{x}$ t. Substituting this expression for " $\mathrm{r}$ " and the expression for "P" from equation 4 into equation 3 yields a solution for determining the transverse pressure capacity of a stopping wall (equation 5).

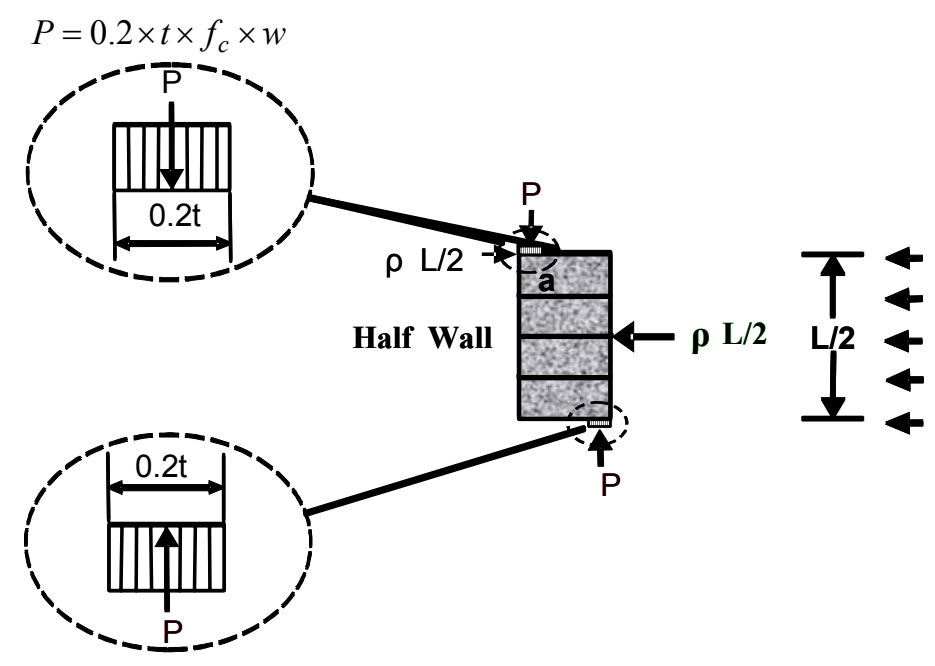

Figure 3. Examination of the thrust force developed in rigid arch load conditions.

$$
\rho=1.28 \times f_{c} \times\left(\frac{t}{L}\right)^{2}
$$

Where $\quad f_{c}=$ compressive strength, psi

An example is considered using a 6-in thick wall that is 72-in high and constructed from concrete blocks with a compressive strength of 1,000 psi. The term $f_{c} x$ $(\mathrm{t} / \mathrm{L})^{2}$ equates to $6.94 \mathrm{psi}$ for this example, which computes a predicted transverse pressure capacity of 8.9 psi or 1,279 psf.

Using moment equilibrium relationships based at the upper left corner of the wall (Figure 3), it can be shown that the transverse pressure acting on a full-scale stopping can be computed from the measured horizontal force (HF) at the base of a half-wall as used in the MRS laboratory testing from equation 6 , where " $w$ " is the width of the wall and " $L / 2$ " is the half-wall height. 


$$
\rho=\frac{2 \times H F}{w \times(L / 2)}
$$

A relationship between lateral displacement and transverse pressure can be developed from Figure 2. In Figure 2, the equivalent horizontal force is shown acting on edge of the wall while the resultant arching thrust is acting perpendicular to the horizontal force. As the wall rotation increases the lateral displacement will increase decreasing the horizontal force as shown in equations $7 \mathrm{a}, 7 \mathrm{~b}, 7 \mathrm{c}$, and 8 .

$$
\begin{aligned}
& \sum M=0=P \times r-H F \times \frac{L}{2}=P(0.8 \times t-\delta h)-H F \times \frac{L}{2} \\
& P \times\left(0.8 \times t-\delta_{h}\right)=H F \times \frac{L}{2} \\
& H F=\frac{P \times\left(0.8 \times t-\delta_{h}\right)}{\frac{L}{2}} \\
& \rho=\frac{2 \times P \times\left(0.8 \times t-\delta_{h}\right)}{w \times\left(\frac{L}{2}\right)^{2}}
\end{aligned}
$$




\subsection{FACTORS THAT AFFECT THE TRANSVERSE PRESSURE OF MINE VENTILATION STOPPINGS}

\subsubsection{Impact of various block constructions}

There are a variety of concrete blocks available in a wide range of types, sizes, and shapes. The physical properties of the concrete blocks, such as compressive strength, effective modulus, and weight, can all contribute to the transverse pressure capacity of a mine ventilation stopping wall. By examining the transverse pressure capacity design equation developed previously, several parameters affect the transverse pressure of mine ventilation stoppings under aching loading conditions. 


\subsubsection{Wall Thickness}

The transverse pressure capacity is directly related to the thickness of the ventilation stopping wall. Ultimately, the thickness of the wall determines the arch thrust moment arm, which is the distance between the resultant thrust hinge points as represented by the factor $\left(0.8 \times \mathrm{t}-\delta_{\mathrm{h}}\right)$. Show in Figure 4 by increasing the thickness of the wall will increase the transverse pressure capacity using equation 8 .

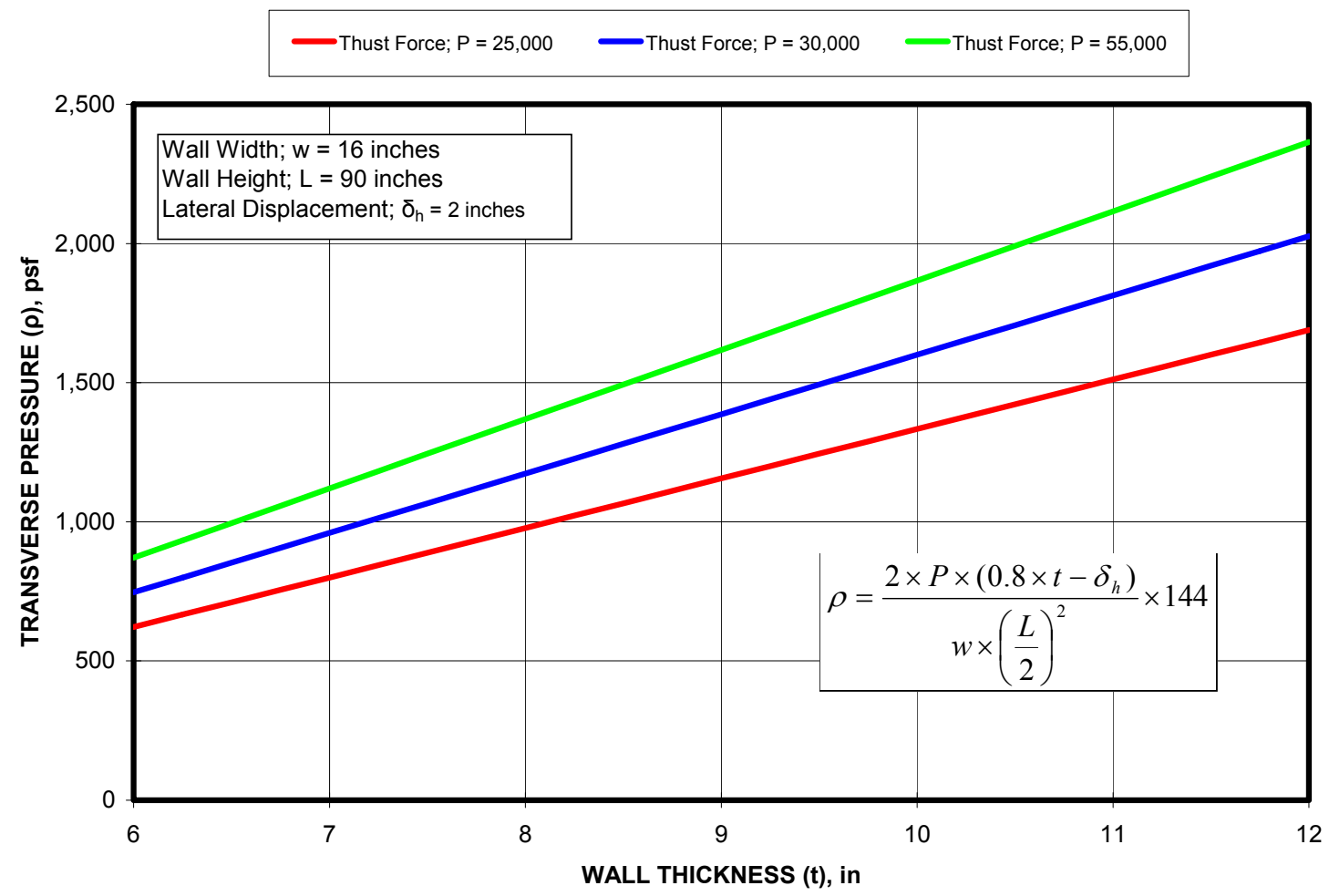

2005).

Figure 4. Impact of wall thickness on transverse pressure capacity (after Barczak 


\subsubsection{Wall Height}

The wall height is also a critical parameter for the transverse pressure capacity of the stopping wall. An increase in wall height causes a significant reduction in the transverse pressure capacity of a mine ventilation stopping. The transverse pressure varies inversely with the square of the half-wall height because of the moment equilibrium requirements. The impact of the wall height will be greater for shorter heights and become less of a factor as the wall height increases. Using equation 8 we can demonstrate the theoretical relationship of varying the wall height in a stopping (Figure $5)$.

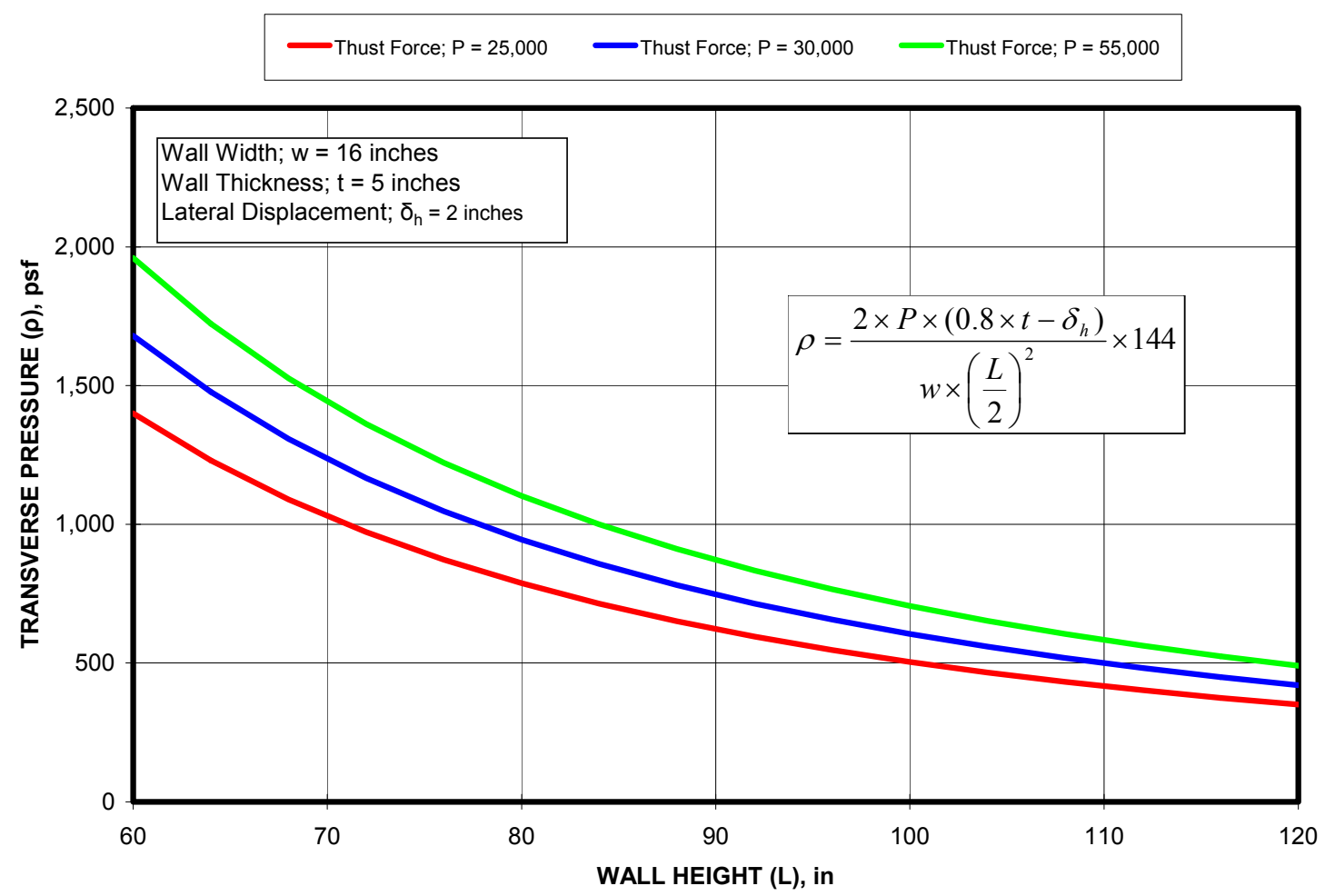

Figure 5. Impact of wall height on the transverse pressure capacity (after Barczak 2005). 


\subsubsection{Block Strength}

The compressive strength and the elastic modulus of the block play important roles in defining the transverse pressure capacity of a mine ventilation stopping. The material modulus along with the boundary stiffness controls the lateral displacement of the wall. In general, the lateral displacement will increase as the modulus decreases causing a reduction in the transverse pressure capacity. The transverse pressure capacity will be greater for higher modulus materials for a wall of a given geometry (thickness and height). It is possible that the maximum transverse pressure capacity can be reached without the block material failing, particularly if the boundary stiffness allows excessive lateral displacement. Also, masonry materials are assumed to have not strength recovery properties beyond the elastic range. Whenever the crushing strength is exceeded and the strain decreases, the drops to zero. (McDowell)

\subsubsection{Impact of lateral wall displacement}

When sufficient transverse pressure is applied to mine ventilation stopping, rigid arching can occur creating a curvature of the stopping and/or a three-hinged mechanism. As the wall rotates, the mid-span of the wall will move laterally creating a lateral displacement $\left(\delta_{\mathrm{h}}\right)$. This lateral displacement of the wall is controlled by the stiffness and elastic response of the block wall. The transverse pressure capacity will decrease as the wall stiffness decreases since more lateral displacement will occur (Barczak, 2008). Figure 6 shows the free body diagram of a half-wall from Figure 2. By summing the moments about the top left corner, equation 9 can be produced showing the relationship between the thrust load $(\mathrm{P})$, horizontal force $(\mathrm{HF})$, and the lateral displacement $\left(\delta_{\mathrm{h}}\right)$. 


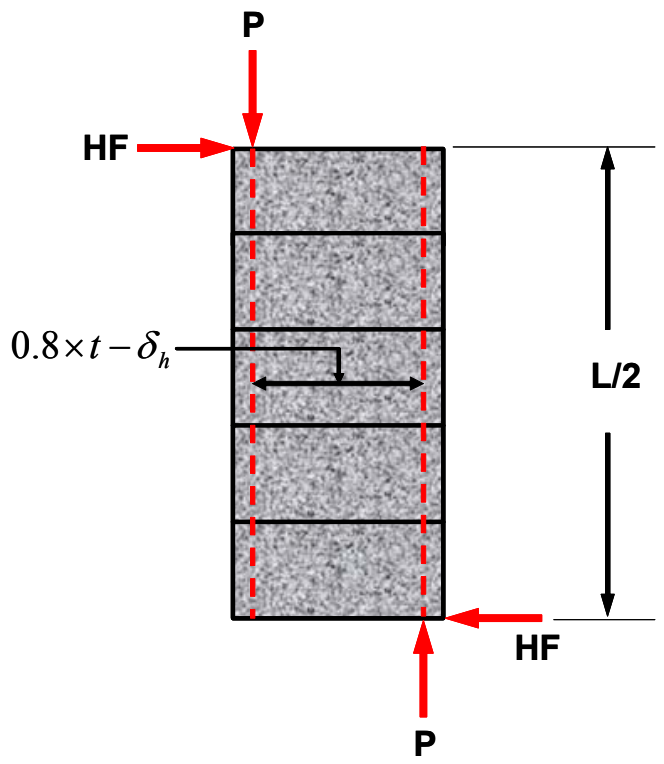

Figure 6. Half-wall statics showing the width of the arching thrust varies as a function of the wall displacement (after Barczak 2005).

$$
\begin{aligned}
& P \times\left(0.8 \times t-\delta_{h}\right)=H F \times L / 2 \\
& \rho=\frac{2 \times H F}{w \times \frac{L}{2}} \times 144
\end{aligned}
$$

Equation 10 computes the transverse pressure $(\rho)$ by dividing the horizontal force acting on the half-wall by the area of the wall. By integrating these two formulas equation 11 shows expression for the transverse pressure as a function of the lateral displacement of the wall.

$$
\rho=\frac{2 \times P \times\left(0.8 \times t-\delta_{h}\right)}{w \times\left(\frac{L}{2}\right)^{2}} \times 144
$$

Figure 7 shows the impact of the lateral displacement of the stopping wall on the transverse pressure capacity. This figure shows the transverse pressure decreases with increasing of lateral displacement of the wall. For this example a stopping wall with a thickness of 6 inches was used. Based on equation 11, at 4.8 inches of lateral 
displacement the transverse pressure capacity would be zero due to the moment arch and stability of the wall.

In Figure 7, the lateral displacement is governed by the physical geometry of the wall, however it can be influenced by the surrounding roof and floor boundaries and physical properties of the wall itself. This will be described in sections 4.3 and 4.4.

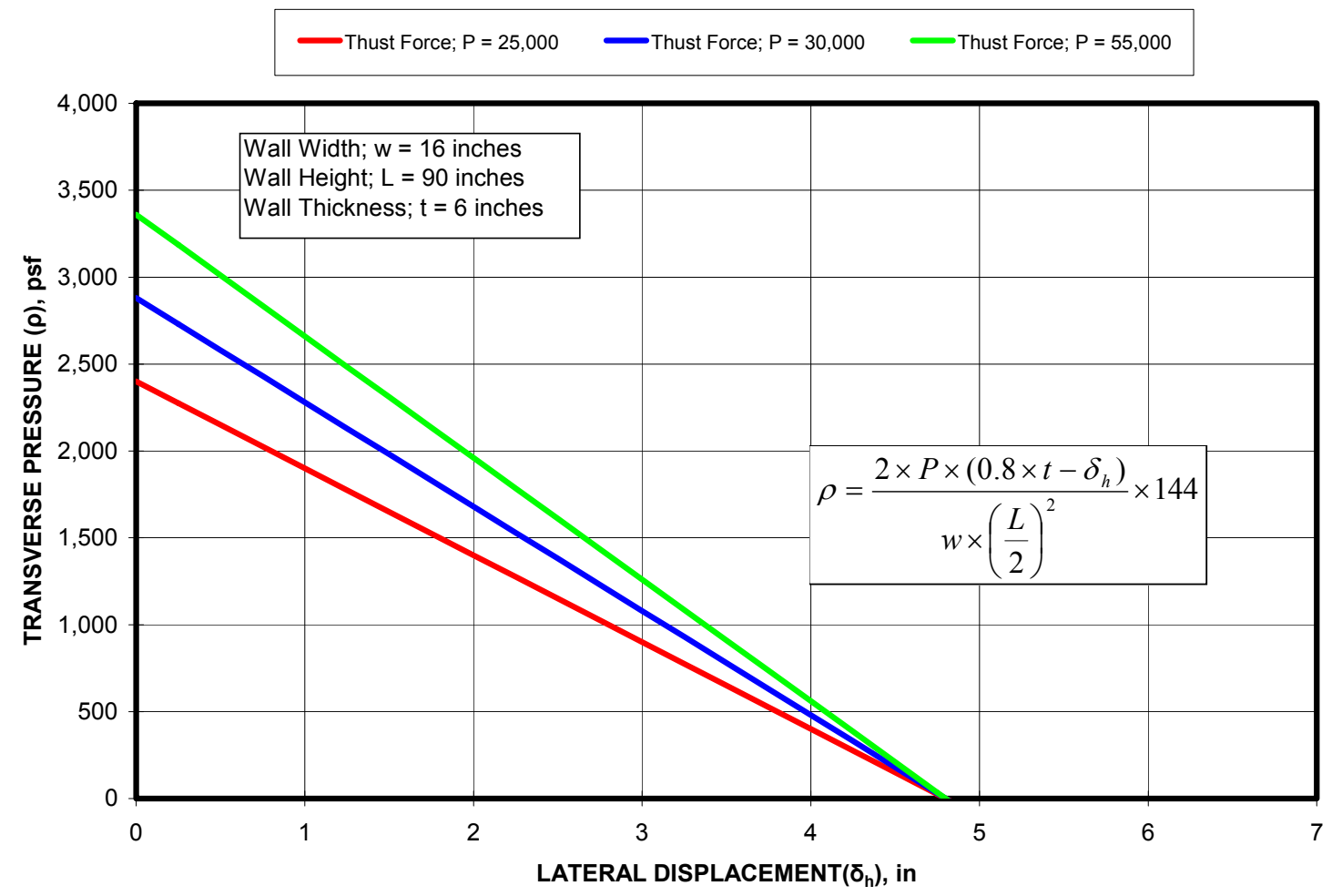

Figure 7. Impact of lateral displacement on transverse pressure capacity(after Barczak 2005).

\subsubsection{Impact of ground pressures from roof to floor convergence}

Although they are not intended for ground support, block stoppings can resist vertical loads of at least 607 to 674 kips (Oyler, 2002). The convergence causes increased vertical thrust on the wall that makes it more difficult for the transverse pressure to offset the moment induced by the thrust force to cause the wall to deflect outward, thus 
resulting in higher transverse pressure capacity. This benefit from the convergence will be lost once the block strength is reached.

Barczak addressed how arching relies on the force couple developed from the thrust load to provide the transverse pressure capacity in a stopping wall (Barczak, 2005). When ground pressure is applied to a stopping it can be assumed that a uniform load distribution is acting on the top and bottom contact surfaces of the wall. The resultant load under these conditions is acting along the centerline of the wall thickness. In the arching analysis, the resultant thrust load from the arching was assumed to act a distance of one-tenth the wall thickness from the edge of the block. When these two loading elements, arching thrust and ground pressure, are combined the resultant load will act somewhere between the two, moving toward the block centerline as the magnitude of the ground increases (Figure 8).

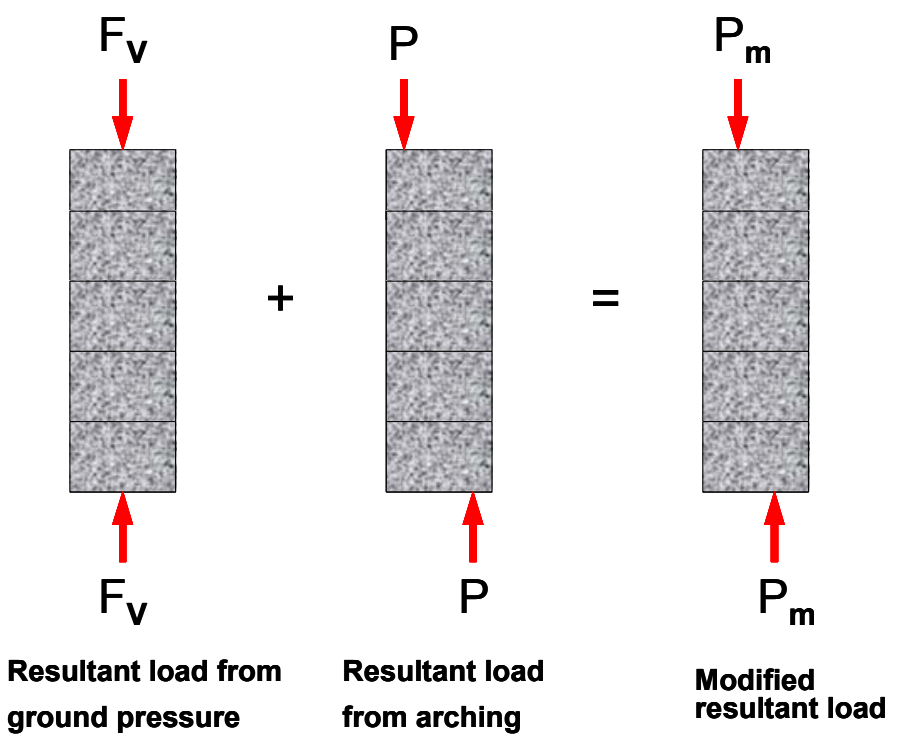

Figure 8. Combining arching with axial loading caused by ground pressures (convergence) moves the resultant arch thrust more towards the centerline of the wall (after Barczak 2005). 
To solve for the location of the resultant thrust force equation 11 has to be evaluated. Previously with no superimposed load, 0.8 has been the default value for the location of the thrust force. However with superimposed loading, the value will need to be derived and a new term "d" used. The new formula solving for the adjustment factor for the position of the resultant trust force is shown in equation 12 (based on equation $11)$.

$$
\begin{aligned}
& \rho=\frac{2 \times P \times\left(d \times t-\delta_{h}\right)}{w \times\left(\frac{L}{2}\right)^{2}} \times 144 \\
& d \times t-\delta_{h}=\frac{\rho \times w \times\left(\frac{L}{2}\right)^{2}}{2 \times P \times 144} \\
& d=\frac{\rho \times w \times\left(\frac{L}{2}\right)^{2}+2 \times P \times \delta_{h}}{2 \times P \times t}
\end{aligned}
$$

Figure 9 shows the effects of preload on a half-wall specimen. There are two important observations from these tests. As preload value increases, so does the transverse pressure capacity of the wall. This is a result of the increase in the resultant load (P) by combining the arching thrust and the ground pressure. Also as the preload increases the lateral displacement (at peak transverse pressure capacity) occurs at shorter distances. This is due to increased axial pressure, it is difficult for the wall to rotate at the hinge points. 


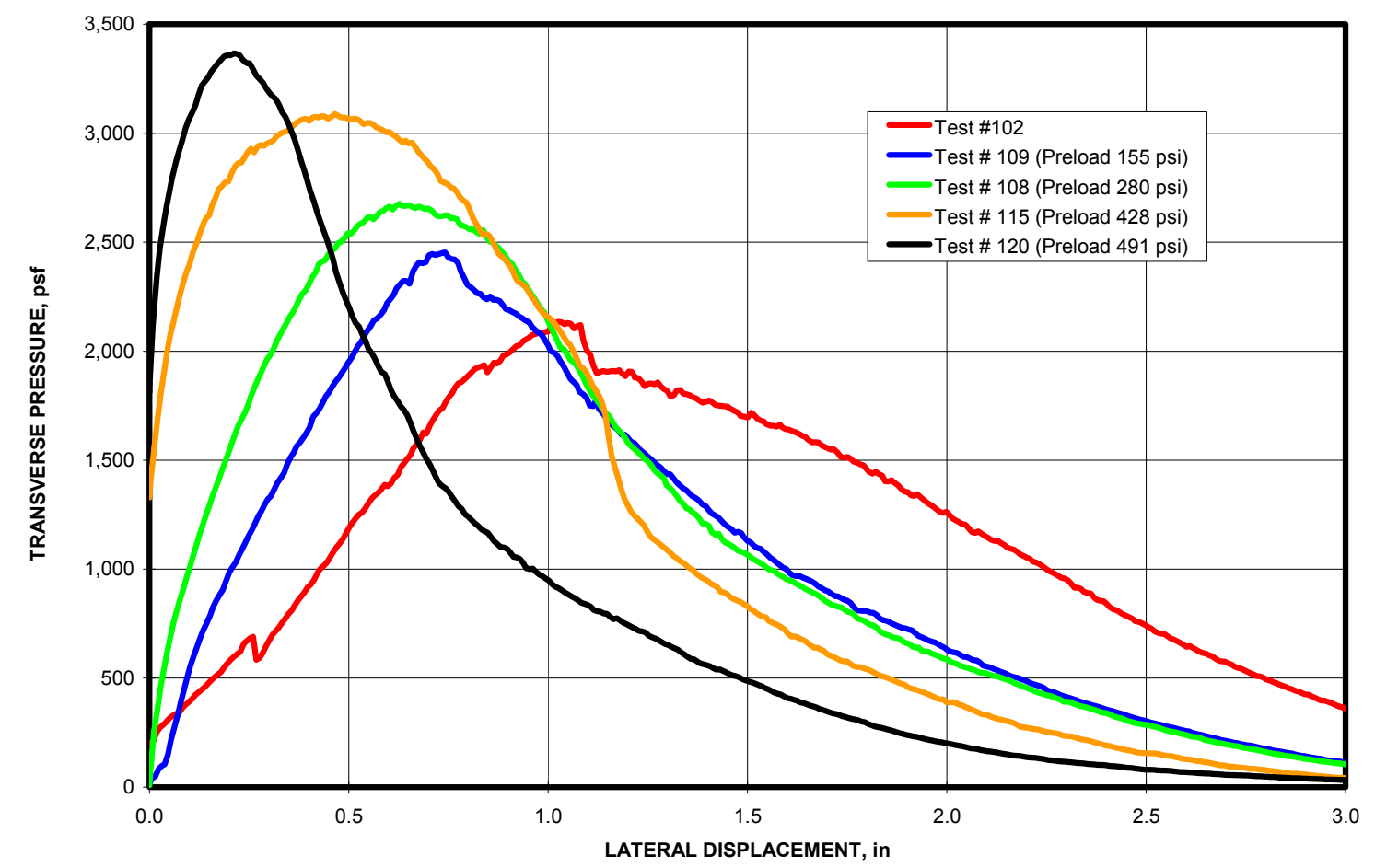

Figure 9. Effects of preload (convergence) on the transverse pressure capacity of the wall (after Barczak 2005).

\subsubsection{Impact of deformable materials to absorb ground deformation}

In order to prevent premature failure from convergence, deformable materials can be incorporated into the stopping construction. Currently, the most commonly used material is expanded polystyrene foam, formed into squeeze blocks or planks that are sandwiched between one or more courses of a block stopping (Barczak, 2005). Although foam is effective in enhancing the yield capability of the wall and extending the service life of the stopping response to the closure of the mine opening, any deformable material in the wall can degrade the transverse pressure capacity of the stopping.

Introducing a deformable material into the stopping construction reduces the stiffness of the ventilation stopping wall by lowering the effective system modulus. The 
system modulus is related to the individual modulus by the relationship expressed in equation 13. Adding a polystyrene foam layer to a mine stopping can significantly reduce the effective system modulus. For example, a standard CMU wall has a modulus of elasticity of 60,000 psi and a wall height of 45 inches. Adding a 1-in-thick plank of polystyrene with a modulus of elasticity of 350 psi can lower the system modulus to $12,800 \mathrm{psi}$, a reduction of approximately $80 \%$.

$$
E_{s y s}=\frac{E_{w} \times E_{d m} \times\left(L_{w} \times L_{d m}\right)}{L_{w} \times E_{d m}+L_{d m} \times E_{w}}
$$

Where $\quad \mathrm{E}_{\mathrm{sys}}=$ system modulus of elasticity, psi

$$
\begin{aligned}
& E_{w}=\text { wall modulus of elasticity, psi } \\
& E_{d m}=\text { deformable material modulus of elasticity, psi } \\
& L_{w}=\text { wall height, in } \\
& L_{d m}=\text { deformable material height or thickness, in }
\end{aligned}
$$

The modulus of elasticity greatly affects the resultant load on the mine stopping. Prior to arching, the resultant load (thrust load) can be calculated using equation 14 . When the system modulus of elasticity decreases due to deformable material or other factors (i.e. boundary conditions,) the thrust load decreases due to increased lateral deflection of the wall. The amount of preload as a function of convergence on the mine stopping also depends on the modulus of the block and deformable material. Lower modulus materials can accommodate more convergence before reaching their peak compression strength than higher modulus materials of the same length.

$$
P=\frac{2 \times A \times E \times y}{\frac{L}{2}}
$$

Where $\quad \mathrm{P}=$ arching thrust, lbs 


$$
\begin{aligned}
& A=\text { axial loading area of the wall, } \text { in }^{2} \\
& E=\text { elastic modulus, psi } \\
& L / 2=\text { half-wall height, in } \\
& y=\text { deformation in each of two crush zones on half-wall section, in }
\end{aligned}
$$

\subsubsection{Impact of boundary conditions}

Similar to adding deformable materials to a mine stopping, a reduction in transverse pressure capacity could be created by softening the roof or floor boundary conditions compared to a rigid abutment situation. A theoretical assessment was made by varying the stiffness of the boundaries of the roof and/or floor, which would change the system stiffness comprising of the stopping wall, mine roof, and mine floor (Barczak, 2008). The theoretical assessment reduced the system modulus to 75,50 , and 25 percent of the rigid boundary condition. Figure 10 shows the theoretical impact of the reduction of system modulus. This figure also indicates that the impact from the reduction in system modulus diminishes when preload (convergence) increases. 


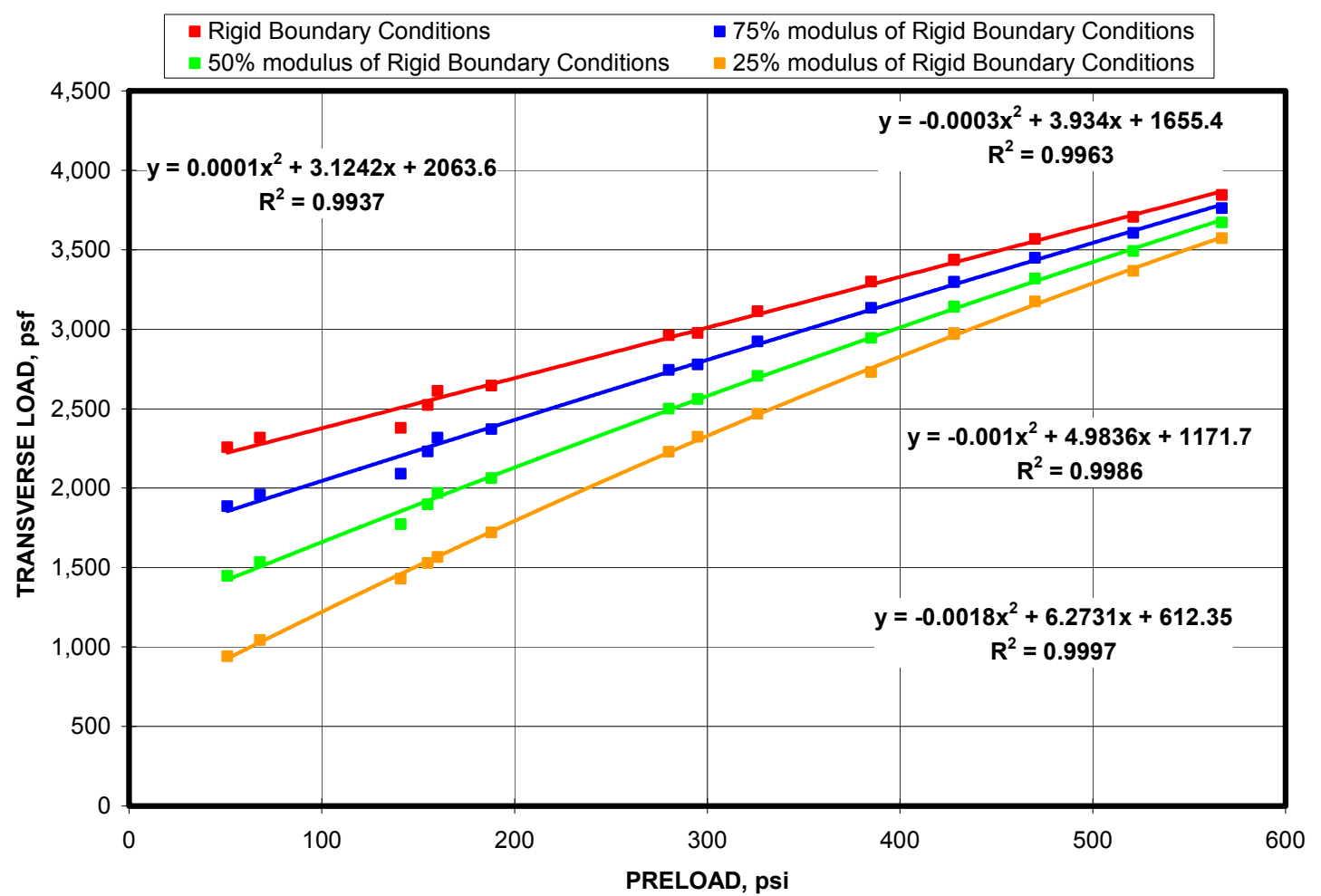

Figure 10. The impact on reducing the modulus of elasticity on the transverse pressure capacity of a stopping wall (after Barczak 2005). 


\subsection{SIMULATING ARCHING THROUGH BIAXIAL LOADING IN THE MINE ROOF SIMULATOR}

\subsubsection{Description of Mine Roof Simulator}

NIOSH's Mine Roof Simulator (MRS), is designed specifically for conducting full-scale tests of mine roof support structures and is the most sophisticated load frame of its kind in the world (Figure 11). Vertical (compressive) loads up to 3 million pounds through a 24-inch stroke and horizontal (shear) loads up to 1.6 million pounds through a 16-inch stroke can be applied independently or simultaneously to support structures to simulate in-mine conditions. The simulator's biaxial load frame can accommodate specimens up to 16 feet high, 20 feet wide, and 20 feet long. Precision load testing is achieve by closed-loop, servo controlled actuators with six degrees of freedom control of the lower platen.

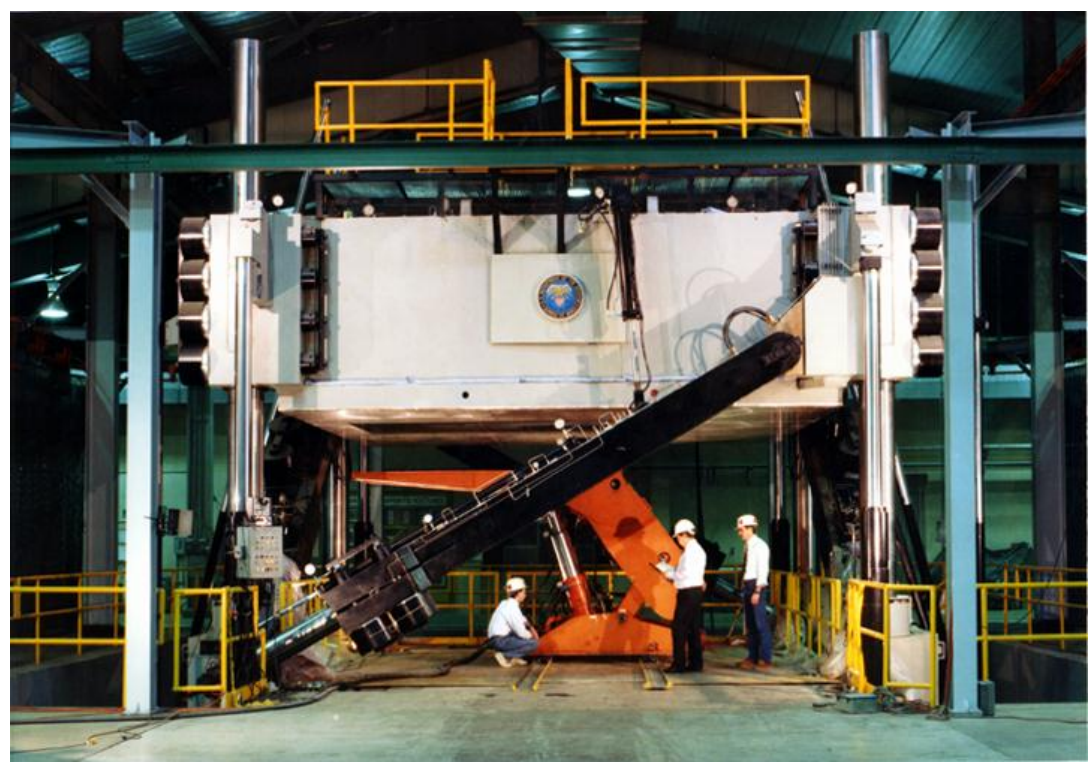

Figure 11. Photo of NIOSH's Mine Roof Simulator. 


\subsubsection{Simulation of rigid arching through biaxial loading}

Ventilation stoppings bridge the gap between the mine floor, roof, and pillars providing a restrained boundary condition. When a transverse pressure acts against the face of a stopping, the wall deflection is restrained by the mine roof and floor abutments creating a three-hinge arch. In order to simulate this arching mechanism, a half-wall section of a stopping is placed in the NIOSH's Mine Roof Simulator (MRS) (Figure 12). The half-wall is then hydraulically clamped to a fixed vertical height. The upper platen remains fixed in place as the lower platen moves horizontally, causing the wall to rotate. As the base of the wall is forced to move horizontally, hinge points and deformation zones are created at the ends of the wall on opposite sides, consistent with the arch loading mechanism. The horizontal force applied to the ends of the half-wall is measured and is equated to the transverse pressure acting on the wall (Figure 13) (Barczak, 2005).

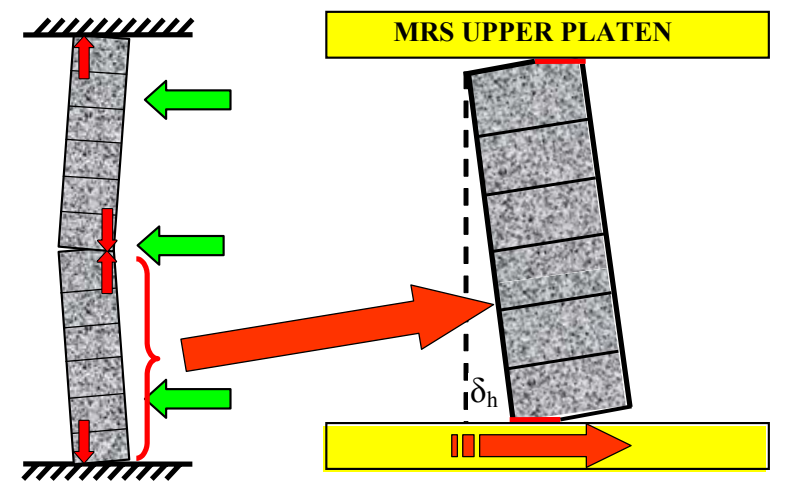

Figure 12. Simulating rigid arching in the NIOSH Mine Roof Simulator (after Barczak 2005). 


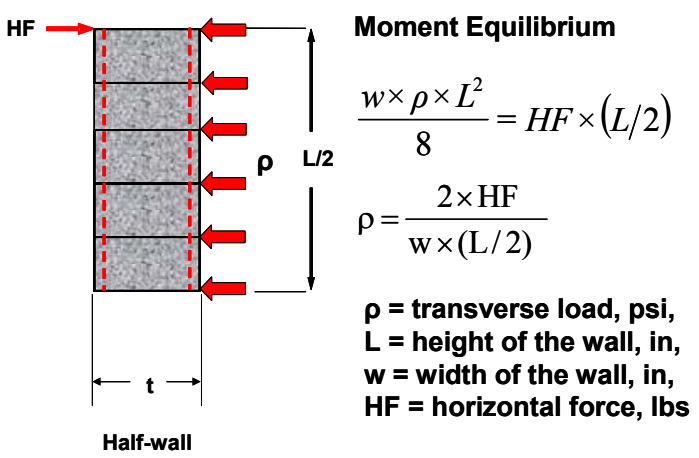

Figure 13. Half-wall moment equilibrium equation showing the half-wall geometry (after Barczak 2005).

\subsubsection{Simulation of arching with deformable materials}

Deformable materials in a stopping wall can significantly degrade the transverse pressure capacity of the stopping. A new test program was designed to conduct a series of half-wall transverse pressure tests, using the protocol establish to simulate arch loading, with a variety of materials that provide a range of capability to prevent premature failure of the stopping due to convergence. The deformable material was placed on the top of a 48-in-high half-wall as show in Figure 14 to evaluate conditions that do not provide rigid arching behavior. A representative cellular concrete block with a strength of about 500 psi was used for this study. This is lightweight block with a material density of $38.6 \mathrm{lbs} / \mathrm{ft}^{3}$ and a unit weight of $51.5 \mathrm{lbs}$ for an $8 \times 12 \times 24$-in block.

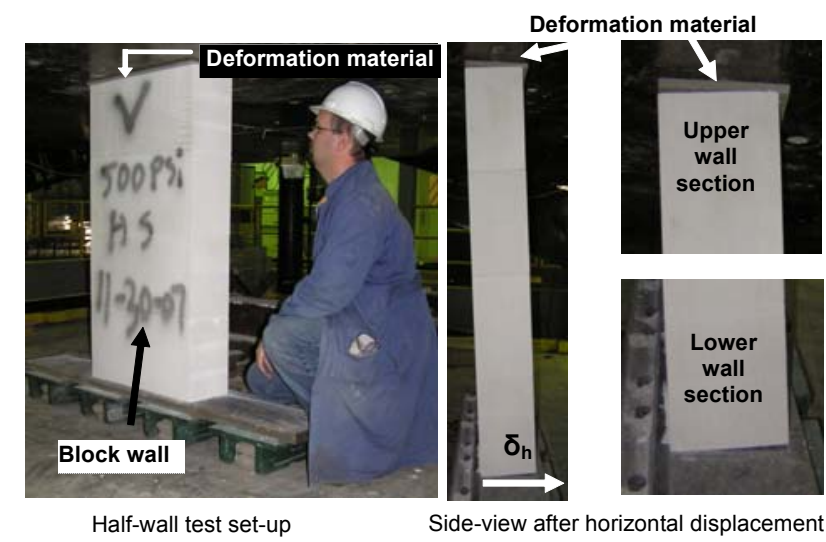

Figure 14. Deformable material placed at the roof interface in the MRS testing program 


\section{CHAPTER 3 - ABUTMENT STIFFNESS}

\subsection{Introduction}

In the Barczak dissertation (2005), over 500 tests were preformed to determine the transverse pressure capacity of mine ventilation stoppings. These tests were preformed using a new lab testing protocol that simulates arching, in rigid conditions, of stopping wall by biaxial loading of half-walls. These tests were validated by full-scale tests of stopping walls in the NIOSH Experimental Coal Mine at the Pittsburgh Research Laboratory and the NIOSH Lake Lynn facility. However, the question remains over the issue of the significance of the abutment stiffness and its impact on arching. The theoretical analysis of the impact of the abutment stiffness concludes that it can significantly affect the arching capability and degrade the transverse pressure capacity of a stopping. It also indicates that arching will continue to occur even under relative soft boundary conditions. Also how much does the impact of superimposed axial loading from ground pressures offset the impact of lowering the stiffness boundary conditions? This chapter will focus on the effect of abutment stiffness and its impact on arching.

\subsection{Background information}

Using the rigid arching test protocol, a systematic study of the design parameters that affect arching capability in block stoppings, under rigid arching conditions, was conducted. Several different block materials and types were used in this study to depict the strength variations utilized. The previous chapters emphasized this work and how these differences in material properties can provide a wide range of transverse pressure capacities for mine ventilation stoppings. These tests were conducted on half-wall single 
column block walls as documented in the protocol. The parameters varied in the test program were the wall height, wall thickness, and the axial preload. All the walls were dry-stacked block configurations, which consistent with the practice utilized in U.S. mines. Generally, three tests were conducted of each configuration to evaluate the consistency of the results. The objective of his study was to determine the transverse pressures characteristics and capacity limitation of various block constructions (Barczak).

Only a few experiments were conducted to show the significance of the strain-softening (deformable materials). From Barczak's premise, a low-density material will not preserve the arching load mechanism, and can severely degrade the transverse pressure capacity of the stopping. Barczak recommended further research be done on deformable materials and the effects on transverse pressure capability.

\subsection{Impact of deformable materials on transverse pressure}

Deformable materials are sometimes added to ventilation stoppings constructions to prevent damage cause by convergence in coal mines. However adding deformable materials can significantly reduce the capacity of the stopping to resist transverse pressure. Several tests were conducted to research the effect of various materials with different deformational properties on the transverse pressure capability of a stopping wall. The impact of the modulus of elasticity of various deformable materials was then examined. The purpose of this section is to determine the relationship between the modulus of elasticity of the deformable material and the transverse pressure capacity of the stopping under arch loading conditions.

First the properties of several deformable materials were evaluated (Test results shown in appendix C). The varieties of deformable materials were selected based on 
their modulus of elasticity to create a range of boundary conditions to study. These are not materials that are currently used in mine constructions. Table 3 documents the relevant properties of the test materials used in the study. The stress-strain response of some of these materials is nonlinear, many with strain-hardening behavior as they deform. For those materials, the modulus was approximated by taking the slope of the stress-strain response at the level of deformation which was consistent with the preload applied to the stopping prior to the application of transverse pressure. The effective system modulus ( $\left.\mathrm{E}_{\mathrm{sys}}\right)$ of the block wall and deformable material was computed using the series stiffness relationship described in equation 13 with the block wall modulus $\left(\mathrm{E}_{\mathrm{w}}\right)$ of 45,000 psi computed from testing of a unit block column. The preload is necessary to simulate the condition where convergence causes deformation of the deformable material prior to the application of transverse pressure. Two levels of preloading were evaluated: (1) a nominally small preload of about 50 psi and (2) high preload of about 275 psi equating to about 60 pct of the block strength.

Table 3. Material properties of deformable material

\begin{tabular}{|c|c|c|c|c|}
\hline Material & Thickness, in & Strain, \% & Modulus, psi & System Modulus, psi \\
\hline \multicolumn{5}{|c|}{ Low preload tests } \\
\hline Plywood & 0.472 & 14 & 5,000 & 41,631 \\
\hline Hard Rubber & 0.367 & 14 & 2,666 & 40,084 \\
\hline Soft Rubber & 0.386 & 12 & 600 & 28,260 \\
\hline Drywall & 0.513 & 8 & 1,000 & 28,752 \\
\hline Homasote & 0.515 & 17 & 2,222 & 34,911 \\
\hline Thick Foam & 0.815 & 77 & 130 & 6,475 \\
\hline \multicolumn{5}{|c|}{ High preload tests } \\
\hline Plywood & 0.472 & 29 & 10,800 & 45,000 \\
\hline Hard Rubber & 0.367 & 32 & 2,750 & 43,781 \\
\hline Soft Rubber & 0.386 & 28 & 1,000 & 40,224 \\
\hline Drywall & 0.513 & 24 & 1,125 & 33,261 \\
\hline Homasote & 0.515 & 40 & 6,500 & 30,647 \\
\hline Thick Foam & 0.815 & 99 & 2,000 & 40,049 \\
\hline
\end{tabular}


Under arch loading conditions, the transverse pressure capacity of a stopping is determined by the force-couple formed by the thrust force at the hinge points generated by the deflection of the wall from the application of the transverse pressure against the face of the stopping. As the diagram in Figure 15 illustrates, the thrust moment reduces as the lateral displacement of the wall increases. Hence, all other things being equal, the transverse capacity of a stopping wall decreases as the deflection of the wall increases.

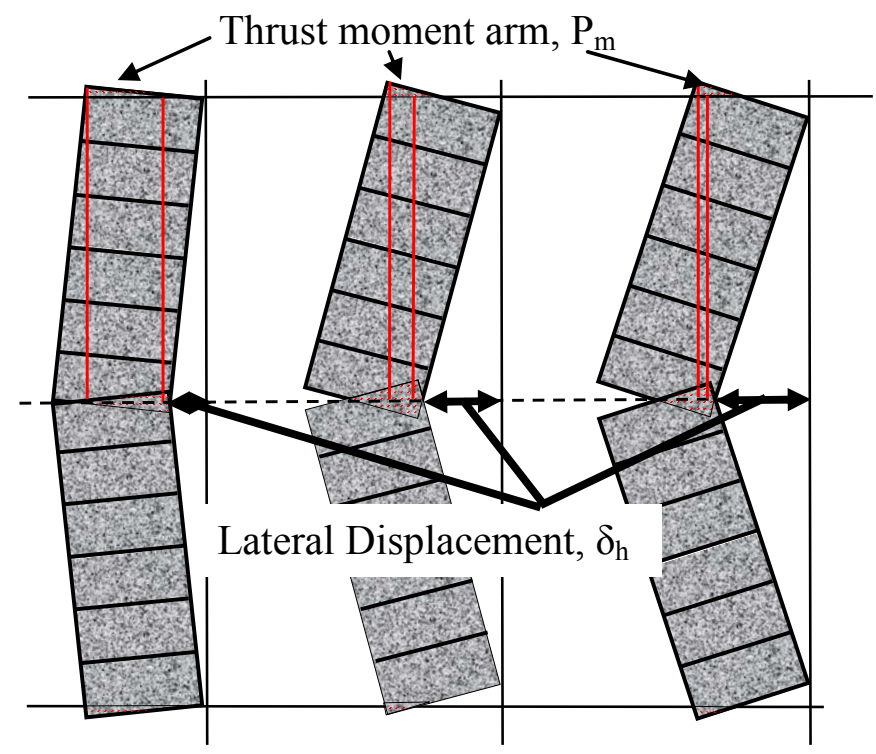

Figure 15. Diagram showing that increased lateral displacement of the stopping reduces the arch thrust which reduces the transverse pressure capacity of the stopping.

The deflection is governed by the deformational properties of the wall and the surrounding roof and floor boundaries. The theoretical relationship between the wall deflection and transverse pressure develop is verified in the test data shown in Figure 16. Two conclusions are drawn from these results. First, the amount of lateral displacement decreases with increasing preload, thereby increasing the transverse pressure capacity of the stopping. Second, the slope of the curve increases for the high preload test with the same deformable material applications that were used for the low preload test. 


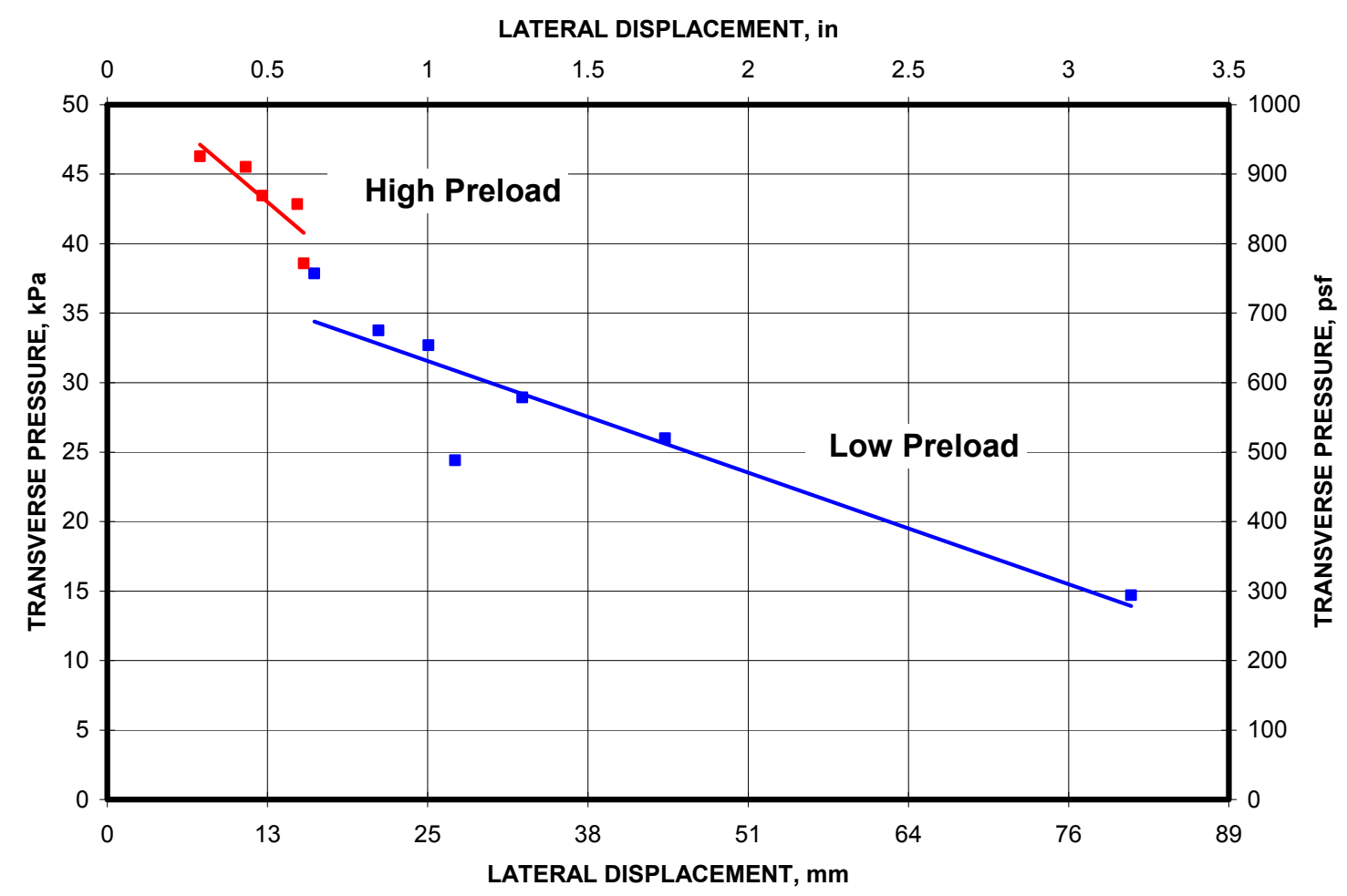

Figure 16. Transverse pressure capacity is reduced as the lateral displacement of the wall increases.

The analysis also indicates that the lateral deflection would be governed by the effective material modulus or stiffness of the system. Test data shown in Figure 17 confirms this relationship. The modulus of the deformable material incorporated in the stopping ranged from a low of 130 psi for a foam material to as high as 10,800 psi for plywood. To put this in perspective, the block wall had an effective modulus of 45,000 psi. The lateral displacements increased from a low 0.5 inches to approximately 3 inches for the low preload tests and from 0.4 to 0.6 inches for the high preload tests. The slope of trendline for the high preload tests was about six times greater than the low preload test trendline. The reason for this is due in part to the strain-hardening of the material resulting in a higher system modulus at the higher preload. 


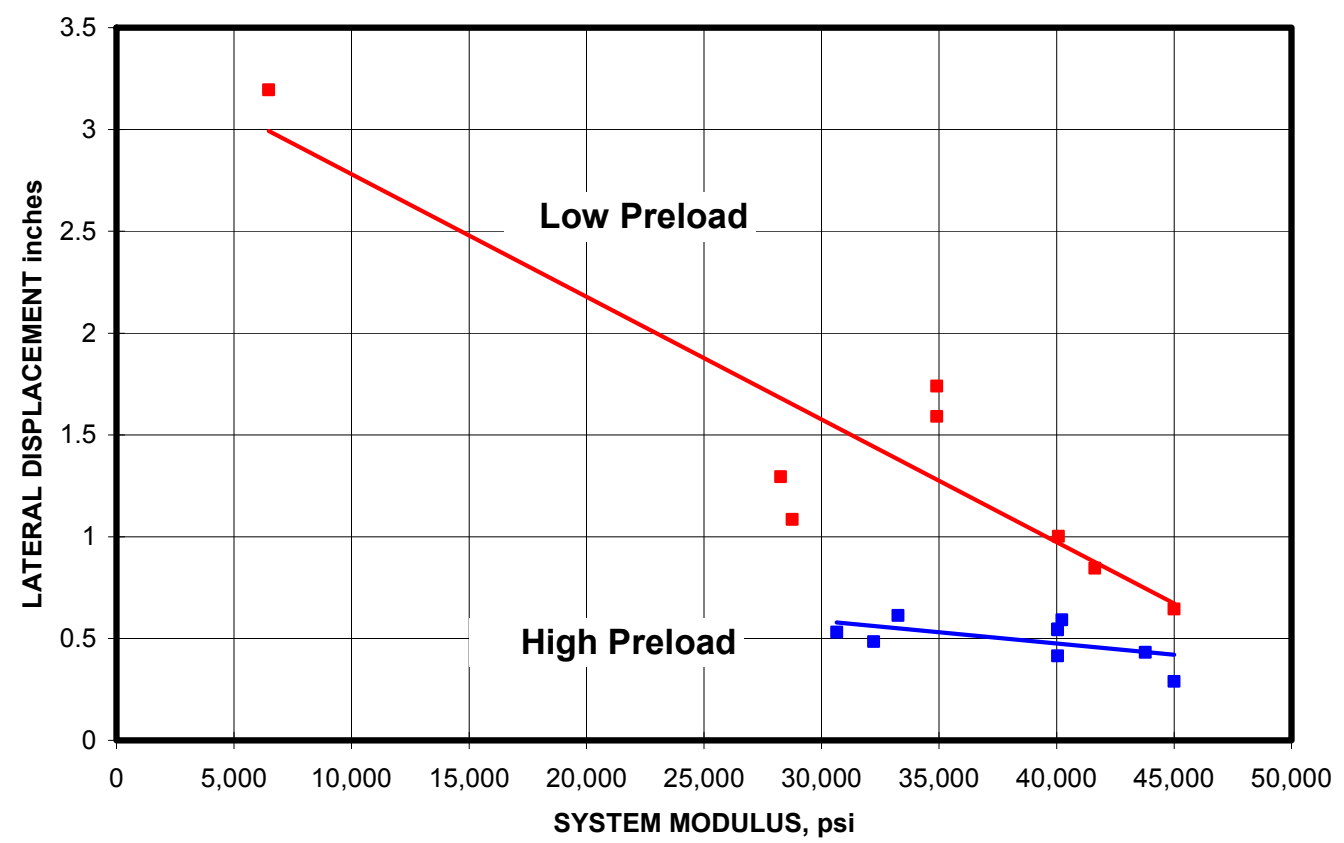

Figure 17. Lateral displacement decreases as the modulus of elasticity of the deformable material of the wall increases, causing an increase in system modulus.

Figure 18 shows the transverse pressure as a function of the system stiffness. This graph shows that the transverse pressure capacity (low pre-load situation) can be reduced by a factor or 2.5 by reducing the system stiffness by an order of magnitude through the addition of deformable materials to the wall construction. This reduction in transverse capacity could also be created by softening the roof or floor boundary conditions compared to a rigid abutment situation. 


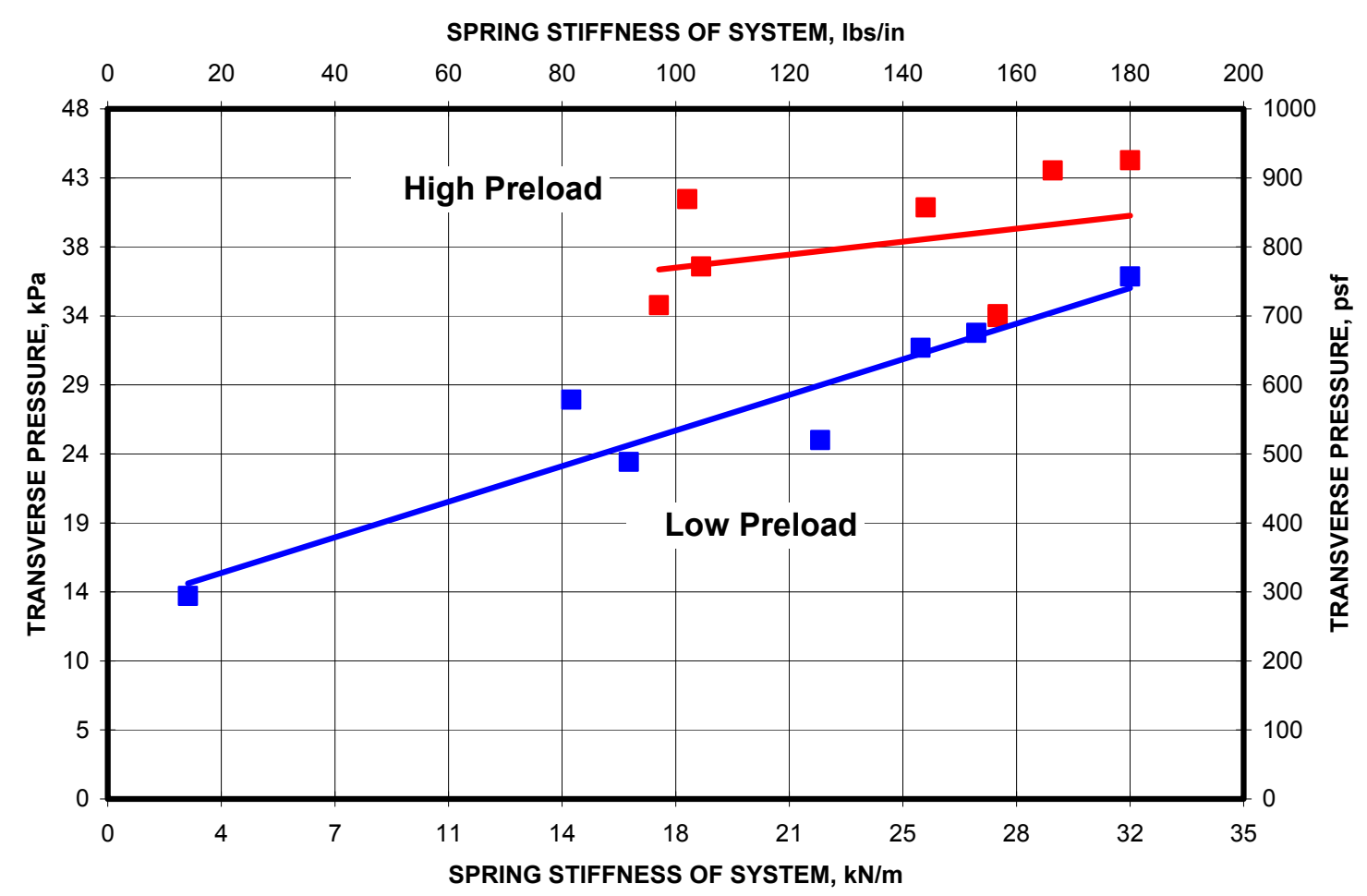

Figure 18. Transverse pressure capacity is increase as the system stiffness of the material of the wall increases due to the use of a higher modulus strain-softening.

\subsection{Impact of convergence on transverse pressure}

Convergence causes increased thrust on the wall that makes it more difficult for the transverse pressure to offset the moment induced by the trust force to cause the wall to deflect outward, thus resulting in higher transverse pressure capacity. Convergence (preload) has a significant effect on the response. As mentioned early, the stress-strain response of some of these deformable materials is nonlinear, many with strain-hardening behavior as they deform. For those materials, it is important that the modulus of elasticity is taken at the slope of the stress-strain response at the level of deformation which is consistent with the preload applied to the stopping prior to the application of transverse pressure. 
As seen in Figure 16, lateral displacement decreases with increasing preload, thereby increasing the transverse pressure capacity of the stopping. As anticipated, increasing the preload on a wall constructed with deformable material will result in a higher system modulus. Figure 17 displays the system modulus for all the deformable materials evaluated in this study under low and high preloads. The slope trendline for the high preload test is about six times greater than the low preload test trendline. This is due in part to the strain-hardening response of the material.

The impact of the deformable material to reduce the transverse pressure capacity of a stopping can be mitigated by convergence that would induce a (vertical) preload on the wall. The slope of the low preload trendline is about twice that of the high preload tests shown in Figure 18. The high preload test indicated that the transverse pressure decreased by about $100 \mathrm{psf}$ for a 30 pct reduction in system stiffness. 


\section{CHAPTER 4 - DEVELOPENT OF A COMPUTER PROGRAM FOR ASSESSMENT OF STOPPING PREFORMANCE}

\subsection{Introduction}

Determining the transverse pressure capacity of a mine ventilation stopping requires assessment of several variables. Ventilation block characteristics can vary in dimension, strength, modulus of elasticity, material type (cellular vs. aggregate), and weight. Other factors that can greatly affect the transverse pressure capacity include roof/floor boundary conditions, mine opening dimensions, and deformable materials included in the wall evaluation. Using the analytical evaluation of the fundamental behavior of mine ventilation stoppings shown in previous chapters, it is possible to demonstrate the transverse pressure ability and to predict the mine ventilation stopping's response.

A computer program was developed to assess the transverse pressure capacity of various mine ventilation block stopping constructions. This software will assist the user in making engineering decisions regarding the selection and orientation of mine ventilation blocks to provide a desired stopping performance. Included within the software is a database of several currently used block characteristics and loading profiles obtained through performance testing of these stoppings at the NIOSH MRS Facility. This software can provide an engineering foundation to ensure that inadequate stopping designs as well as ultra conservative stopping applications are avoided. Safety will be 
improved by properly matching the ventilation stopping performance to the mine conditions.

\subsection{Features of V-STOP}

Since determining the transverse pressure capacity involves several factors and calculations, a computer program was developed to compute the transverse pressure capacity of a specific stopping construction. The outcome of implementing the rigid-arch theory model into a full-featured program is called V-STOP for Ventilation Stopping Technology Optimization Program. The scope of the program has four primary elements:

(1) A user-friendly interface with appropriate visual diagrams to input the necessary parameters for stopping design and evaluation, including the mine opening characteristics (mine height, width, and boundary conditions) as well as the block characteristics (block size, weight, and type).

(2) A computational subroutine to determine the transverse loading capabilities of a stopping wall based on the user-specified input parameters.

(3) Both graphical and tabular outputs as well as visual illustrations of the stopping wall concepts when appropriate.

(4) Graphical display of a detailed performance data for various stopping wall designs after evaluating several block types under transverse pressure conditions.

\subsection{Organization of $\mathrm{V}$-STOP}

V-STOP is intended to be used by people with different backgrounds including students, professors, on-site mine personnel, government researches, etc. A user-friendly 
layout was then developed for this compilation of users. The program follows three basic steps: (1) receiving input from users, (2) computes the transverse pressure capacity using the numerical solutions from the design guidelines, and (3) presenting the results.

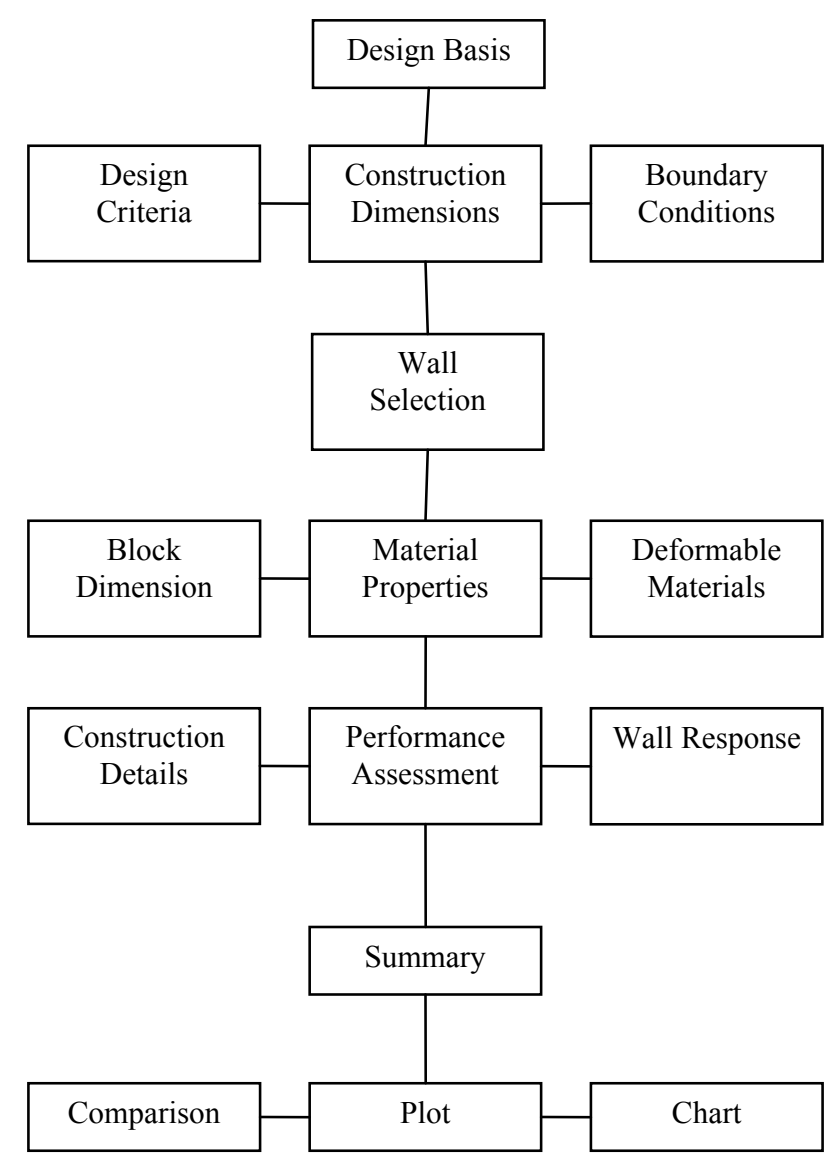

Figure 19. Flowchart for V-STOP

The flowchart, shown in figure 15, shows the general layout of V-STOP. Each segment in the flowchart is described in greater detail in the following sections including relevant methodology and equations used for each step. 


\subsubsection{Design Basis}

The first requirement is to specify the design criteria. What pressure capacity and yield capability (convergence) do you what the stopping to provide? Shown in Figure 20 is a display for the design criteria of the mine stopping. In this window, the design criteria for the stopping are designated. A minimum limit can be inputted to determine if the designed transverse pressure capacity of the wall and convergence of the wall is infringed. Next, the program requires the construction dimensions determined by the entry's width and height. The following requirement is to determine the boundary conditions. The chooses for boundary conditions are between Strong Rock (Sandstone), Moderate Rock (Shale), Weak Rock (Mudstone), and Coal. The selection for the surface contact is made between Strong, Moderate, Weak, and Very Weak.

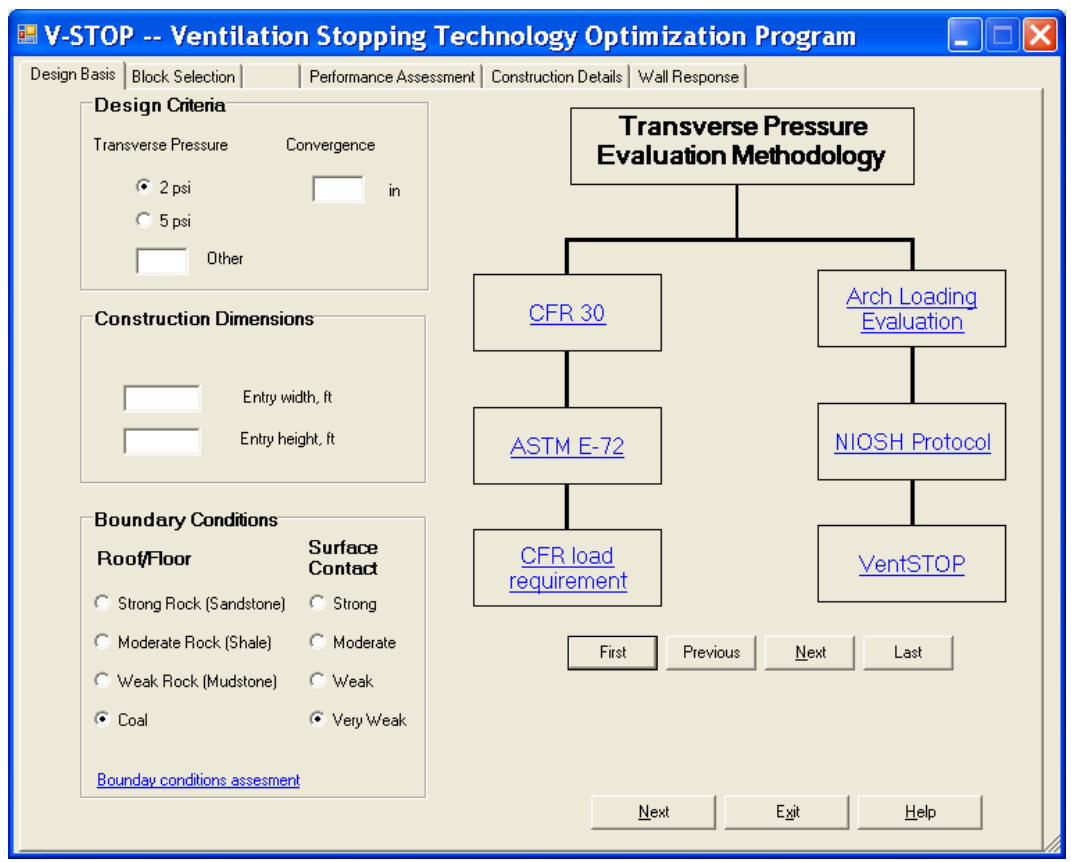

Figure 20. Design Basis window for V-STOP showing the design criteria for the stopping and properties of the mine boundary conditions. 
The effect of boundary stiffness is analyzed by reducing the effective modulus of the system. The model used to determine the transverse pressure is based on the laboratory tests. Lateral displacement is minimized when rigid boundaries conditions exist, thereby creating the maximum transverse pressure capacity. The model predicts the lateral displacement of the half-wall based on the material modulus, wall thickness and height. The arch thrust force is also predicted from the modulus and lateral displacement. These factors allow the transverse pressure to be determined. As the boundary stiffness (i.e. roof and floor) decreases, the transverse pressure capacity of the stopping decreases due to increased lateral displacement.

The effective system modulus of the block wall, roof, and floor was computed using the series modulus relationship described in equation 15 and the modulus values shown in table 3. This equation uses an estimated total distance for the length of the surface contact $(0.5 \mathrm{ft})$ and the length of the core roof/floor boundary condition $(6.0 \mathrm{ft})$. Table 4 displays the modulus values used by the V-STOP program for assessing the roof and floor boundary conditions. This data was based on the material properties for different rock types described by Runsnak and Mark (1999) and Zipf (2005) and laboratory tri-axial testing of rock core specimens from the Pittsburgh Seam mines (Strata Testing Services, 2003).

$$
E_{s y s}=\frac{L_{s y s}}{\frac{L_{w}}{E_{w}}+\frac{L_{R F}}{E_{R F}}+\frac{L_{s c}}{E_{s c}}}
$$

Where $\quad E_{\mathrm{sys}}=$ system modulus of elasticity, psi

$$
\begin{aligned}
& E_{\mathrm{w}}=\text { wall modulus of elasticity, psi } \\
& E_{\mathrm{RF}}=\text { roof/floor modulus of elasticity, psi } \\
& E_{\mathrm{SC}}=\text { surface contact modulus of elasticity, psi } \\
& L_{\mathrm{w}}=\text { wall height, in }
\end{aligned}
$$


$\mathrm{L}_{\mathrm{RF}}=$ roof/floor height, in

$\mathrm{L}_{\mathrm{SC}}=$ surface contact height, in

Table 4. Boundary conditions for V-STOP.

\begin{tabular}{|l|l|}
\hline Roof/Floor Description & Modulus \\
\hline Strong Rock (Sandstone) & $3,600,000 \mathrm{psi}$ \\
\hline Moderate Rock (Shale) & $1,080,000 \mathrm{psi}$ \\
\hline Weak Rock (Mudstone) & $720,000 \mathrm{psi}$ \\
\hline Coal & $360,000 \mathrm{psi}$ \\
\hline Surface Contact & $5,000 \mathrm{psi}$ \\
\hline Strong & $2,500 \mathrm{psi}$ \\
\hline Moderate & $1,000 \mathrm{psi}$ \\
\hline Weak & $500 \mathrm{psi}$ \\
\hline Very Weak &
\end{tabular}

\subsubsection{Block Selection}

After selecting the stopping design criteria, the next program step is the Block Selection window (Figure 21). This window provides a list of defined blocks and permits adding new blocks, deleting blocks, editing existing blocks, or renaming blocks. Also, individual blocks can be saved to and loaded from stored files.

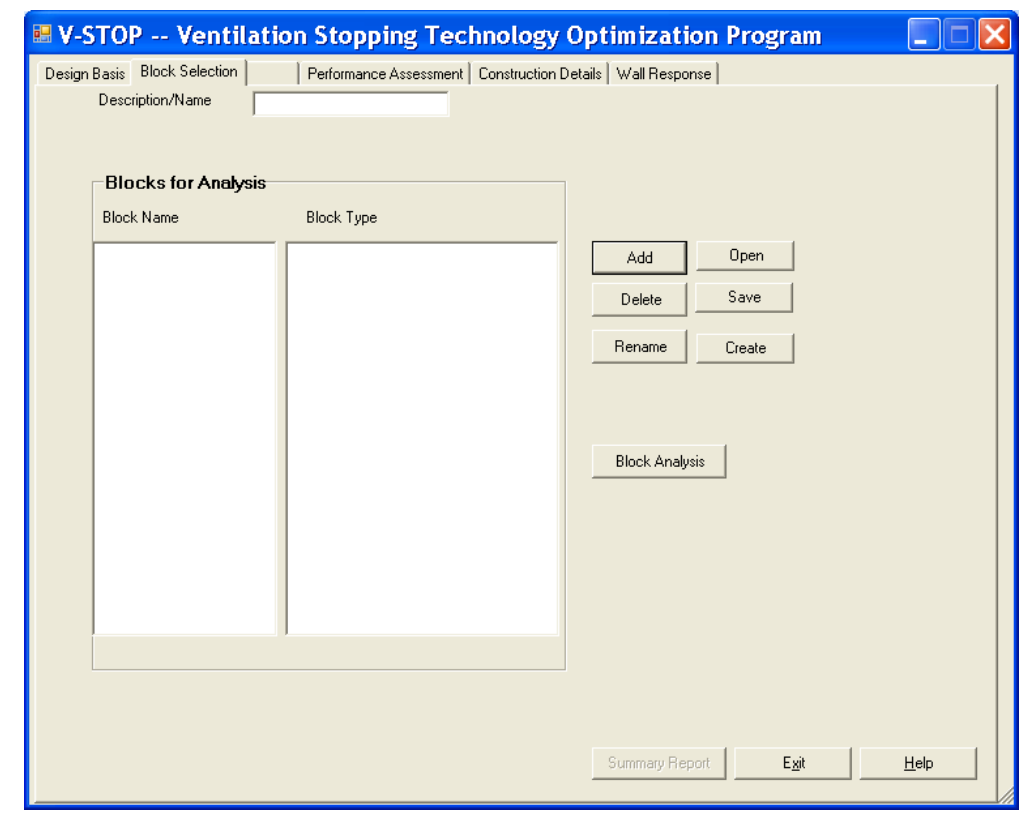

Figure 21. Block Selection window for V-STOP allows the user to add/modify blocks for analysis. 
To rename a previous created block, select a previously defined block from the list, modify the name in the "Description/Name" box and select the Rename button. To delete a defined block from the list, select the "Delete" button. If a key is pressed by mistake the operation can be cancelled. To load a previously saved filed block/blocks click the "Open" button, this opens a file dialog window and can select the previously created file name. The block will be added to the list, retaining previous design settings and any cost or material handling values. To save a block click the "Save" button, which opens a file dialog window, and specify a name for the file. Note that the "Save" function saves the entire list of blocks selected for analysis.

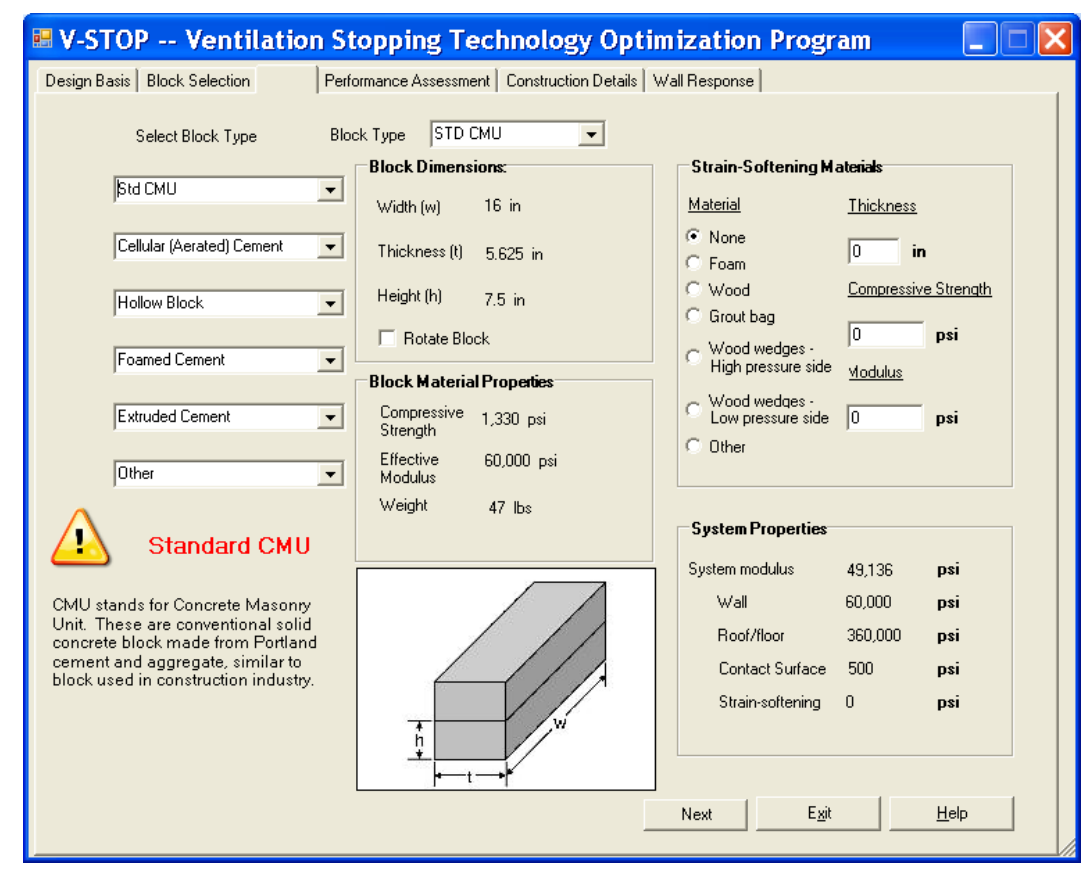

Figure 22. Block window for V-STOP allow user to select from block categories and add deformable materials.

To add a block for analysis, select the "Add" button to bring up the Block window (Figure 22) which permits selecting from available block types, grouped by category and is used to add a block to the list of defined stoppings used for comparison. Similarly, when you press the "Block Analysis" you can view the previous selected block. When 
you press the "Create" button the Block window will permit you to create the physical properties of a new block and add the block to the list.

Due to the various block types, each block was placed into separate categories that best represents its reaction to transverse pressure capacity and failure mechanisms. The block categories, shown in Figure 22, with brief description as follows:

Standard CMU: CMU stands for concrete masonry unit. These are conventional solid concrete blocks made from Portland cement and aggregate, similar to blocks used in the construction industry.

Cellular (Aerated) Cement: Aerated cement is characterized by pockets or air voids. These are created by hydrogen bubbles formed by a chemical reaction of the ingredients and Portland cement, which cause the concrete to expand to about five times its original volume. The highly cellular concrete is formed in molds, cut to size and steam-cured in a pressurized chamber (an autoclave).

Hollow Block: Hollow block is made from conventional Portland cement and standard aggregate with the same basic formulation that is used to make the solid CMU blocks. The thin webs and facing contribute to the lower strength when a full block is tested, typically less than 1,000 psi compressive strength.

Foamed Block: Foamed cement normally has a density of between 25 and 40 $\mathrm{lbs} / \mathrm{ft}^{3}$, compared with about $125 \mathrm{lbs} / \mathrm{ft}^{3}$ for ordinary concrete. It is made of a cementitious material, a filler or aggregate, and an aerated foaming agent.

Extruded Block: An alternative approach to creating a low density material is to embed polystyrene pellets in the concrete mix, which are easily seen as part of the block construction. Extruded foam cement has a compressive strength of less than 200 psi with 
a fairly wide range depending on the volume and dispersion of the foam pellets within the concrete structure.

Also, strain-softening material (deformable material) can be added in this window (see Figure 22). You can select from the available strain-softening materials or create a new one. Although various deformable materials exist, the most common materials were added to the program to assess the transverse pressure of such stopping wall construction. The effective system modulus of the block wall and deformable material was computed using the series modulus relationship described in equation 13 on page 24. However, the stress-strain response of some of these materials is nonlinear, many with strain-hardening behavior as they deform. For this applications the modulus was approximated by taking the slope of the stress-strain response at the level of deformation which was consist with the preload applied to the stopping prior to the application of transverse pressure. Listed below are the deformable materials used in the program with a brief description:

Foam: Expanded polystyrene foam has air inclusions which gives it moderate flexibility, a low density, and a low thermal conductivity. Estimated modulus is approximately 50 psi.

Wood: Wood is a hard, fibrous, lignified structure. Estimated modulus is approximately 10,000 psi.

Grout bag: The grout bag is placed between the ventilation stopping and mine roof and is pumped full of a cementitious grout. This can pre-stress the ventilation stopping increasing the moment resistances to lateral loading of the blocks. (Barczak, 1995) Estimated modulus is approximately 20,000 psi. 
Wooden Wedges: Depending on the placement of the wedges they can aide or hinder the transverse capacity of the wall. Demonstrated in Figure 23, it shows the placement effect of wedges on the lateral displacement of the wall which affects the transverse load capacity. The estimated effective system modulus for the "high" pressure side and "low" pressure side wedge application is approximately 10 psi and 10,000 psi respectfully.

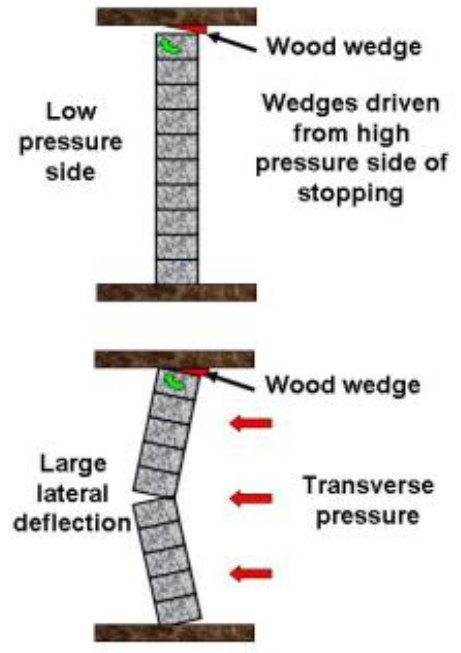

A

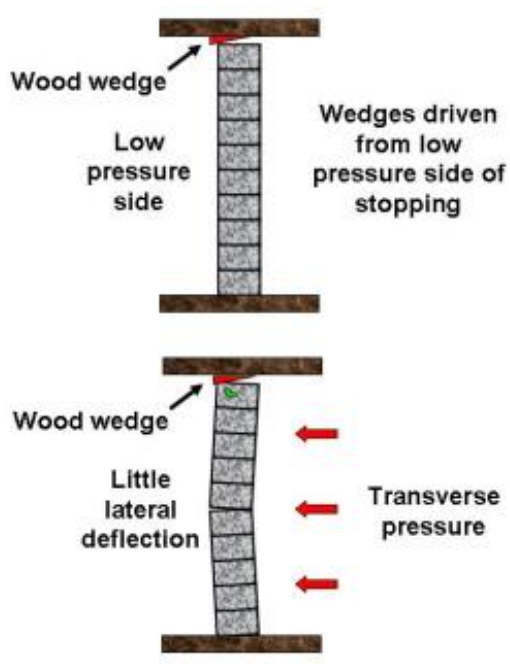

B

Figure 23. Wedges placed on high pressure side (A) and low pressure side (B).

After handling the input data, V-STOP allocates and initializes the storage arrays for the main variables.

\subsubsection{Solution Phase of V-STOP}

To develop a program to determine the transverse pressure of mine ventilation stopping a model was developed based on the wall geometry (thickness and height), the elastic modulus of the material, and utilized empirical data from the laboratory testing. All the parameters for the stopping construction were inputted during the initial phase. The program then uses an updated Hybrid Theoretical Lateral Displacement Model 
described in Figure 24. The Hybrid Lateral Displacement Model determines the lateral displacement force from a multivariable relationship from $\mathrm{E}^{*}(\mathrm{t} / \mathrm{L})^{2}$ term and preload, both of which are considered to be known parameters. Similarly, a multivariable linear regression analysis was preformed to determine the thrust resultant position factor as a function of wall height and preload. The multivariable linear regression analyses were based on laboratory test of various wall constructions and are summarized in Appendix A. The flowchart below demonstrates how the data obtained from the initial phase is used to determent the results used in the final output. As more test become available, these empirical based formulas can be improved creating a more accurate value for the transverse pressure calculations. 


\begin{tabular}{|c|c|}
\hline Determine Design Criteria & Design Transverse Pressure and Convergence \\
\hline $\begin{array}{l}\text { Determine Construction } \\
\text { Dimension }\end{array}$ & Measured: $\mathrm{W}_{\text {wall }}$ and $\mathrm{L}$ \\
\hline $\begin{array}{l}\text { Determine Boundary } \\
\text { Conditions }\end{array}$ & Measured: $\mathrm{E}_{\mathrm{rf}}$ and $\mathrm{E}_{\mathrm{sc}}$ \\
\hline Determine Block Selection & $\begin{array}{l}\text { Measured: w, t, h, CS, } \mathrm{E}_{\mathrm{bl}} \text {, and } \mathrm{W} \\
\text { Block Trpe and/or Specific Block }\end{array}$ \\
\hline $\begin{array}{c}\text { Determine Deformable } \\
\text { Material (Strain-Softening) }\end{array}$ & $\begin{array}{l}\text { Measured: Deformable material type, } \mathrm{t}_{\mathrm{df}}, \mathrm{CS}_{\mathrm{df}} \text {, } \\
\text { and } \mathrm{M}_{d f}\end{array}$ \\
\hline Calculate System Modulus & $E_{s y s}=\frac{L_{s y s}}{\frac{L_{b l}}{E_{b l}}+\frac{L_{d f}}{E_{d f}}+\frac{L_{r f}}{E_{r f}}+\frac{L_{s c}}{E_{s c}}}$ \\
\hline $\begin{array}{l}\text { Determine Lateral } \\
\text { Displacement }\end{array}$ & $\begin{array}{l}\text { Multivariable regression analysis relating } \\
\text { displacement to } E^{*}(t / L)^{2} \text { and preload }\end{array}$ \\
\hline Determine Preload & Measured or PL $=\Delta \mathrm{L} \times \mathrm{k}$ \\
\hline $\begin{array}{l}\text { Calculate "Hinge Point } \\
\text { Deformation" }\end{array}$ & $y=\frac{2 \times L \pm \sqrt{4 \times L^{2}-32 \times t \times \delta_{h}^{2}}}{8}$ \\
\hline Calculate Arch Thrust & $P_{\text {arch }}=\frac{2 \times A \times E_{s y s} \times y}{L / 2}$ \\
\hline Add Preload to Arch Thrust & $\mathrm{P}_{\mathrm{m}}=\mathrm{P}_{\mathrm{arch}}+\mathrm{PL}$ \\
\hline Calculate Horizontal Load & $H F=\frac{P_{m} \times\left(d \times t-\delta_{h}\right)}{L / 2}$ \\
\hline $\begin{array}{l}\text { Calculate Transverse } \\
\text { Pressure }\end{array}$ & $\rho=\frac{2 \times H F}{w \times L / 2}$ \\
\hline
\end{tabular}

Figure 24. Flowchart of V-STOP calculations for transverse load capacity solution. 


\subsubsection{Performance Assessment}

After the program performs the solution phase, the cumulative output file is generated. The Performance Assessment window is then displayed (Figure 25). This window displays a graphical plot of the performance curve for the stopping wall based on the block specifications, well construction and boundary contact stiffness.

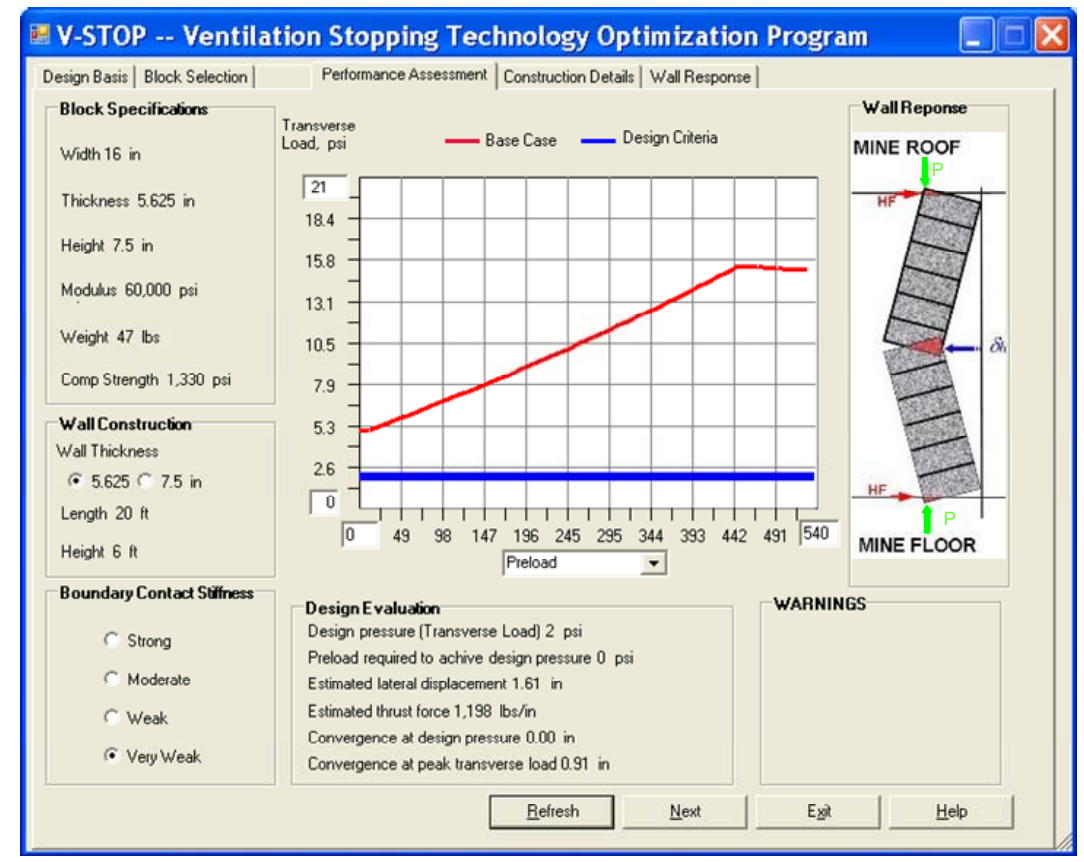

Figure 25. Performance Assessment window for V-STOP simulates peak transverse pressure capacity for selected block.

This window also displays a design evaluation of the ventilation stopping. It lists the design pressure (selected on the Design Basis window, Figure 20) and the preload that would be required to achieve the design pressure. The design evaluation also included an estimate for thrust and lateral displacement at the maximum transverse pressure capacity based on the Hybrid Lateral Displacement Model shown in Table 2. Convergences at the design pressure and at the peak transverse pressure are calculated using equation 15. By determining the preload on a stopping wall the convergence of the 
wall can be calculated using wall height and system modulus. The preload can be determined by the designated design preload or maximum preload which is based on the maximum wall strength. Another function for this window is the ability to select convergence or preload for the x-axis on the graph. A warning is displayed in the lower right hand side of the screen if the wall can not meet the design criteria.

$$
y=\frac{P L \times L}{E}
$$

Due to the post-peak behavior of ventilation stopping walls, a peak thrust performance limit needs to be added to the Hybrid Theoretical Lateral Displacement Model. This limit is due to the material strength of the block/wall and defines the post peak response. The thrust force reaches its predetermined maximum limit due to the material failure of the CMU block. This constant thrust results in a decrease in the postpeak transverse pressure. The post-peak limit is based on modulus of elasticity and block strength and a specific limit is designed set for each block category and block type. 


\subsubsection{Construction Details}

The next window in the program is called Construction Details (Figure 26). The program calculates the total number of blocks and wall installation time. Using a material cost per block, labor cost, and available time per shift the cost of installation can be calculated. Work is based on the block weight and the lifting height. The unit block weight is dependent on the particular block type and can be specified as $1 \mathrm{~b} /$ piece. The default unit weights are specified in the data file for the block. The program determines the total wall weight based on the unit block weight and the number of blocks (pieces/ feet of height). The wall weight is added to a fixed weight and multiplied by the average lifting height ( $1 / 2$ the entry height) to determine the average work required per block.

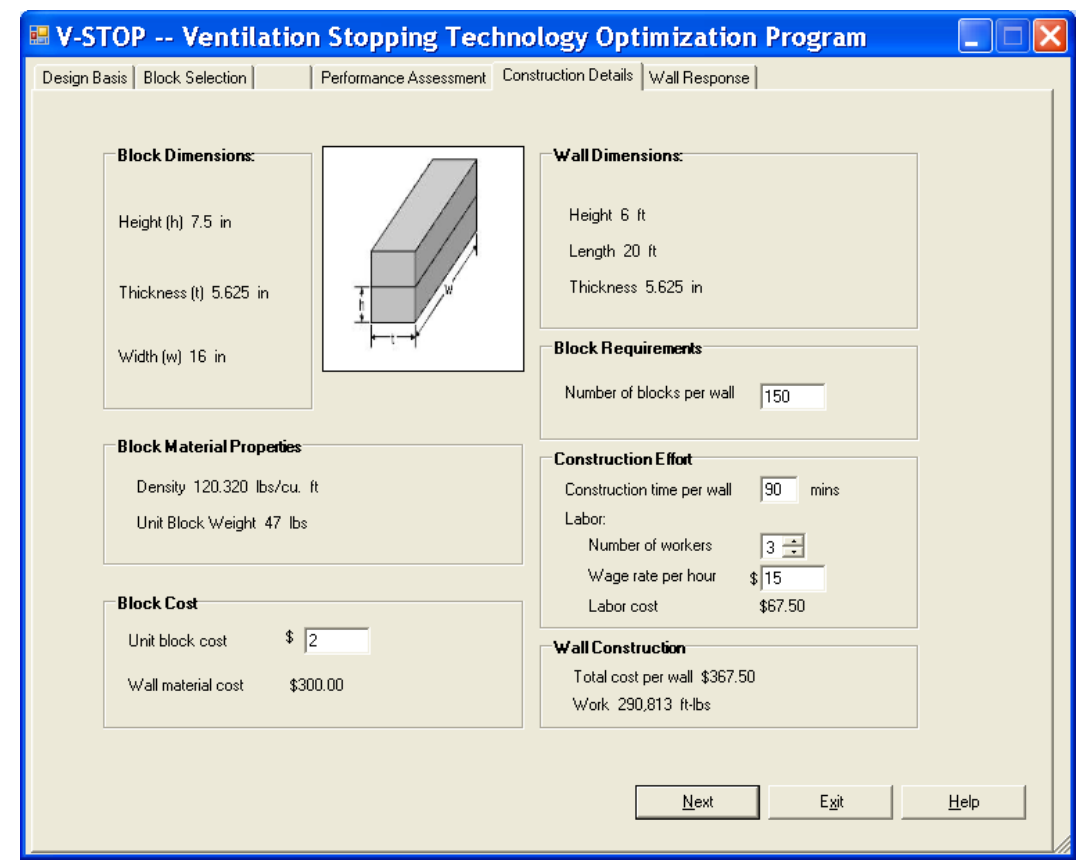

Figure 26. Construction Details window for V-STOP for selected block. 


\subsubsection{Wall Response}

The Wall Response window (Figure 27) shows a comparison of the wall performance for three different configurations. The first configuration displays a graph showing the transverse pressure as a function of preload pressure for the selected wall height (red), and thickness plus two additional curves (blue and green) that are one block height higher and lower, respectfully, than the originally selected wall height. This graph demonstrates the effect of wall height on the transverse pressure capacity of the wall. The second configuration (Figure 28) displays a graph showing the transverse pressure performance with the selected wall height and thickness (red) and a second curve when an isotropic block is rotated (blue) to change the wall thickness. This graph demonstrates the effect of wall thickness on the transverse pressure capacity of the wall. The final configuration (Figure 29) displays the transverse pressure performance graph with the four different surface contact conditions. This configuration shows the theoretical impact of the boundary stiffness by varying the system modulus of the system.

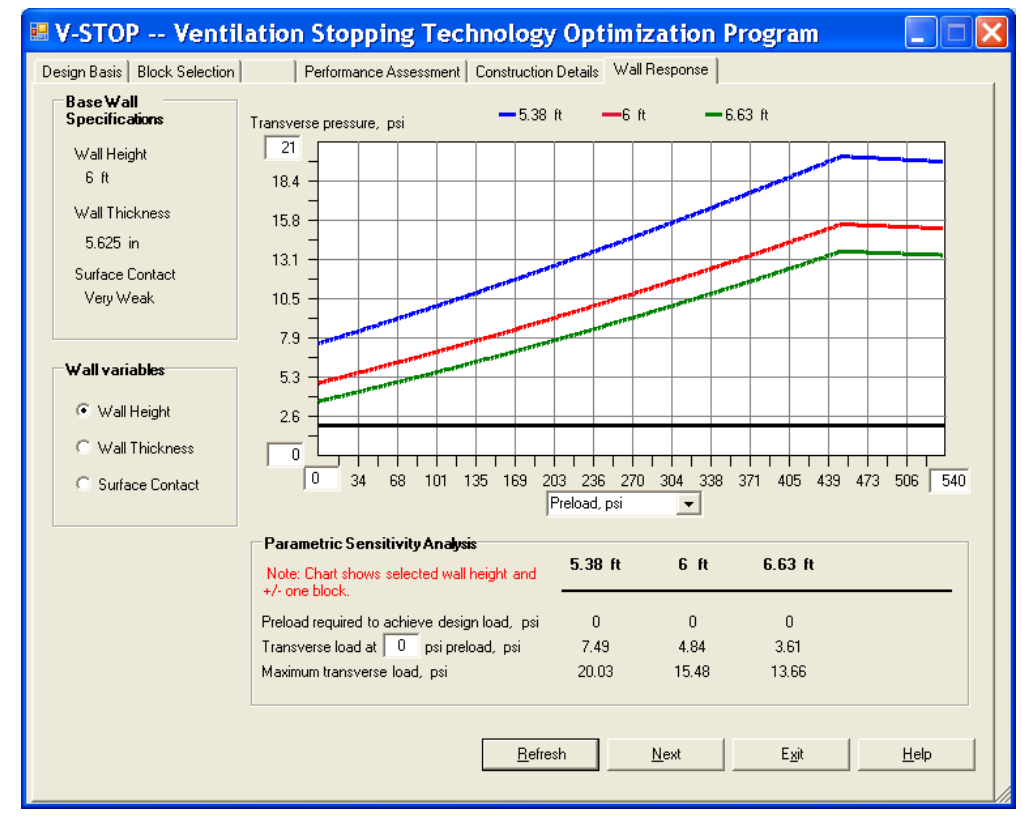

Figure 27. Wall Response window displaying the height variable for V-STOP. 


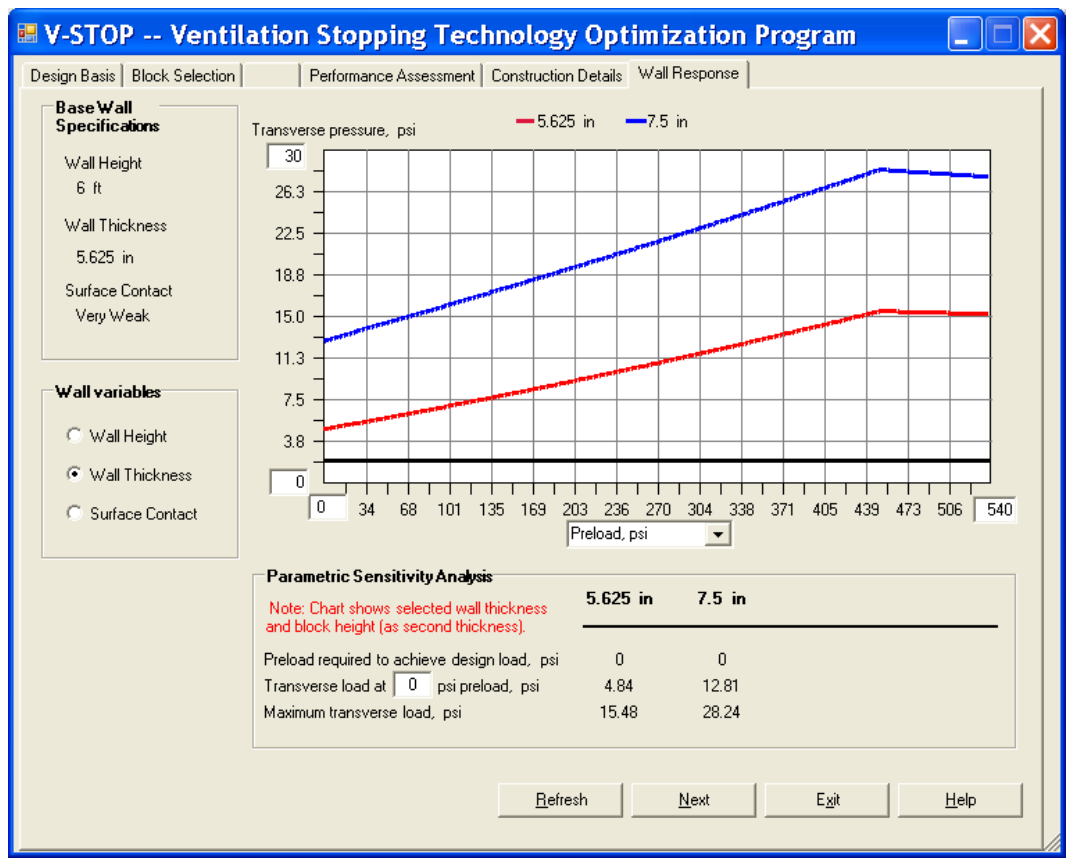

Figure 28. Wall Response window displaying the thickness variable for V-STOP

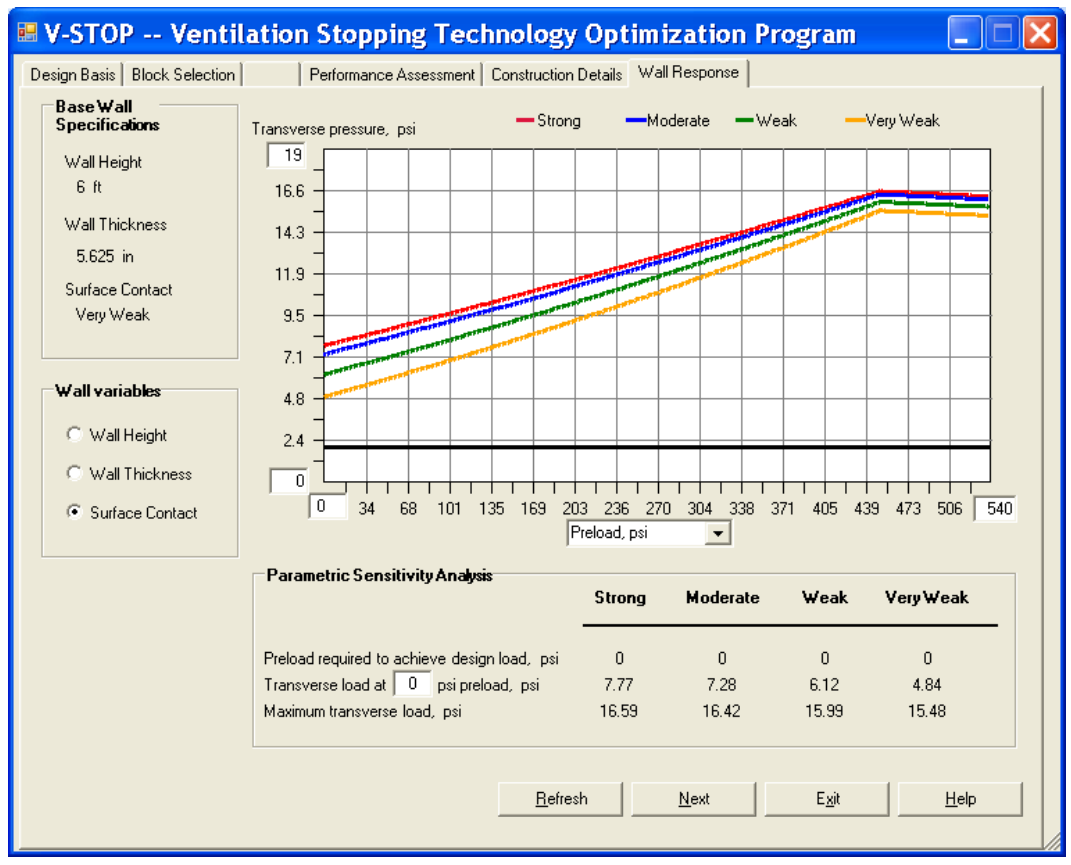

Figure 29. Wall Response window displaying the surface contact in V-STOP 


\subsubsection{Details of deformable material}

Deformable materials are sometimes added to ventilation stoppings constructions to prevent damage caused by convergence in coal mines. However, adding deformable materials can significantly reduce the capacity of a stopping to resist transverse pressure. Figure 30 and Figure 31 show the transverse pressure capacity response to adding a 2-in layer of polystyrene foam to a 6-ft high mine ventilation stopping. By design, the deformable material is a weaker material (lower modulus of elasticity) than the material used to construct the ventilation stopping. Therefore, the wall will create its "hinge Points" at the location of the deformable material. Demonstrated in Figure 31 the response to the transverse pressure is significantly delayed allowing for more convergence before the wall is able to withstand the stopping walls without deformable materials.

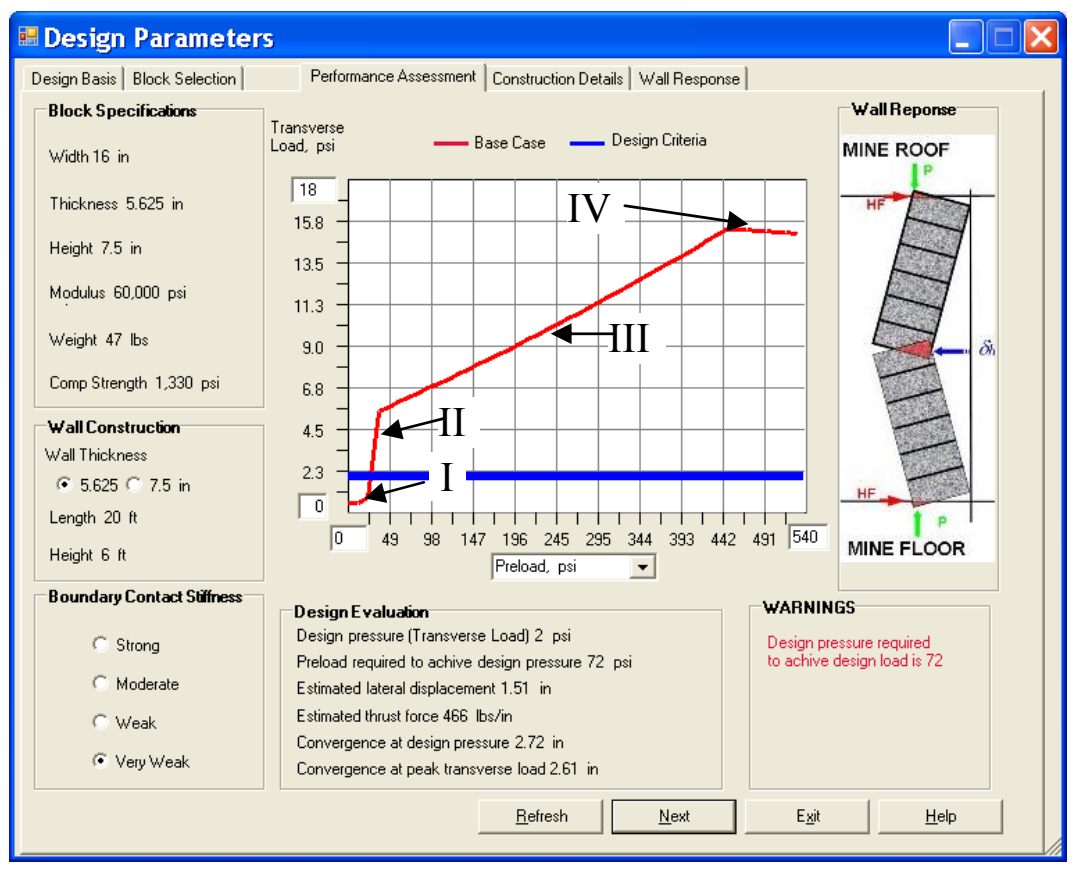

Figure 30. Transverse pressure vs. preload comparison with 2 -in foam layer. 


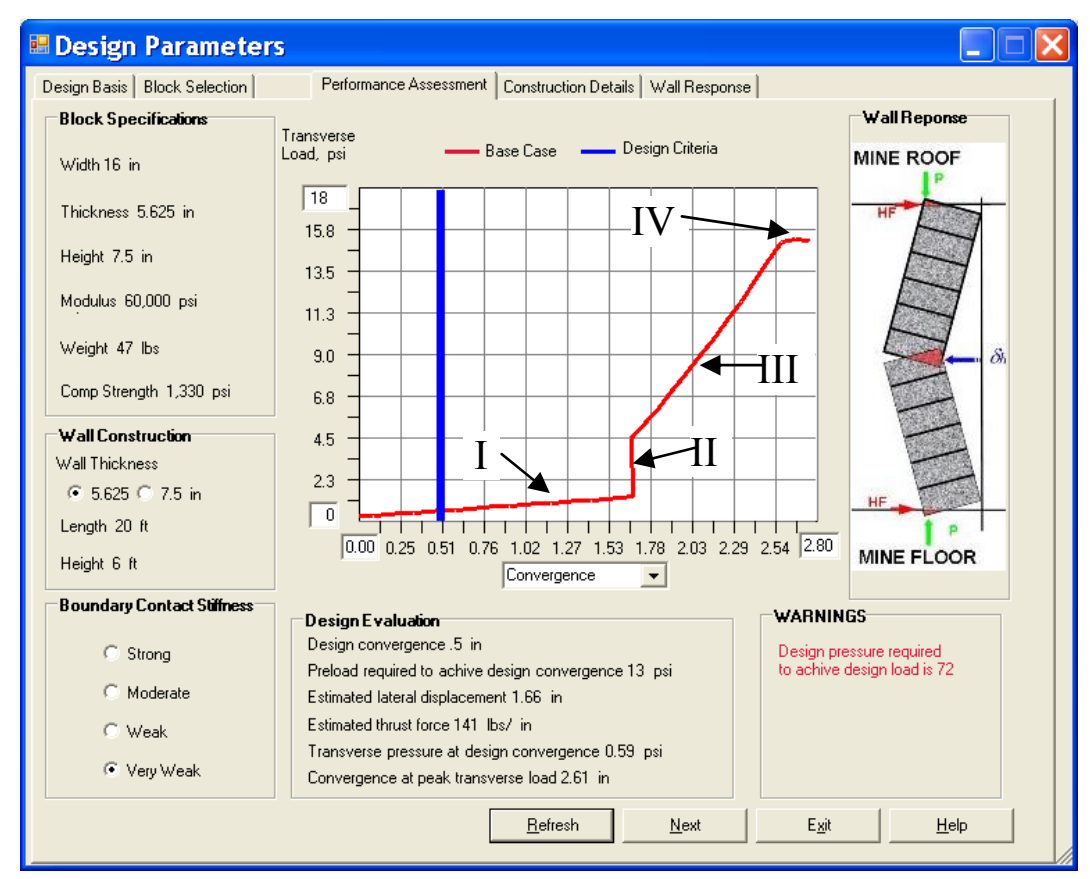

Figure 31. Transverse pressure vs. convergence comparison with 2-in foam layer.

The performance chart in Figure 30 indicates a significant increase in transverse load capacity at 27 psi of preload (Phase II). This is due to the change in the system modulus of elasticity of the stopping wall. As preload causes increased convergence, the system modulus of elasticity of the wall can change. At higher preloads the compressive forces developed within the wall can strain-harden or crush the deformable material to reach a system modulus closer to the rigid abutment situation (Phase III). Shown in the Figure 30 example, using 2-in polystyrene foam in a 6-ft tall CMU wall provides an unloaded initial system modulus of 4,824 psi (Phase I). Eventually, the foam causes the wall to react with a modulus of elasticity of approximately 60,307 (Phase III). This creates a rigid abutment type system similar to a stopping wall without any deformable material. Based on test preformed (Appendix C) the foam achieves a rigid abutment type system at approximately $80-90$ percent of the foams thickness. 


\subsubsection{Summary Report}

After the analysis of various stopping wall constructions and loading conditions, a summary table lists the design parameters for each configuration. When the Block Selection window is selected the list of blocks used in the analysis appears. Then by selecting the "Summary Report" button, a new window (Figure 32) will appear displaying the block parameters. This Summary window will display a tabular output of all the blocks characteristics chosen for analysis. The scroll bars can be used to move through the table or maximize the window to show more of the table. The table can be printed by selecting the "Print" button at the bottom of the window.

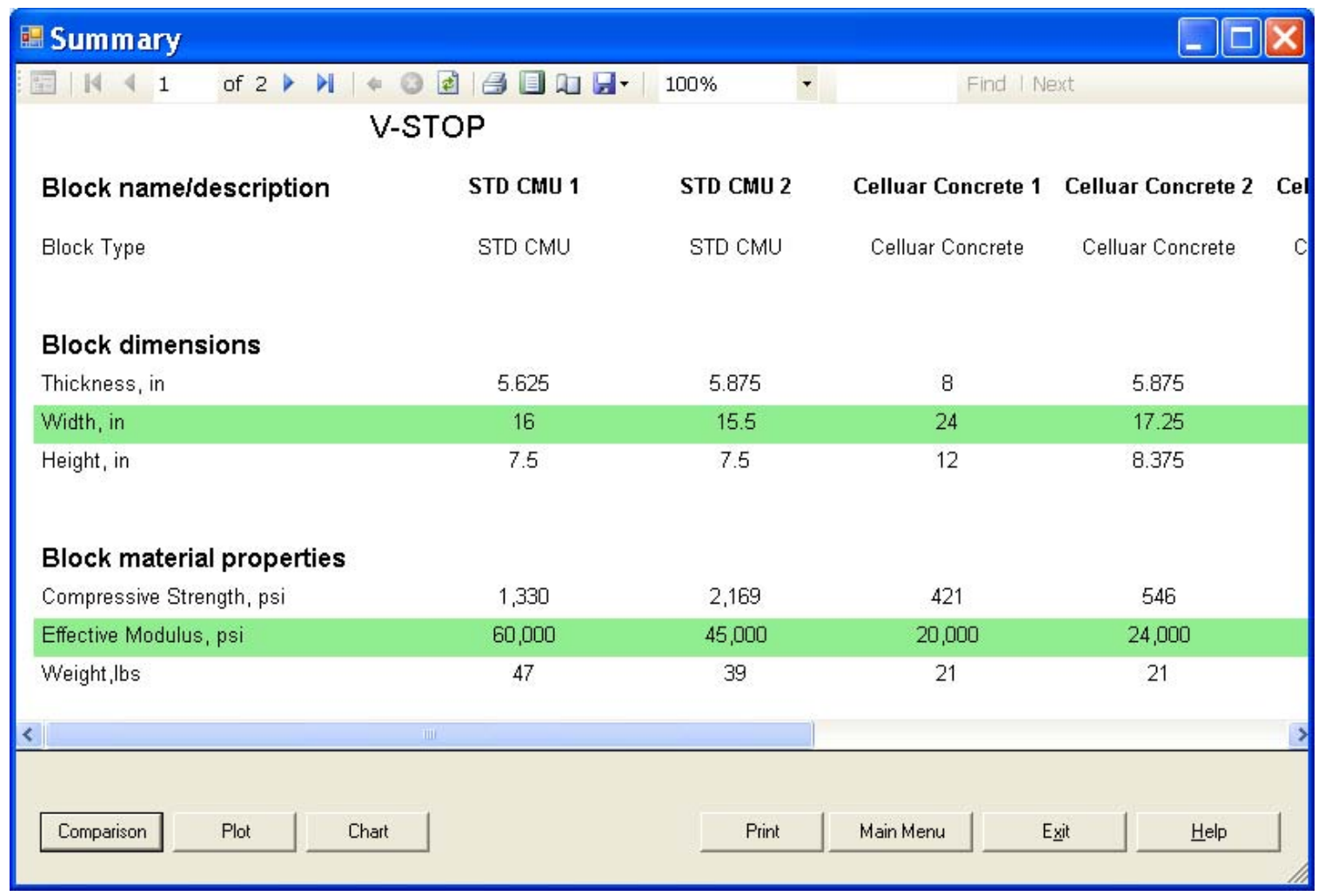

Figure 32. Summary window displaying the Comparison of selected ventilation blocks. 
A plot of the transverse pressure as a function of either preload or convergence is displayed when the "Plot" button is selected in the summary window (Figure 33). In the "Block names" block, the list of defined blocks used for the wall construction is shown. By selecting the checkbox associated with a specific block name will plot a curve on the graph. If the checkbox is unchecked it will hide the appropriate line from the graph. The scaling for the axis can be user-specified or the automatic scaling for the maximum axis limit. This graph can also display convergence on the $\mathrm{x}$-axis by selecting the convergence radio button in the "Plot comparison" box.

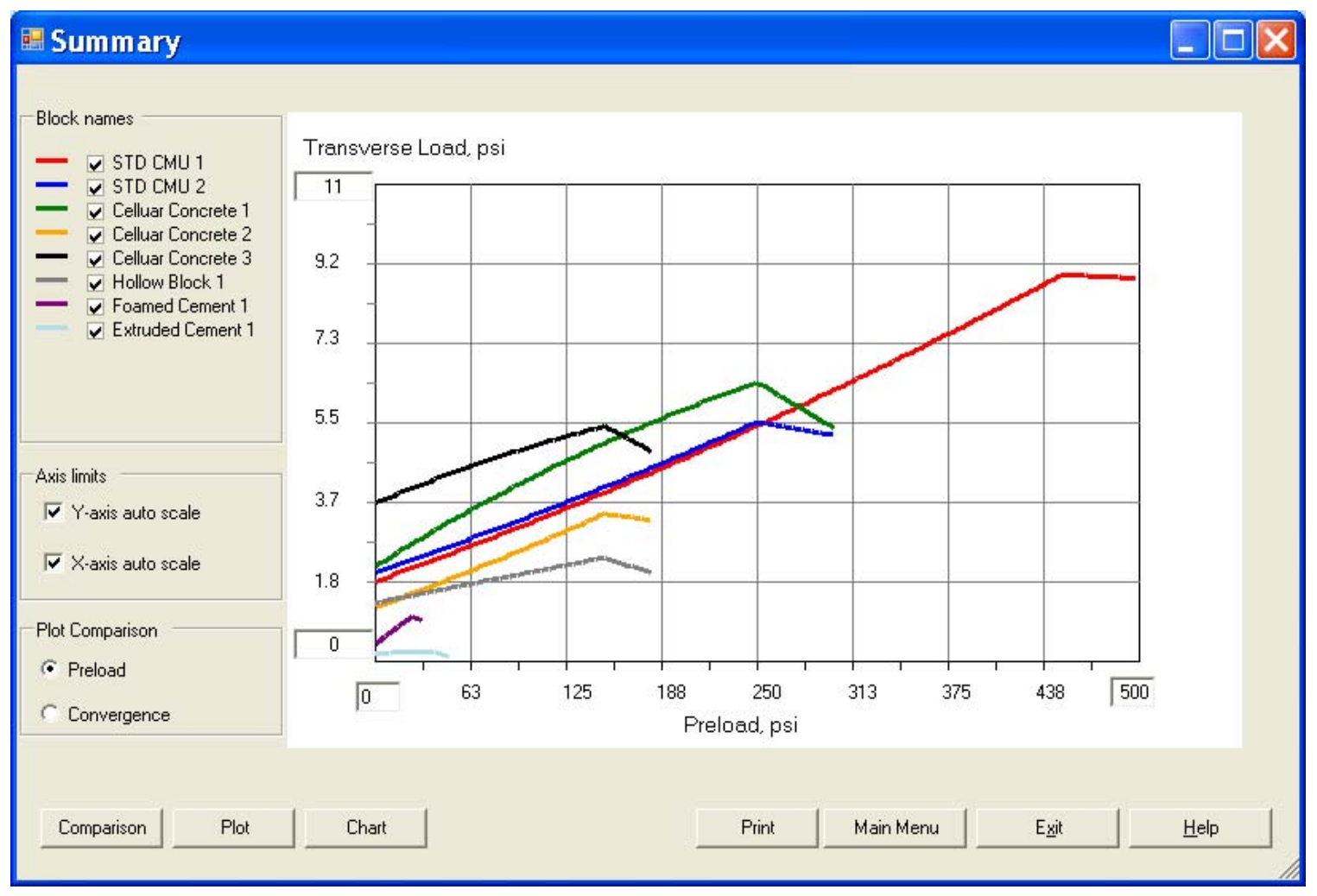

Figure 33. Summary window displaying the Plot of selected ventilation blocks. 
Figure 34 is displayed when the "Chart" button is selected in the summary window. In the "Block names" block, the list of defined blocks will be shown. If the box next to the block name is checked, it will show the parameter to be plotted and the color of the bars selected. The drop-down menus are used to group the parameters into three categories, corresponding to the groups displayed in the comparison table:

- Design Evaluation

- Block Material Properties

- Construction Details

The full list of parameters can be found in appendix B.

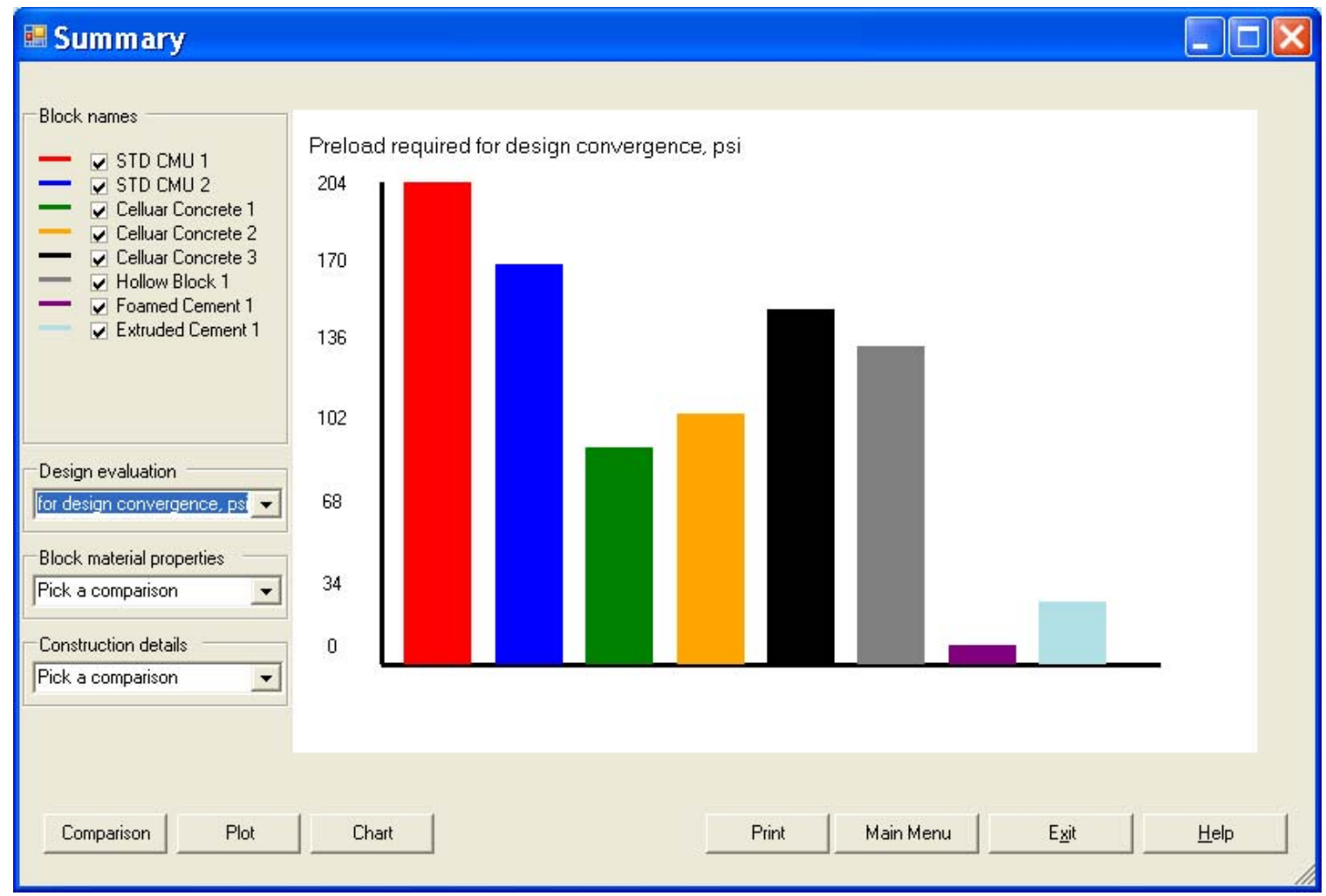

Figure 34. Summary window displaying the Chart of selected ventilation blocks 


\subsection{Verification of V-STOP}

Several tests were preformed in order to confirm that V-STOP is properly representing the loading mechanism controlling the transverse pressure capacity of mine ventilation stoppings. These tests used the MRS half-wall rigid arching testing protocol and were conducted at the Pittsburgh Research Laboratory. Test data were also analyzed for deformable material wall constructions to verify its behavior in V-STOP. 


\subsubsection{Example 1}

Specific assessment is needed to verify the accuracy of the V-STOP program. For the first example, the MRS tests utilize a conventional solid concrete aggregate block wall with a thickness of 5.625 inches and a wall height of 5 feet. The modulus of elasticity of the wall was 60,000 psi and load frame platens represent a rigid boundary conditions. Figure 35 illustrates the results of the tests at the MRS and the V-STOP solution. The red squares represent the measured MRS laboratory test results for the peak transverse pressure as a function of the preload pressure. The red line represents the V-STOP solution for a 5 -ft high, 5.625-in thick wall with a modulus of elasticity of 60,000 .

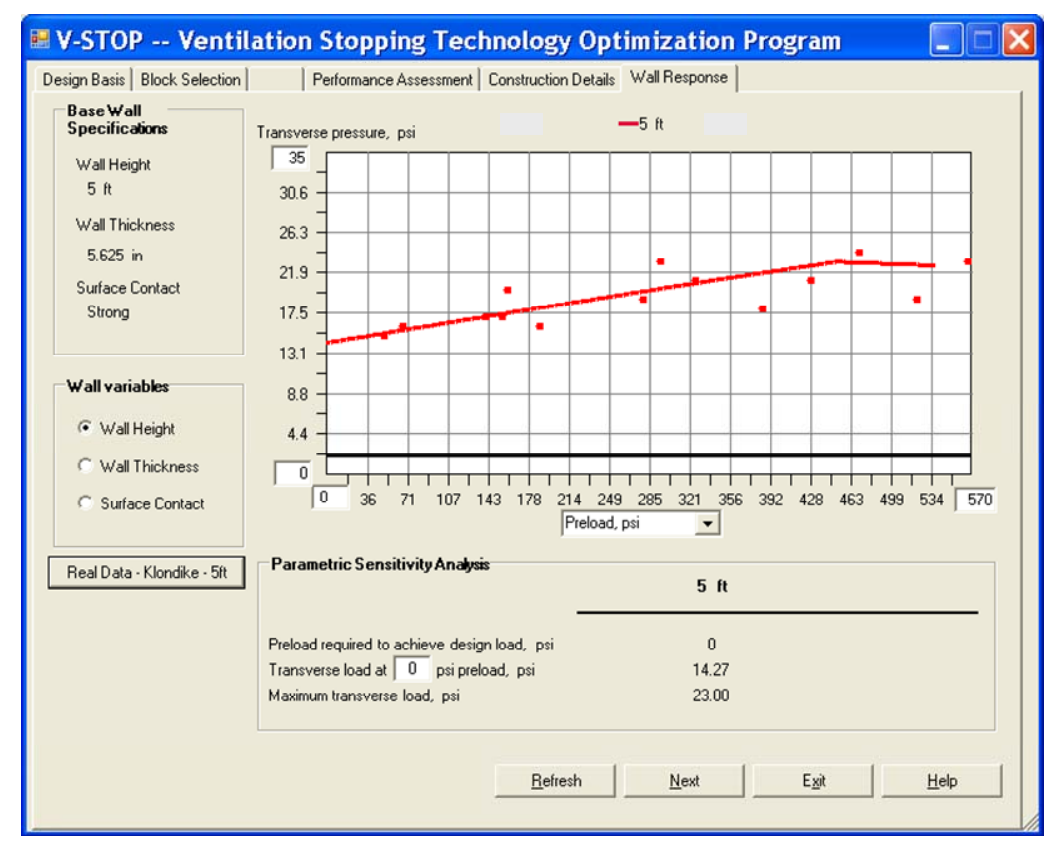

Figure 35. Comparison of CMU half-wall rigid-arch test in MRS to V-STOP simulation.

As seen from Figure 35, V-STOP simulation typically predicted the half-wall behavior in the MRS test within a 7 percent error. It is seen that 92 percent of the data 
falls within this variation. The discrepancies of the results may be attributed to the nonhomogeneous material of the concrete blocks.

\subsubsection{Example 2}

The Cellular (Aerated) Cement block is a different class of block than the conventional CMU. The low density allows for a larger block size while maintaining a similar weight to the CMU. Figure 36 displays the accuracy of the V-STOP simulation relative to the MRS tests. The MRS tests evaluated stopping half-walls there were 8-in thick and 48-in high representing a full height of 8-ft. The modulus of elasticity of the block was 20,000 psi and the boundary conditions represent a nearly rigid condition. This comparison also demonstrates the accuracy of the V-STOP analysis.

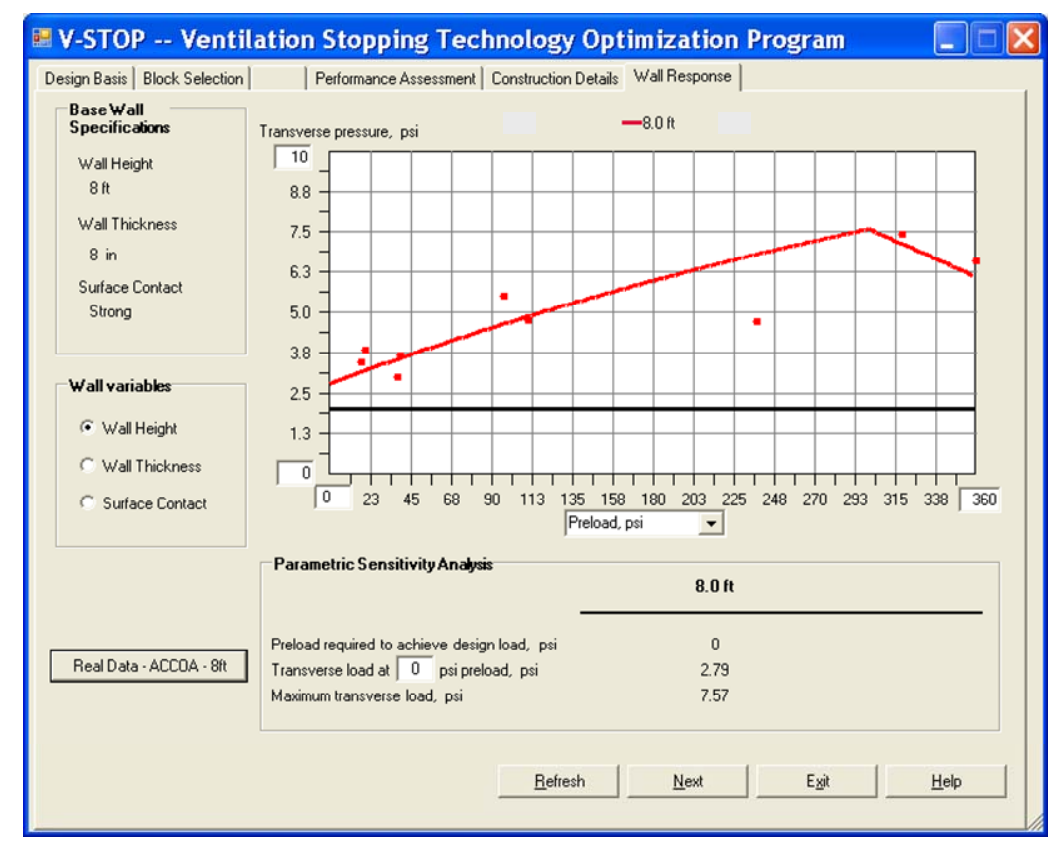

Figure 36. Comparison of Cellular half-wall rigid-arch test in MRS to V-STOP simulation.

As seen from Figure 36, V-STOP simulation typically predicted the halfwall behavior in the MRS test within an 8 percent error. The discrepancies of the results 
again may be attributed to the non-homogeneous material of the concrete blocks. It is seen that 88 percent of the data falls within this variation.

\subsubsection{Example 3}

Deformable materials can have a large effect on the transverse capacity of the mine ventilation stopping. These deformable materials can have a large effect when minimal preload in action on the wall, however it can still affect the performance of the wall at higher preloads. V-STOP uses the series equation for the modulus of the deformable material and the wall to determine the effect of the additional material (Section 4.4). The graph in Figure 37, shows the effect of a 0.8 inch of polystyrene foam on an 7.5-ft tall CMU concrete wall with a thickness of 5.625 inches and a modulus of elasticity of $60,000 \mathrm{psi}$ on the transverse pressure capacity of a mine stopping. This result is verified by the MRS tests shown as red squares.

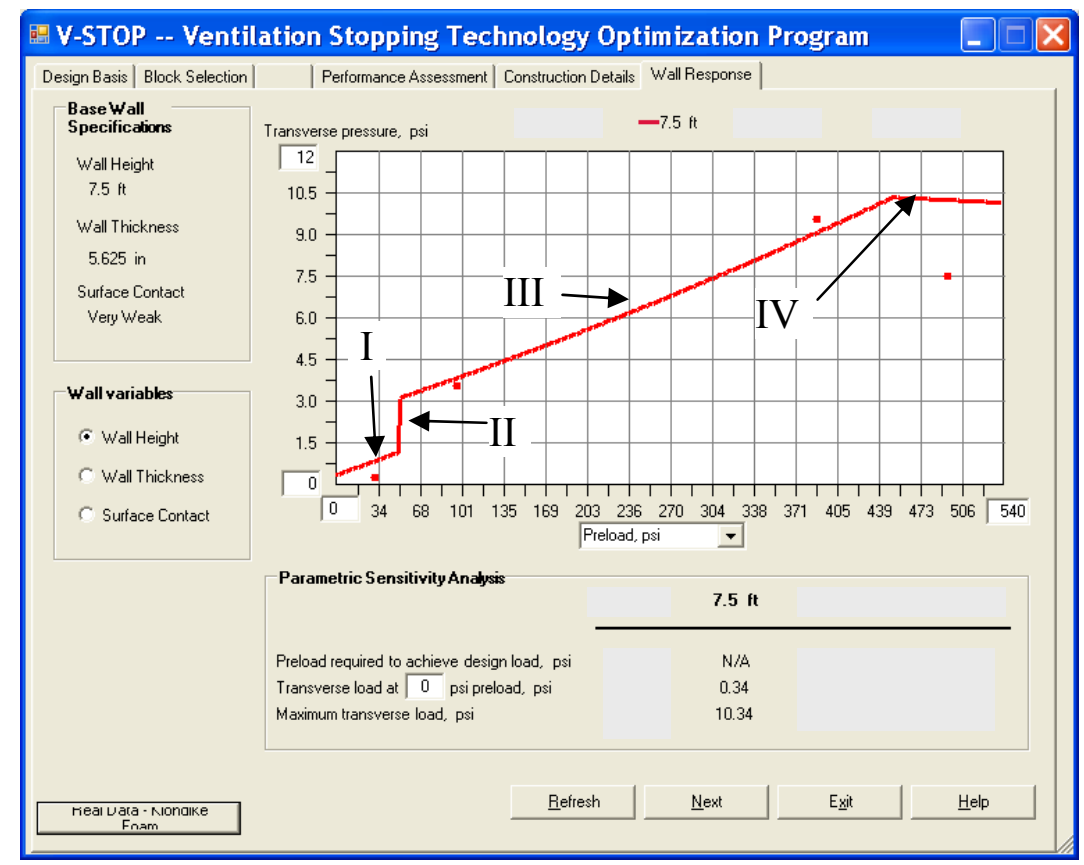

Figure 37. Comparison using deformable material (foam) on a CMU half-wall arch test to V-STOP simulation. 
Phase I shows the results of the polystyrene foam in the ventilation walls and its effect of lowering the transverse pressure. During phase II the polystyrene foam reaches its peak compressive strength and crushes out causing the stopping wall to react in a nearly rigid state. Phase III shows the walls reacting similarity to a wall without polystyrene foam and as the preload increase the wall will react in a nearly rigid abutment system. Phase IV shows the wall after it has reached its peak compressive strength. During this phase the stability of the wall can weaken and lower the transverse load capacity of the stopping wall. For this example, four test were preformed demonstrating polystyrene foam as a deformable material. Preloads on the walls were: 31, 98, 388, and 494 psi respectfully. The results for the three lower preload tests were consistent with V-STOP prediction. V-STOP predicted the wall behavior of the MRS test within 6 percent error. The forth test (494 psi preload) failed at a lower value than the predicted transverse load capacity. Transverse pressure is directly related to the material modulus of the stopping wall. When the preload (convergence) on a wall exceed the strength of the wall, the wall can fail at a lower transverse load capacity. This type of wall failure occurs in phase IV of V-STOP. Since the forth test (494 psi preload) was weakened by the preload it lowered the transverse pressure capacity of the wall.

\subsubsection{Example 4}

The next example shows the comparison of wood in the V-STOP analysis. This analysis uses a CMU concrete wall with the same material properties and dimensions as the previous example. However, the polystyrene foam was replaced with a 0.45 -in thick plank of wood. As seen in Figure 38 (phase II), the impact of the wood is not as drastic 
as the polystyrene. The V-STOP simulation (red line) does correlate with the MRS tests (red squares).

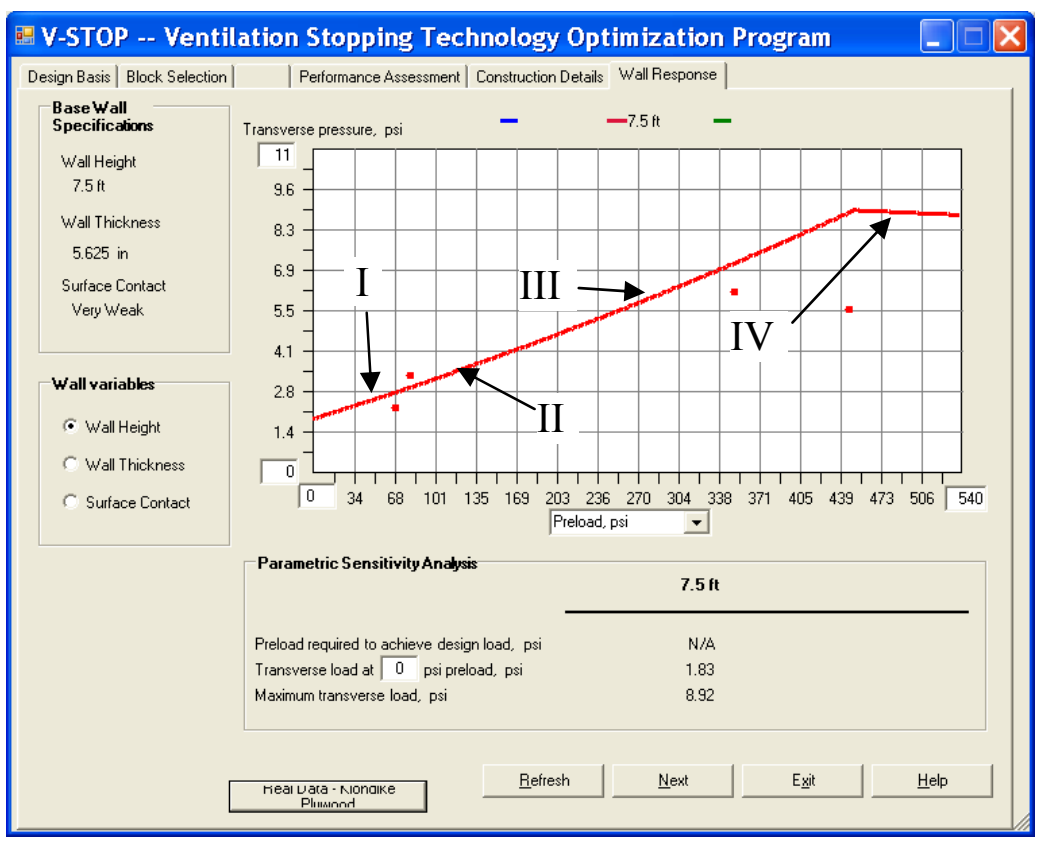

Figure 38 Comparison using deformable material (wood) on a CMU half-wall arch test to V-STOP simulation.

Phase I shows the results of the wood plank in the ventilation walls and its slight effect of lowering the transverse pressure capacity. During phase II the wood plank reaches its peak compressive strength causing the stopping wall to react in a nearly rigid state. Phase III shows the walls reacting similarity to a wall without wood plank and as the preload increase the wall will react in a nearly rigid abutment system. Phase IV shows the wall after it has reached its peak compressive strength. During this phase the stability of the wall can weaken and lower the transverse load capacity of the stopping wall. For this example, four test were preformed demonstrating a wood plank as a deformable material. Preloads on the walls were: $68,81,350$, and 446 psi respectfully. The results for the three lower preload tests were relatively consistent with V-STOP prediction. V-STOP predicted the wall behavior of the MRS test within 13 percent error. 
The forth test (446 psi preload) failed at a lower value than the predicted transverse load capacity again weakened by the preload.

Based on the half-wall tests preformed in NIOSH's Mine Roof Simulator, VSTOP can predict the transverse pressure capacity of a mine ventilation stopping. As seen in the above figures, the test wall data matched with the predicted response generated by V-STOP. 


\section{CHAPTER 5 - CASE STUDY}

This case study demonstrates how V-STOP can be used to design a mine ventilation stopping for a particular mining condition. The stoppings are to be designed for a three-entry longwall gateroad system having equal-sized chain pillars on 100-ft centers and crosscuts $184-\mathrm{ft}$ centers with a width $16 \mathrm{ft}$. The coal seam height is $7.5 \mathrm{ft}$. The crosscuts are driven $90^{\circ}$ to the gateroads. The roof/floor boundary conditions for the mine are a sandstone rock with a strong surface contact where the wall will interface with the mine roof and floor.

V-STOP was used to determine a mine ventilation stopping wall that can withstand 5 psi transverse pressure capacity and withstand a 0.5 in of convergence. The first step is to input the design criteria, construction dimension and boundary condition data into the program (Figure 39).

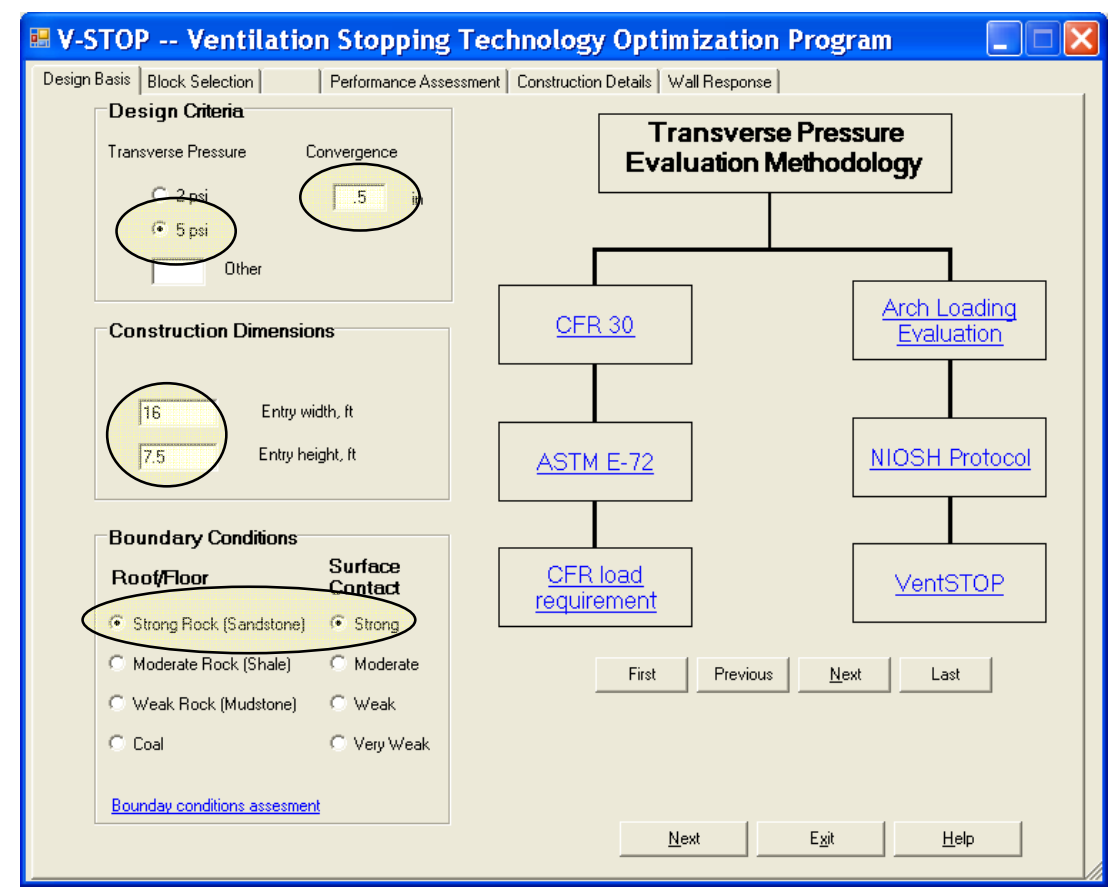

Figure 39. Design criteria, construction dimensions, and boundary conditions entered into V-STOP. 
The second step is to select the type of block used for the mine ventilation stopping wall. For this example a 7.5-in-wide standard CMU block was used with no stain-softening (deformable) material (Figure 40).

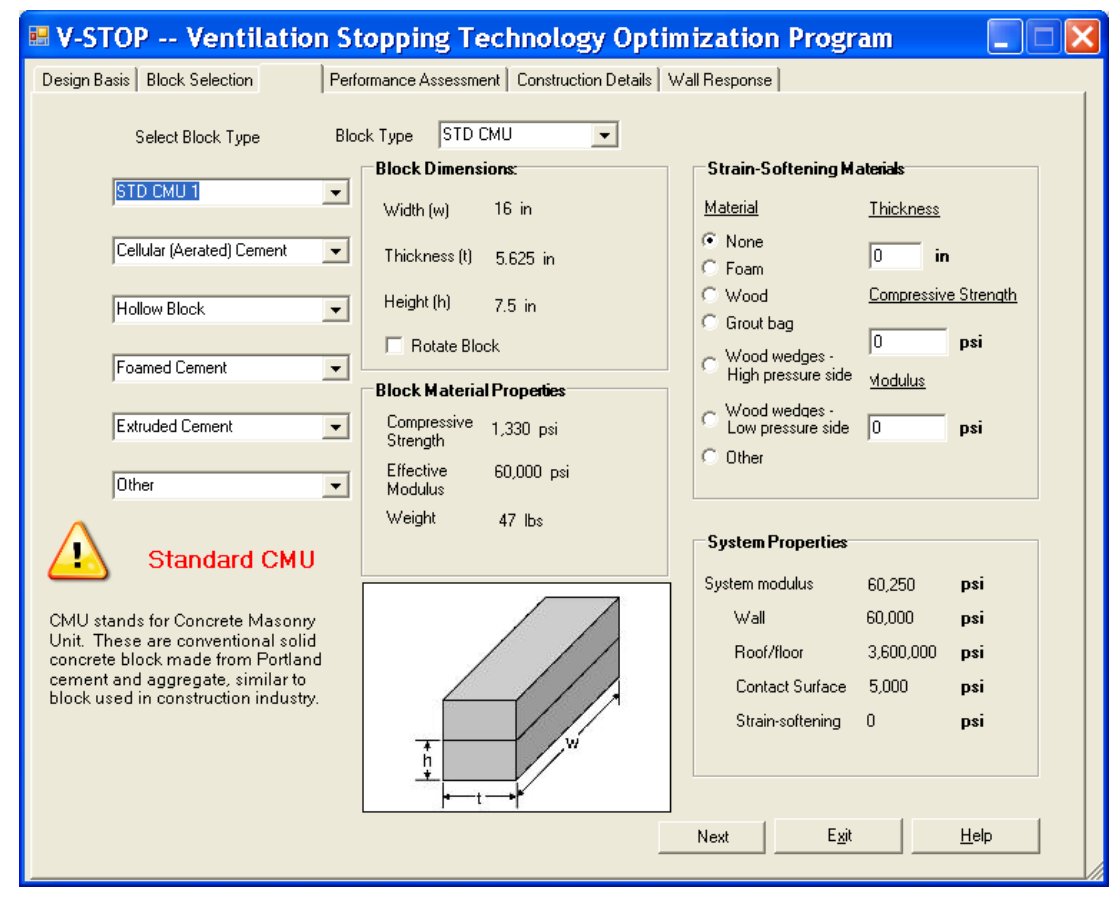

Figure 40. Standard CMU block parameters used for an example mine ventilation stopping.

After analyzing the block wall, a display is generated showing the transverse pressure capacity of the wall. Shown in Figure 41, the standard CMU wall is able to meet the 0.5-in design criteria for convergence (blue line). The green shaded section indicates the range of transverse pressure capacity under the 0.5 -in convergence design criteria. Also note, at 0.5 in convergence, the wall is still able to withstand 8.8-psi transverse pressure capacity well above the 5.0-psi design criteria for this scenario.

Figure 42 displays the transverse pressure response for the stopping wall as a function of preload pressure acting vertically on the wall This figure indicates that at low preload (highlighted in light blue), the wall will not meet the design criteria of 5 psi for 
transverse pressure capacity (blue line). However at preloads above 99 psi (highlighted in red), the wall will meet the design criteria.

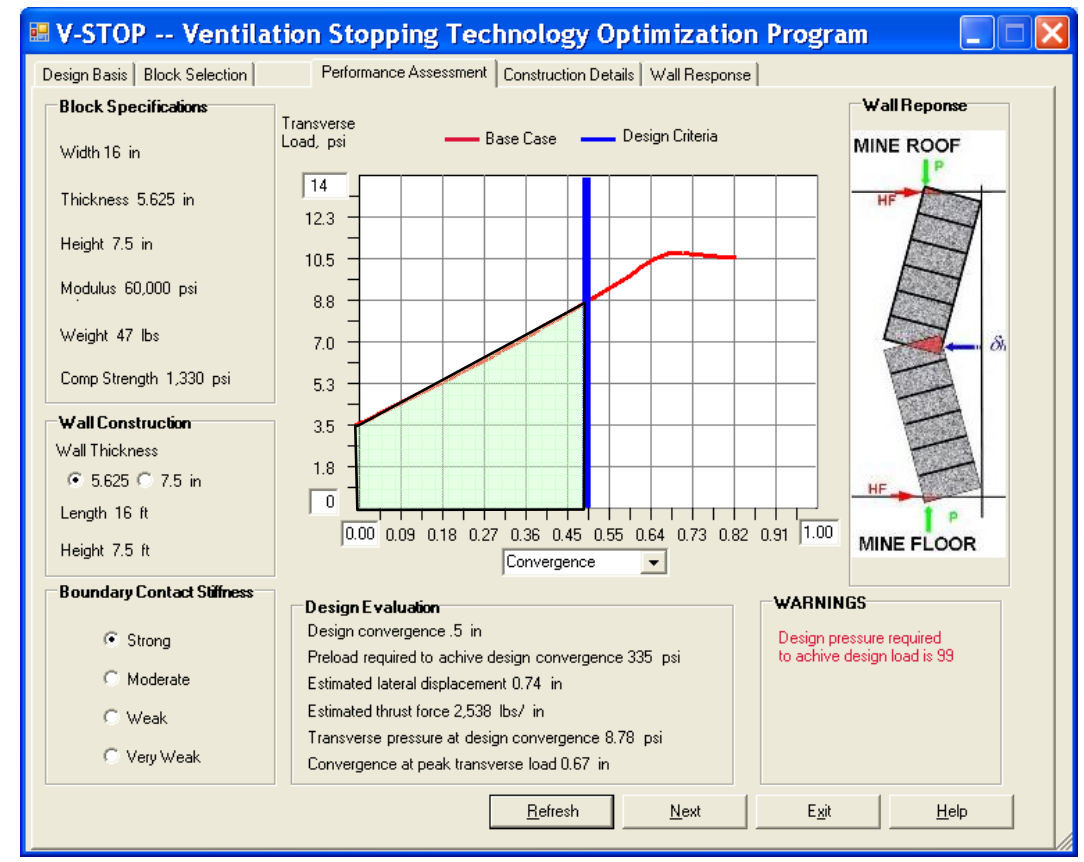

Figure 41. The green highlighted area on the graph shows that the standard CMU wall is able to withstand the 0.5 in of convergence design criteria.

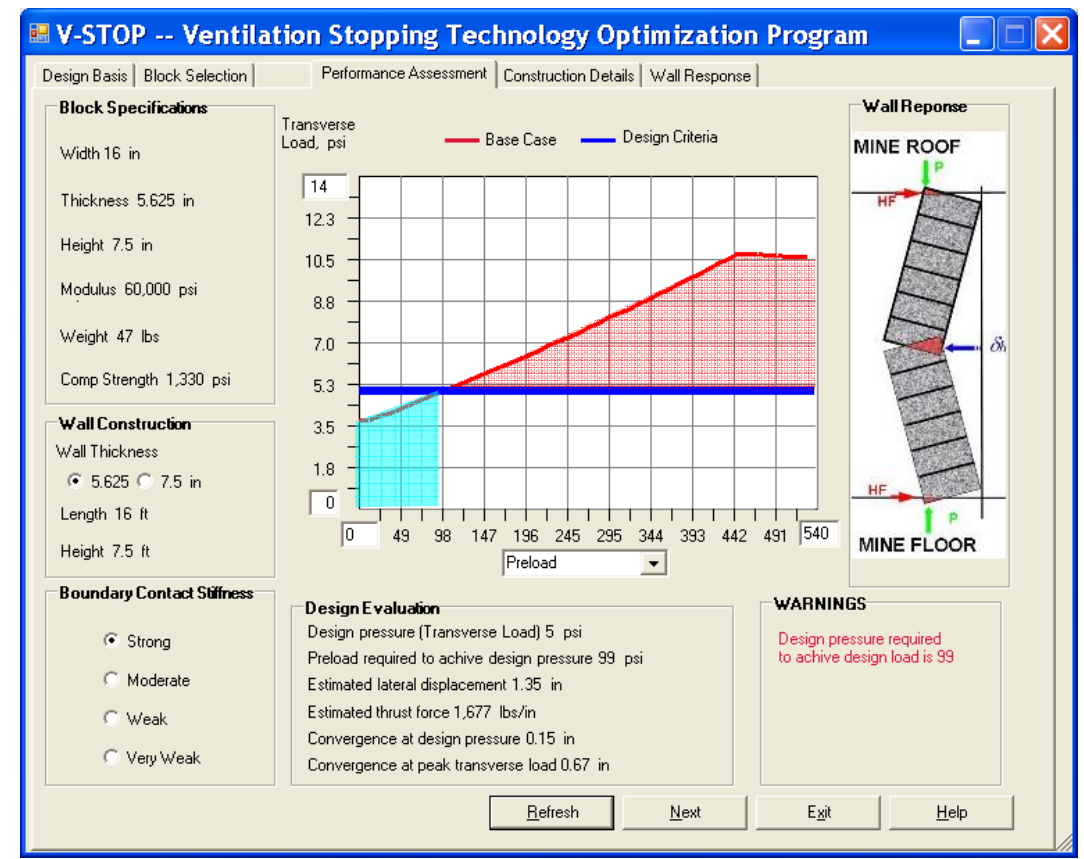

Figure 42. The red highlighted area demonstrates that the standard CMU wall can meet the 5 psi design criteria after initial preloading. 
The design criteria for the current stopping wall selection will only be satisfied if the wall has a preload above 99-psi or a convergence of 0.15 -in. The design criteria can be satisfied (highlighted in red in Figure 43) by rotating the block and changing the thickness to 7.5 in instead of 5.625 in. This will allow the wall to achieve the 5-psi criteria and still allow for the 0.5 in of convergence.

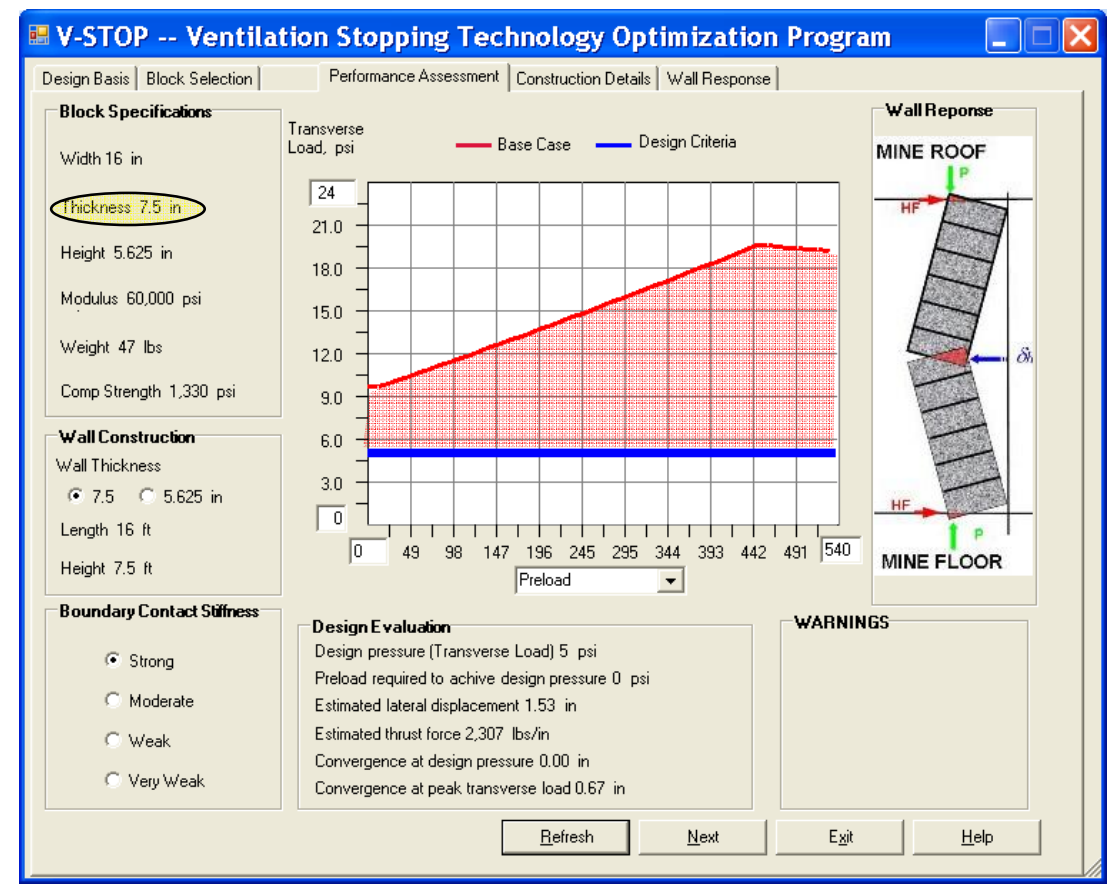

Figure 43. CMU block rotated to a thickness of 7.5 in to meet the transverse pressure design criteria of 5-psi.

The next example shows a stopping wall that is unable to meet the design criteria. This stopping wall uses an 8-in-wide foam cement block with no strain-softening (deformable) material. As seen in Figure 44, the stopping wall is able to meet the 0.5 -in convergence design criteria. However, Figure 45 shows the wall is not able to meet the 5-psi design transverse pressure criteria under any preloading situation. This example demonstrates how using a relatively thick wall $(8$ in) still does not meet the design criteria, since the wall strength and modulus are lower than the standard CMU wall. 


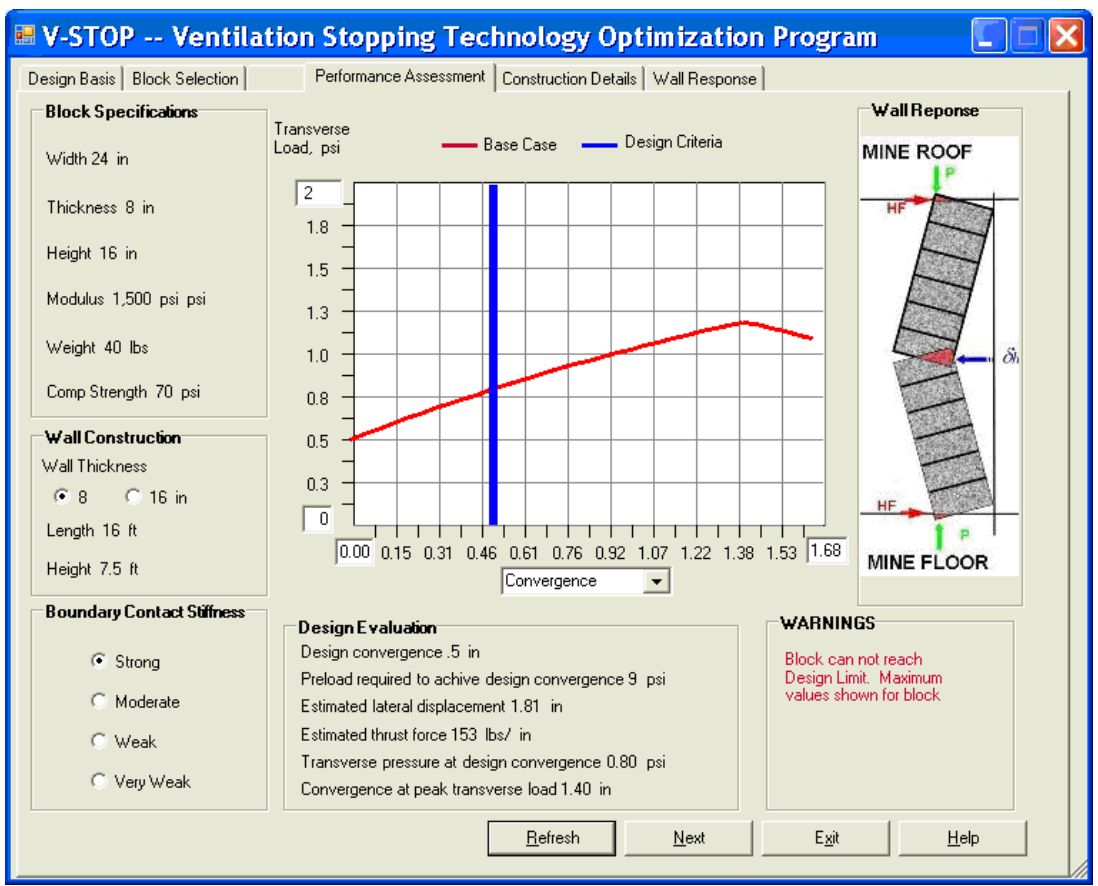

Figure 44. Foam block stopping wall able to withstand 0.5 in of convergence.

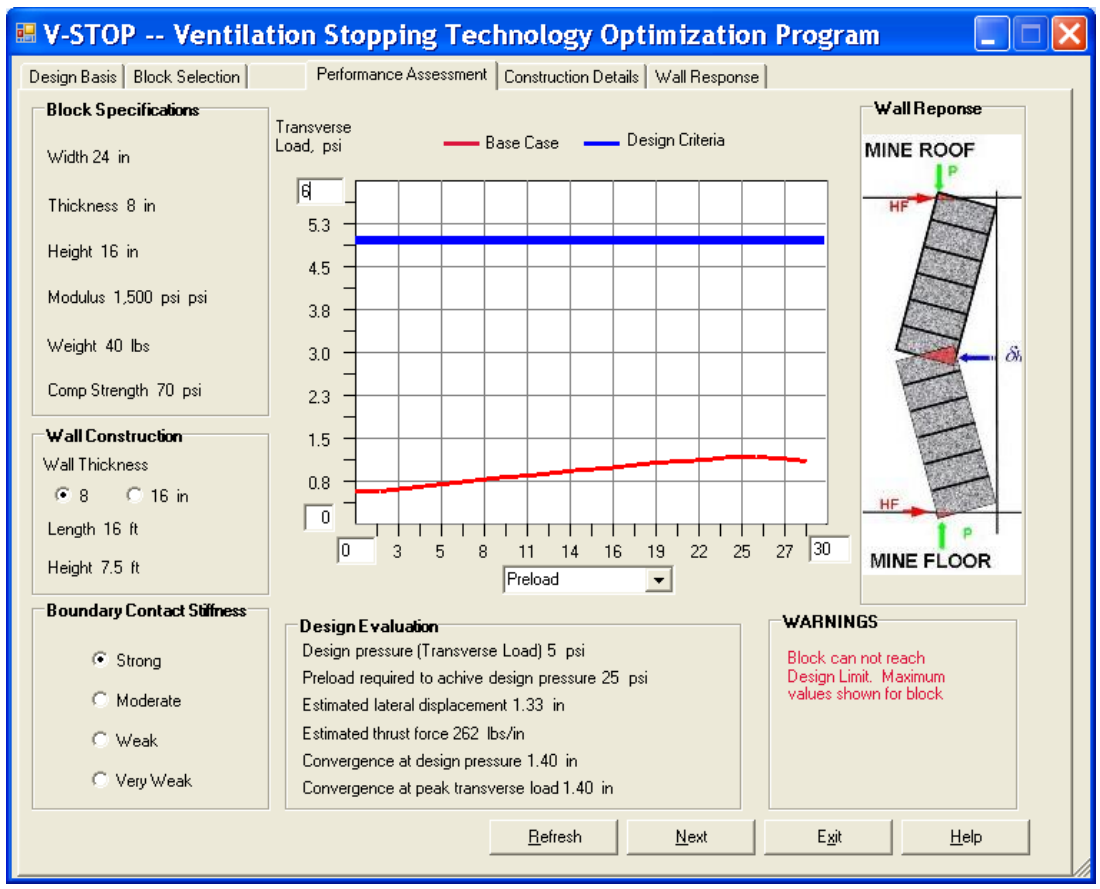

Figure 45. Foam block stopping wall unable to meet design criteria of 5 psi. 
Figure 46 shows a comparison plot of several different stopping wall constructions and the how they relate to the 5-psi transverse pressure design criteria. This plot indicates three of the stopping walls will meet the 5-psi design criteria without any preloading of the wall: STD CMU 1 (7.5-in thickness), STD CMU 2 (7.5-in thickness), and Cellular Concrete 2 (8.375-in thickness). Several of the others stopping walls will meet the design criteria after initial preloading: STD CMU 1 (5.625-in thickness), STD CMU 2 (5.875-in thickness), and Cellular Concrete 1 (8-in thickness). However, some of the walls will never reach the design criteria for transverse load capacity: Hollow block, foamed cement, and extruded cement. From this comparison graph, several stoppings could be constructed to meet the design criteria and successful used for mine ventilation control in this mine application.

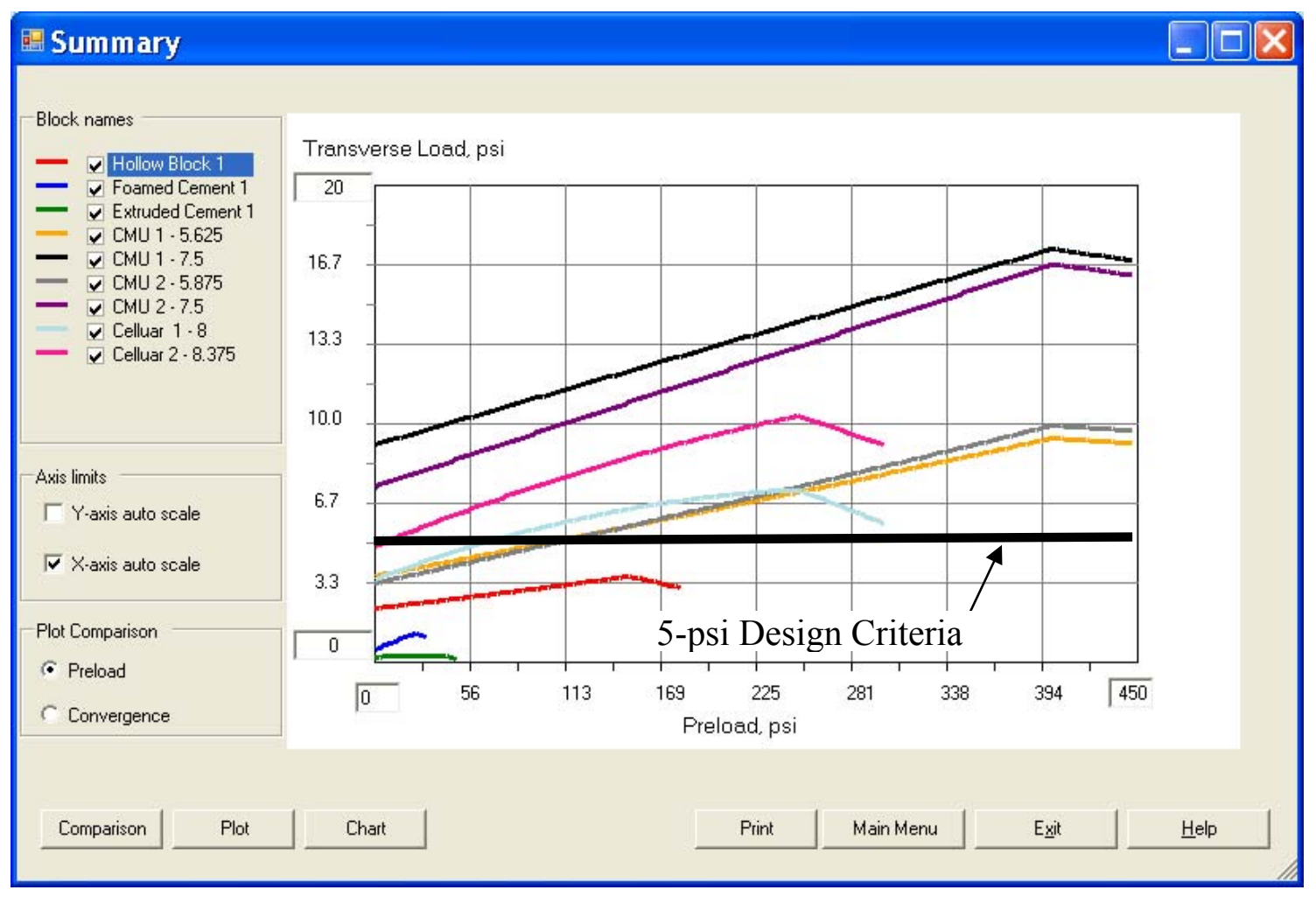

Figure 46. Comparison of various stopping walls constructions to the 5 psi design criteria. 
Figure 47 shows a comparison plot the stoppings walls and how they relate to the 0.5 in convergence design criteria. This plot indicates that all the stopping wall constructions can meet the 0.5 in convergence design criteria with the exception of the hollow block. This will qualify the majority of the walls with meeting the design criteria for convergence.

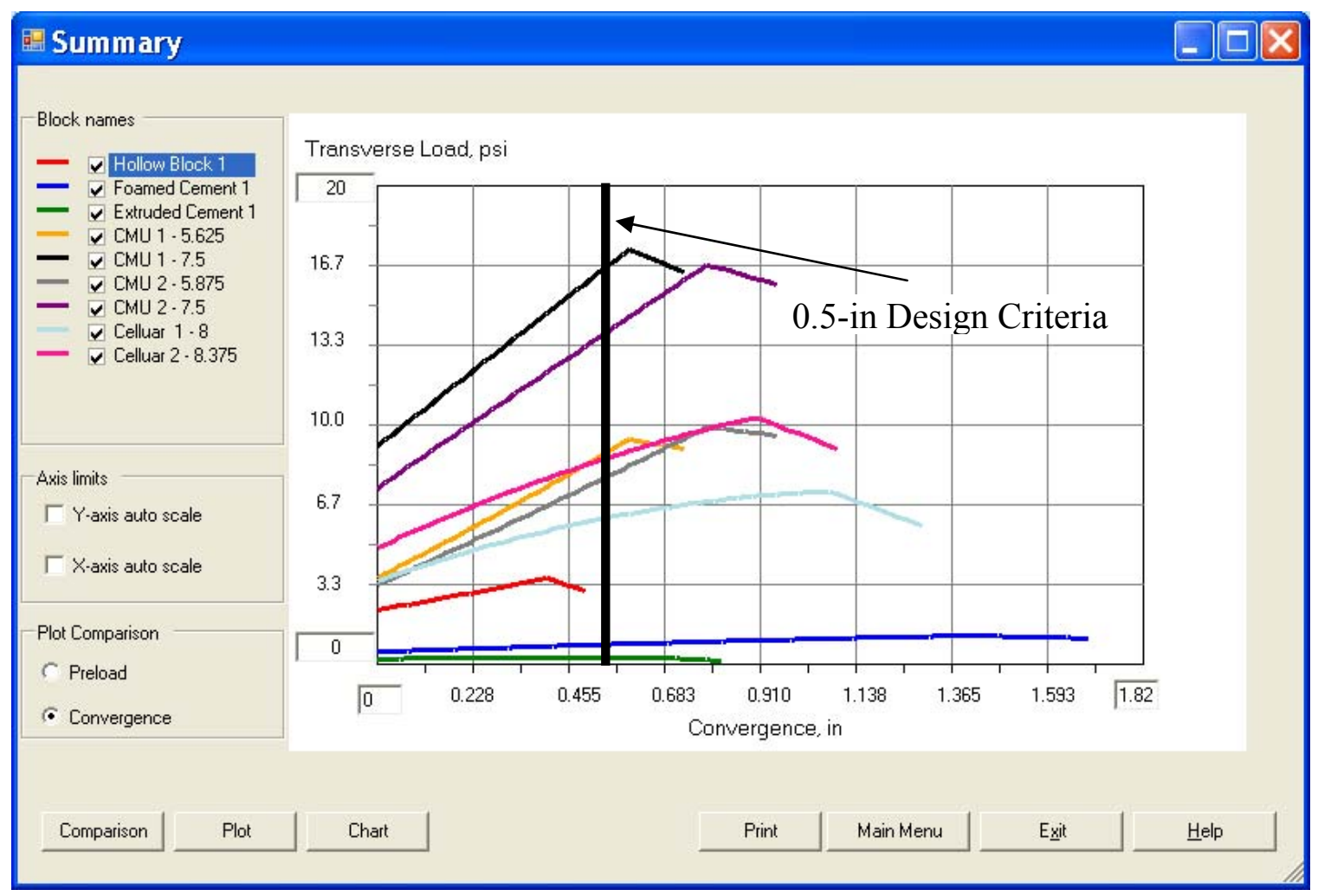

Figure 47. Comparison of various wall construction to the 0.5 in convergence design criteria.

The next case study requires the stopping walls to withstand 2.0 in of convergence and 5-psi of transverse pressure loading. Currently, none of the wall constructions can withstand 2 in convergence without the use of deformable material in the wall construction. For the first example, a 5.625-in thick standard CMU block was used construct a 7.5-ft-high with a 2.1-in-thick polystyrene foam layer at the top of the stopping wall. Figure 48 illustrates that the wall is able to withstand the 2.0 in of 
convergence. However, for the wall to withstand 5 psi of transverse pressure loading, the wall must have a preload of approximately 100-psi or greater, which as a result, essentially crushes the foam layer completely. Figure 49 shows that the addition of foam as a deformable material will allow the wall to yield but not allow the wall to withstand the required 5 psi of transverse loading.

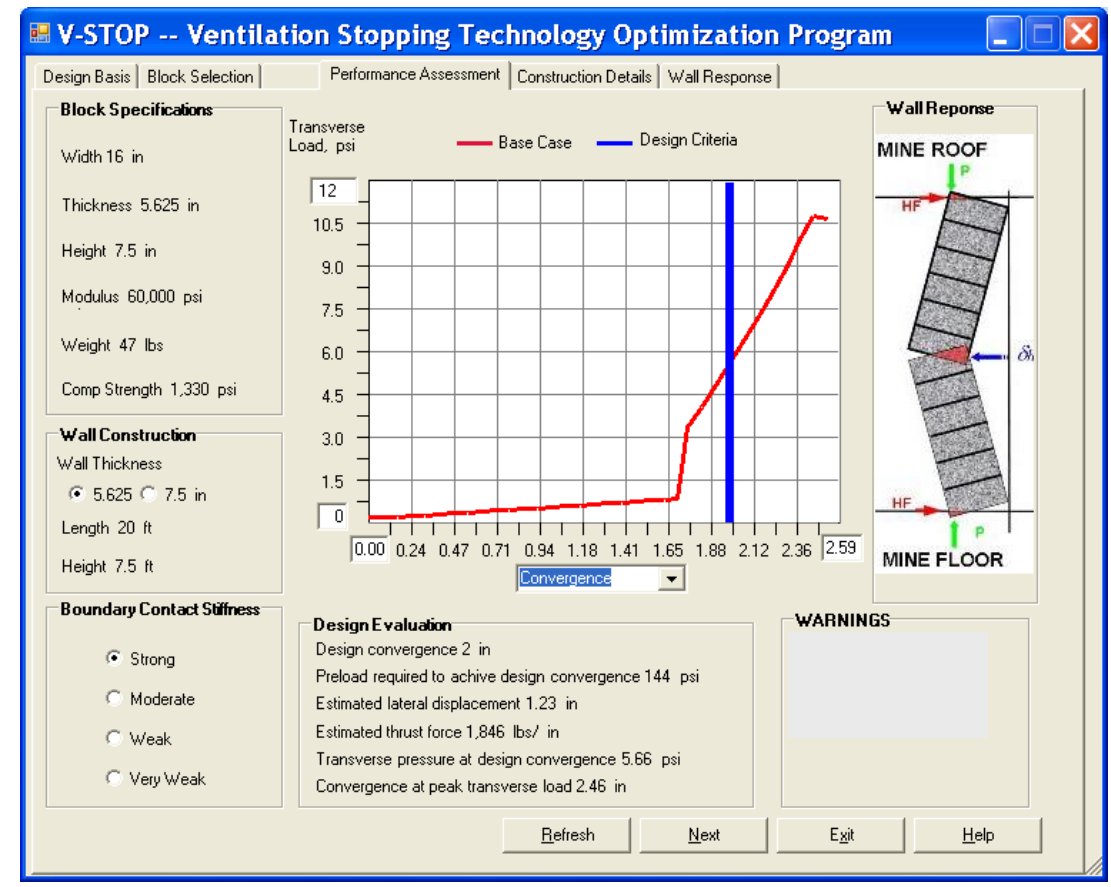

Figure 48. Convergence plot of a 2.1-in polystyrene thick foam layer added to standard CMU stopping wall its yield capability to increase meet 2 in of convergence. 


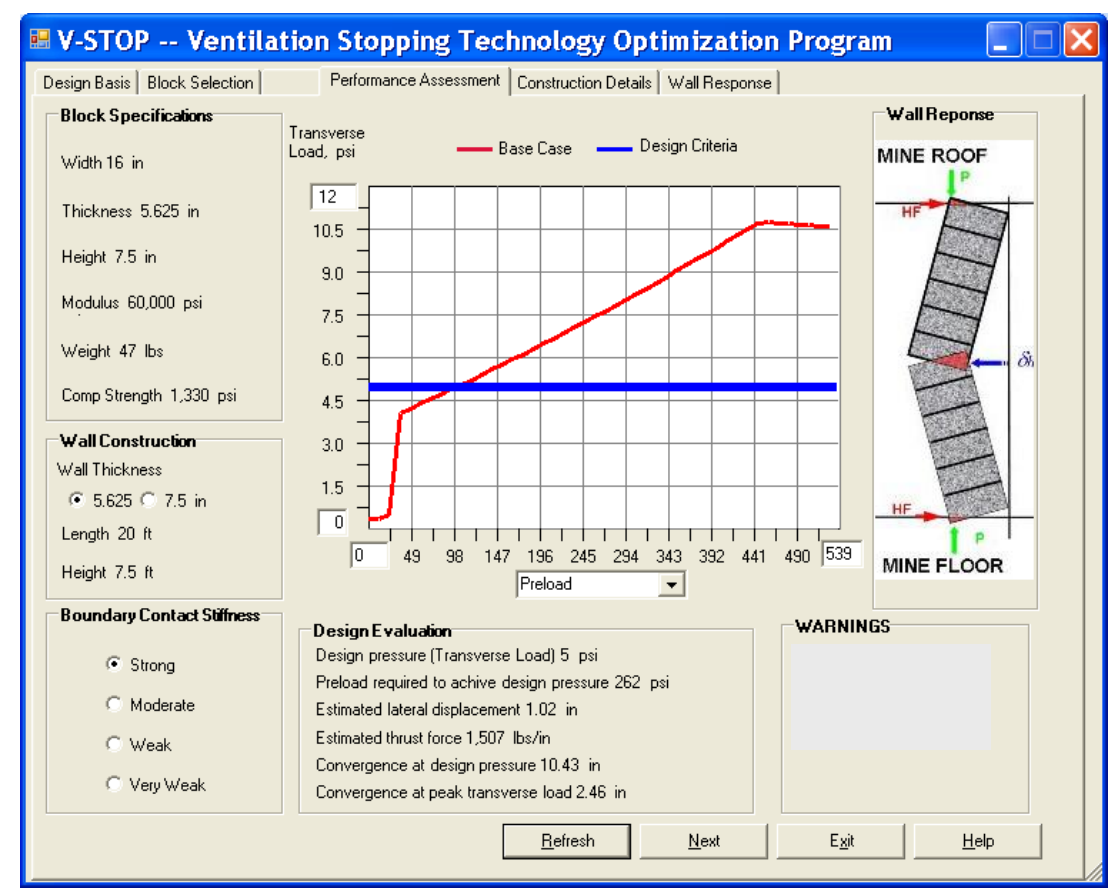

Figure 49. The transverse pressure capacity reaction of a standard CMU stopping to a polystyrene foam layer

In conclusion, the V-STOP program demonstrates that none of the design walls can meet the 5 psi transverse pressure design criteria and the 2.0 in of convergence in all preloading situations. However, it is possible under certain preloading circumstances for the criteria to be met. 


\section{CHAPTER 6 - SUMMARY AND CONCLUSION}

Ventilation stoppings are responsible for controlling the circulation of air throughout the mine. Typically, a ventilation stopping is a dry-stacked concrete block wall erected between the intake and return airways to direct ventilation air throughout the working sections of the mine. Ventilation stoppings are designed to withstand air pressure differentials (transverse pressure) generated by mine fans and can be adversely affected by extraneous events, such as, roof falls and gas ignitions.

Many factors can impact the transverse pressure capacity of a ventilation stopping wall. One of the main focuses of this thesis was the effects of boundary conditions and the use of deformable materials stopping constructions. Although ventilation stoppings have considerable resistance to most loading, they often cannot fully control the ground movement and are still subject to the closure of the mine entry. Introducing a deformable material into the stopping construction reduces the stiffness of the ventilation stopping wall by lowering the effective system modulus.

However, while adding deformable material can prevent premature failure from convergence, it will also degrade the transverse pressure capacity of the stopping under arch loading conditions. Arching theory established a link between elastic modulus of the system (E) is proportional to the arch thrust (P).

The transverse pressure is reduced when the arch thrust is reduced. Examination of the arching mechanics and demonstrates how arch thrust $(\mathrm{P})$ is related to transverse pressure capacity ( $\rho)$. The arching relationship shows that more of the transverse pressure capacity can be preserved by using a higher modulus material that is closer to 
that of the block. However, the compromise is that the higher modulus material reduces the capability of the stopping wall to absorb convergence without failing.

The arching theory was implemented into a full-featured computer program, called V-STOP, that calculates the transverse pressure capacity of mine ventilation stoppings based on the mine conditions and construction materials. However, it also includes numerous other assessments such as:

- Lateral displacement of wall at mid-span

- Impact of deformable materials in wall construction

- Impact of boundary conditions

- Impact of different block materials

- Cost and material handling information

In the initial phase of V-STOP, the program needs information about the mine entry and block materials. A design limit for transverse pressure capacity and convergence are inputted along with the mine entry design parameters (crosscut width, height, boundary conditions). Next, the user is directed to select a block based on block type, dimensions, and strength.

All the parameters for the stopping construction were inputted during the initial phase. The program then uses the Hybrid Theoretical Lateral Displacement Model in the solution phase. The Hybrid Lateral Displacement Model determines the lateral displacement force from a multivariable relationship from $\mathrm{E} \times(\mathrm{t} / \mathrm{L})^{2}$ term and preload, both of which are considered to be known parameters. Similarly, a multivariable linear regression analysis was preformed to determine the thrust resultant position factor as a 
function of wall height and preload. Once this phase is completed, this data is written to an output file.

After the program performs the solution phase, the cumulative output file is generated. This program displays the set of parameters used for a graphical plot of the stopping transverse pressure performance curve for the defined block based on the current design guidelines. When several stopping walls need to be evaluated this program can display both graphical and tabular outputs as well as visual illustrations of the stopping wall concepts when appropriate.

Verification of V-STOP was conducted to verify the results. This was done by comparing the solutions generated by V-STOP and arch loading tests preformed in NIOSH's Mine Roof Simulator. Several tests and simulations were performed using rigid arch conditions, as well as non-rigid conditions when deformable materials were incorporated into the wall construction. The results from V-STOP showed that the coded solutions preformed as expected, and the program was able to determine the transverse pressure capacity of stopping walls evaluated in a case study.

In conclusion, predicting the transverse pressure capacity of a mine ventilation stopping is complex. Several factors can affect the performance of a stopping wall. Increasing the wall thickness will increase the transverse pressure capacity. Decreasing the wall height will increase the transverse pressure capacity. Increasing the wall strength will increase the transverse pressure capacity, but typically lower the amount of convergence the wall is able to withstand. Adding deformable material will allow the wall to deform from convergence more by reducing the system modulus, but can significantly lower the peak transverse pressure capacity. Similarly, softening the 
boundary conditions will lower the peak transverse pressure capacity. The type of block used to construct the wall (CMU, Cellular, Foam) can affect the performance characteristics of the wall. With the complexity of all the parameters, a computer program (V-STOP) was developed to analyze the transverse pressure capacity for the stoppings. This software can provide an engineering foundation to ensure that inadequate stopping designs as well as ultra conservative stopping applications are avoided. Safety will be improved by properly matching the ventilation stopping performance to the mine conditions.

\section{FUTURE RESEARCH RECOMMENDATIONS}

An important factor to consider was demonstrated in the case study. The stopping walls could not meet the design criteria of 2 in of convergence with a 5 psi transverse pressure design criteria under all preloading situations. This factor needs to be evaluated in this regard is the impact of deformable materials that are used to reduce the stiffness of the wall so it can absorb ground deformations without causing damage to the wall. More research should be conducted to determine an ideal deformable material that will allow the stopping walls to accept large amounts of convergence and still maintain the ability to resist transverse pressure. 


\section{Bibliography}

1. Anderson C. (1984). Arching Action in Transverse Pressured Masonry Wall Panels. The Structural Engineer, vol. 62B no. 1, March.

2. Barczak, T., and Wilson, J., (1995). Practical Solutions to Offset the Deficiencies and Increasing Price of Mine Timber. Proceedings of the $35^{\text {th }}$ U.S. Symposium of Rock Mechanics, Reno, NV, pp. 567-572.

3. Barczak, T., (2005). Evaluation of the Transverse pressure Capacity of Block Stoppings for Mine Ventilation Control (Ph.D. Dissertation, West Virginia University).

4. Barczak, T., and Batchler, T., (2006). Development of New Protocols to Evaluate the Transverse pressure of Mine Ventilation Stoppings. Proceedings of the $11^{\text {th }}$ U.S./North American Mine Ventilation Symposium, University Park PA, pp. $569-577$

5. Barczak, T., Esterhuizen, G., Ellenberger, J., and Zhang, P.L., (2008). A First Step in Developing Standing Roof Support Design Criteria Based on Ground Reaction Data for Pittsburgh Seam Longwall Tailgate Support. Proceedings of the $27^{\text {th }}$ International Conference on Ground Control in Mining, Morgantown, WV, pp. 347-357

6. Barczak, T., and Batchler, T., (2008). Comparison of the Transverse Pressure Capacities of Various Block Ventilation Stoppings Under Arch Loading Conditions. Proceedings of the $12^{\text {th }}$ U.S./North American Mine Ventilation Symposium, Reno NV, pp. 225-231. 
7. Drysdale, R., Hamid, A. and Baker, L., (1994). Masonry Structures: Behavior and Design. Englewood Cliffs, NJ, Prentice Hall, ISBN: 0315620260.

8. Hustrulid, W. (1982). Underground Mining Methods Handbook. New York, NY pp. 1604-1628.

9. Kawenski, E., and Mitchell, D., (1966). Evaluation of Materials for Ventilation Structures. Mining congress Journal, March, pp. 49-53.

10. McDowell, E., McKee, K., and Sevin, E., (1956). Arching Action Theory of Masonry Walls. Journal of Structural Division, Proceedings of the American Society of Civil Engineers, Vol. 82, no ST2, Paper 915, March pp. 915-1 - 915-18.

11. Oswald, N., Prosser, B., and Ruckman, R., (2008). Measured Values of Coal Mine Stopping Resistance. Proceedings of the $12^{\text {th }}$ U.S./North American Mine Ventilation Symposium, Reno NV, 103-106.

12. Oyler, D., Hasenfus, G., and Molinda, G., (2002). Load and Deflection Response of Ventilation Stoppings to Longwall Abutment Loading - A Case Study. Proceedings of the $20^{\text {th }}$ International Conference on Ground Control in Mining, Morgantown, WV, pp. 34-41.

13. Rusnzk, J., and Mark, C., (1999). Using Point Load Test to Determine the Uniaxial Compressive Strength of Coal Measure Rock. Proceedings of the $19^{\text {th }}$ International Conference on Ground Control in Mining, Morgantown WV, pp. $362-371$.

14. Sapko, M., Weiss, E., and Harteis, S., (2003). Alternative Methodologies for Evaluating Explosion-Resistance Mine Ventilation Seals. Published in the $30^{\text {th }}$ 
International Conference of Safety in Mines Research Institutes, Johannesburg, South Africa, pp. 615-640.

15. Smith, R., Honkala, T., and Andres, C., (1979). Masonry: Materials Design Construction. Reston, Prentice Hall, pp. 13-31.

16. Strata Testing Services, (2003). 10 North Gateroads, Emerald Mine, Samples from Angled and Vertical Coreholes L083-1 to L093-17. Internal Report, Geotechnical Laboratory Test Report.

17. Thienel, K., and Shah, S., May (1997). Strain-Softening of Laterally Reinforced Concrete Panels in Compression. Journal of Structural Engineering, Kansas pp. $575-582$

18. Zipf, C., (2005). Failure Mechanics is Multiple Seam Mining Interactions. Proceedings of the $24^{\text {th }}$ International Conference on Ground Control in Mining, Morgantown, WV, pp. 93-106. 


\section{Appendix A}

Over 500 tests were preformed to confirm that a loading mechanism controls the transverse pressure capacity of mine ventilation stoppings. These tests used the MRS half-wall rigid arching testing protocol and were conducted at the Pittsburgh Research Laboratory.

Several theoretical models were developed whereby the amount of lateral displacement is determined from a multivariable linear regression analyses of $E^{*}(t / L)^{2}$ term and preload. A second multivariable regression analysis was made to determine the thrust resultant position factor as a function of the wall height and preload (Barczak 2005). Following are the results:

Where $\delta_{\mathrm{h}}=$ Lateral Displacement, in,

$\mathrm{P} / \mathrm{BL}=$ Normalized thrust per unit width of block, kips/in,

$\mathrm{E}=$ Elastic modulus, psi,

$\mathrm{t}=$ wall thickness, in,

$\mathrm{L}=$ height of wall, in,

Preload $=$ preload pressure, psi.

$\mathrm{d}=$ thrust position factor 


\section{CMU Block - CMU Block 1}

$$
\begin{aligned}
& \delta_{\mathrm{h}}=-0.0003 \times \operatorname{Ex}(\mathrm{t} / \mathrm{L})^{2}-0.0017 \times \text { Preload }+1.5337 \\
& \mathrm{~d}=-0.0024 \times \text { Half-wall Height }-0.0027 \times \mathrm{P} / \mathrm{BL}+0.9423
\end{aligned}
$$

Table 5. Multivariable regression analysis for determining thrust position factor for CMU Block 1 SUMMARY OUTPUT - d

\begin{tabular}{lr}
\hline \multicolumn{2}{c}{ Regression Statistics } \\
\hline Multiple R & 0.97837 \\
R Square & 0.957209 \\
Adjusted R Squ & 0.956507 \\
Standard Error & 0.010073 \\
Observations & 125 \\
\hline
\end{tabular}

\begin{tabular}{|c|c|c|c|c|c|c|c|}
\hline & \multicolumn{2}{|c|}{ Coefficients'andard Err } & t Stat & $P$-value & 95\%Upper 95 & ower 95 & per 95.0\% \\
\hline Inte & 0.942277 & 0.005018 & 187.795 & $4.4 \mathrm{E}-152$ & 0.932344 & 0.932344 & 0.95221 \\
\hline $\mathrm{H}$ & . & & 7 & 4. & 68 & 4 & 68 \\
\hline Thr & 663 & $5.22 \mathrm{E}-05$ & 0.9978 & $3.98 \mathrm{E}-84$ & $-0.002766-0.002559$ & -0.002766 & -0.002559 \\
\hline
\end{tabular}

\begin{tabular}{lrrrrr} 
ANOVA & \multicolumn{1}{c}{ SS } & \multicolumn{1}{c}{ SS } & \multicolumn{1}{c}{ ignificance $F$} \\
\hline Regression & 2 & 0.276915 & 0.138458 & 1364.519 & $3.26 \mathrm{E}-84$ \\
Residual & 122 & 0.012379 & 0.000101 & & \\
Total & 124 & 0.289295 & & & \\
\hline
\end{tabular}

Table 6. Multivariable regression analysis for determining lateral displacement for CMU Block 1

SUMMARY OUTPUT - Lateral Displacement

\begin{tabular}{lr}
\hline \multicolumn{2}{c}{ Regression Statistics } \\
\hline Multiple R & 0.700459 \\
R Square & 0.490643 \\
Adjusted R Sqı & 0.482292 \\
Standard Error & 0.39931 \\
Observations & 125 \\
\hline
\end{tabular}

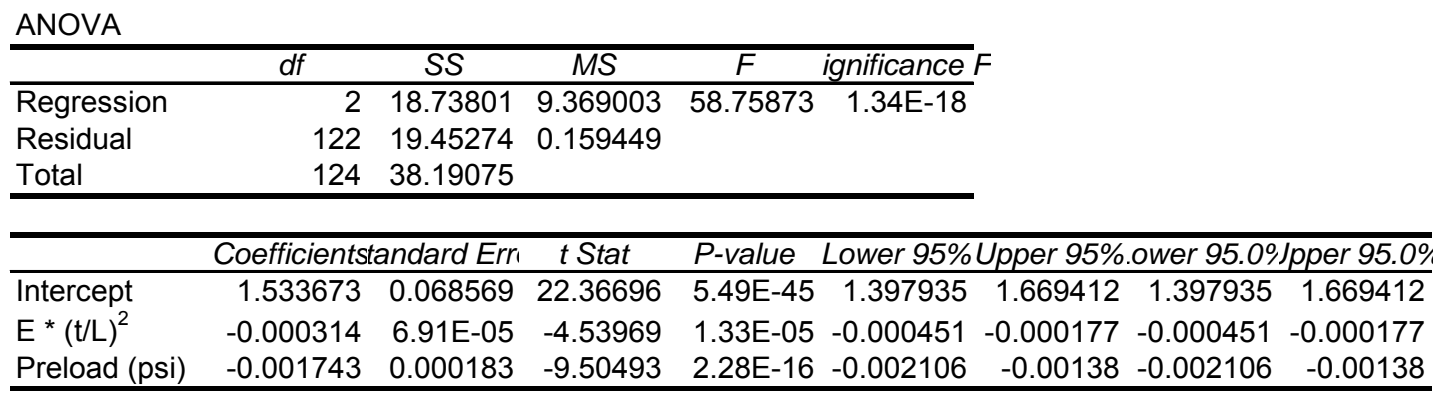




\section{CMU Block - CMU Block 2}

$$
\begin{aligned}
& \delta_{\mathrm{h}}=-0.0003 \times \operatorname{Ex}(\mathrm{t} / \mathrm{L})^{2}-0.0017 \times \text { Preload }+1.5337 \\
& \mathrm{~d}=-0.0028 \times \text { Half-wall Height }-0.0032 \times \mathrm{P} / \mathrm{BL}+0.9707
\end{aligned}
$$

Table 7. Multivariable regression analysis for determining thrust position factor for CMU Block 2 SUMMARY OUTPUT - d

\begin{tabular}{lr}
\hline \multicolumn{2}{c}{ Regression Statistics } \\
\hline Multiple R & 0.959291 \\
R Square & 0.920239 \\
Adjusted R Sqı & 0.914738 \\
Standard Error & 0.008843 \\
Observations & 32 \\
\hline
\end{tabular}

\begin{tabular}{lrcccc} 
ANOVA & \multicolumn{1}{c}{ SS } & MS & $F$ & ignificance $F$ \\
\hline Regression & 2 & 0.026166 & 0.013083 & 167.2925 & $1.19 \mathrm{E}-16$ \\
Residual & 29 & 0.002268 & $7.82 \mathrm{E}-05$ & & \\
Total & 31 & 0.028434 & & & \\
\hline
\end{tabular}

\begin{tabular}{lrrrrrrrr}
\hline \multicolumn{1}{c}{ Coefficientstandard Err } & \multicolumn{1}{c}{$t$ Stat } & \multicolumn{1}{l}{ P-value } & \multicolumn{1}{l}{ Lower 95\% Upper 95\% ower 95.0\%/pper 95.0\% } \\
\hline Intercept & 0.970696 & 0.011519 & 84.26656 & $3.18 \mathrm{E}-36$ & 0.947137 & 0.994256 & 0.947137 & 0.994256 \\
Half-wall Heigh & -0.002812 & 0.000166 & -16.9679 & $1.34 \mathrm{E}-16$ & -0.003151 & -0.002473 & -0.003151 & -0.002473 \\
Thrust & -0.003155 & 0.000203 & -15.5582 & $1.3 \mathrm{E}-15$ & -0.00357 & -0.00274 & -0.00357 & -0.00274 \\
\hline
\end{tabular}

Table 8. Multivariable regression analysis for determining lateral displacement for CMU Block 2. SUMMARY OUTPUT - Lateral Displacement

\begin{tabular}{lr}
\hline \multicolumn{2}{c}{ Regression Statistics } \\
\hline Multiple R & 0.718663 \\
R Square & 0.516476 \\
Adjusted R Sq & 0.48313 \\
Standard Error & 0.332078 \\
Observations & 32 \\
\hline
\end{tabular}

ANOVA

\begin{tabular}{lrrrrr}
\hline & $d f$ & \multicolumn{1}{c}{$S$ S } & MS & $F$ & ignificance $F$ \\
\hline Regression & 2 & 3.415946 & 1.707973 & 15.48818 & $2.65 \mathrm{E}-05$ \\
Residual & 29 & 3.198001 & 0.110276 & & \\
Total & 31 & 6.613948 & & & \\
\hline
\end{tabular}

\begin{tabular}{|c|c|c|c|c|c|c|c|c|}
\hline & Coefficients & andard Err & t Stat & $P$-value & LoW & $p$ & ve & Jpper 95.0\% \\
\hline Inte & 2.344788 & 0.17101 & 13.71144 & -14 & 034 & 542 & 95034 & 2.69454 \\
\hline$E *(t / L)^{2}$ & -0.002278 & 0.000473 & -4.82169 & 4.16 & -0.003245 & -0.001312 & 45 & -0.0 \\
\hline Preload (psi) & -0.002616 & 0.00059 & -4.43634 & 0.000121 & -0.003821 & 00141 & -0.003821 & \\
\hline
\end{tabular}

Coefficientstandard Errı t Stat $\quad P$-value Lower 95\%Upper 95\% ower 95.0\%Jpper 95.0\% 


\section{CMU Block - Block Category}

$\delta_{\mathrm{h}}=-0.0004 \times \operatorname{Ex}(\mathrm{t} / \mathrm{L})^{2}-0.0018 \times$ Preload +1.6317

$d=-0.0026 \times$ Half-wall Height $-0.0028 \times \mathrm{P} / \mathrm{BL}+0.9672$

Table 9. Multivariable regression analysis for determining thrust position factor for CMU Block Category.

SUMMARY OUTPUT - $d$

\begin{tabular}{lr}
\hline \multicolumn{2}{c}{ Regression Statistics } \\
\hline Multiple R & 0.39602 \\
R Square & 0.156832 \\
Adjusted R Sqı & 0.145882 \\
Standard Error & 0.118177 \\
Observations & 157 \\
\hline
\end{tabular}

ANOVA

\begin{tabular}{lrrrrr}
\hline & $d f$ & $S S$ & $M S$ & $F$ & ignificance $F$ \\
\hline Regression & 2 & 0.400044 & 0.200022 & 14.32224 & $1.97 \mathrm{E}-06$ \\
Residual & 154 & 2.150739 & 0.013966 & & \\
Total & 156 & 2.550783 & & & \\
\hline
\end{tabular}

\begin{tabular}{lrrrrrrrr}
\hline & Coefficientstandard Err & \multicolumn{1}{c}{$t$ Stat } & \multicolumn{2}{c}{ P-value } & Lower 95\% Upper 95\%.ower 95.0\%/pper 95.0\% \\
\hline Intercept & 0.967181 & 0.051211 & 18.88631 & $6.24 \mathrm{E}-42$ & 0.866014 & 1.068347 & 0.866014 & 1.068347 \\
Half-wall Heigh & -0.002573 & 0.000883 & -2.91357 & 0.004106 & -0.004317 & -0.000828 & -0.004317 & -0.000828 \\
Thrust & -0.002879 & 0.00055 & -5.23311 & $5.37 \mathrm{E}-07$ & -0.003965 & -0.001792 & -0.003965 & -0.001792 \\
\hline
\end{tabular}

Table 10. Multivariable regression analysis for determining lateral displacement for CMU Block Category.

SUMMARY OUTPUT - Lateral Displacement

\begin{tabular}{lr}
\hline \multicolumn{2}{c}{ Regression Statistics } \\
\hline Multiple R & 0.717364 \\
R Square & 0.514611 \\
Adjusted R Sqı & 0.508307 \\
Standard Error & 0.406095 \\
Observations & 157 \\
\hline
\end{tabular}

ANOVA

\begin{tabular}{lrrrrr}
\hline & $d f$ & \multicolumn{1}{c}{$S S$} & \multicolumn{1}{c}{$M S$} & $F$ & ignificance $F$ \\
\hline Regression & 2 & 26.9256 & 13.4628 & 81.63564 & $6.74 \mathrm{E}-25$ \\
Residual & 154 & 25.39664 & 0.164913 & & \\
Total & 156 & 52.32223 & & & \\
\hline
\end{tabular}

\begin{tabular}{lrrrrrrrr}
\hline & Coefficientstandard Err & \multicolumn{1}{c}{ t Stat } & \multicolumn{2}{c}{ P-value } & Lower 95\% Upper 95\% ower 95.0\%/pper 95.0\% \\
\hline Intercept & 1.631668 & 0.058197 & 28.03708 & $2.25 \mathrm{E}-62$ & 1.516701 & 1.746635 & 1.516701 & 1.746635 \\
$\mathrm{E}^{*}(\mathrm{t} / \mathrm{L})^{2}$ & -0.000379 & $6.78 \mathrm{E}-05$ & -5.59717 & $9.73 \mathrm{E}-08$ & -0.000513 & -0.000245 & -0.000513 & -0.000245 \\
Preload (psi) & -0.001847 & 0.000172 & -10.7069 & $2.41 \mathrm{E}-20$ & -0.002187 & -0.001506 & -0.002187 & -0.001506 \\
\hline
\end{tabular}




\section{Cellular (Aerated) Cement - Block 1}

$$
\begin{aligned}
& \delta_{\mathrm{h}}=0.0001 \times \operatorname{Ex}(\mathrm{t} / \mathrm{L})^{2}-0.0020 \times \text { Preload }+0.9548 \\
& \mathrm{~d}=-0.0030 \times \text { Half-wall Height }-0.0080 \times \mathrm{P} / \mathrm{BL}+1.0364
\end{aligned}
$$

Table 11. Multivariable regression analysis for determining thrust position factor for Cellular (Aerated) Cement Block 1

\begin{tabular}{lr}
\multicolumn{2}{l}{ SUMMARY OUTPUT - d } \\
\hline \multicolumn{2}{c}{ Regression Statistics } \\
\hline Multiple R & 1 \\
R Square & 1 \\
Adjusted R Squar & 1 \\
Standard Error & $4.08 \mathrm{E}-17$ \\
Observations & 33 \\
\hline
\end{tabular}

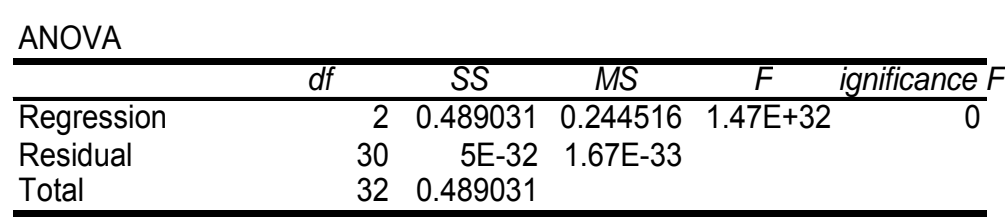

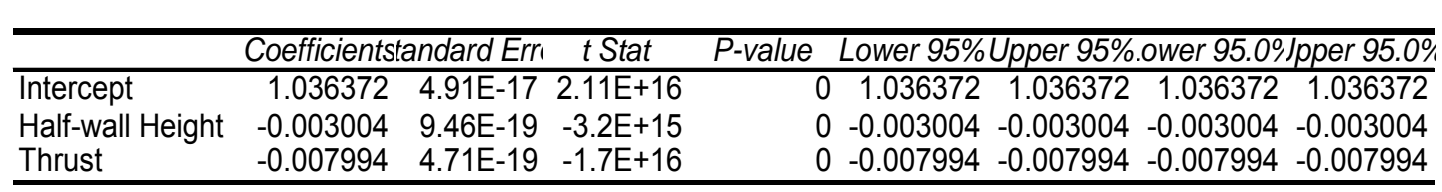

Table 12. Multivariable regression analysis for determining lateral displacement for Cellular (Aerated) Cement Block 1.

SUMMARY OUTPUT - Lateral Displacement

\begin{tabular}{lr}
\hline \multicolumn{2}{c}{ Regression Statistics } \\
\hline Multiple R & 0.487629 \\
R Square & 0.237782 \\
Adjusted R Squar & 0.186968 \\
Standard Error & 0.401677 \\
Observations & 33 \\
\hline
\end{tabular}

ANOVA

\begin{tabular}{lrrrrr}
\hline & $d f$ & $S S$ & $M S$ & $F$ & ignificance $F$ \\
\hline Regression & 2 & 1.509995 & 0.754997 & 4.679415 & 0.017029 \\
Residual & 30 & 4.840331 & 0.161344 & & \\
Total & 32 & 6.350326 & & & \\
\hline
\end{tabular}

\begin{tabular}{lrrrrrrrr}
\hline & Coefficients'andard Errı & \multicolumn{1}{c}{$t$ Stat } & \multicolumn{1}{c}{ P-value } & Lower 95\% Upper 95\% ower 95.0\%/pper 95.0\% \\
\hline Intercept & 0.954813 & 0.177377 & 5.382971 & $7.9 \mathrm{E}-06$ & 0.592562 & 1.317064 & 0.592562 & 1.317064 \\
$\mathrm{E}^{*}(\mathrm{t} / \mathrm{L})^{2}$ & $9.87 \mathrm{E}-05$ & 0.001149 & 0.085914 & 0.932106 & -0.002248 & 0.002445 & -0.002248 & 0.002445 \\
Preload (psi) & -0.001978 & 0.000649 & -3.04664 & 0.004792 & -0.003303 & -0.000652 & -0.003303 & -0.000652 \\
\hline
\end{tabular}




\section{Cellular (Aerated) Cement - Block 2}

$$
\begin{aligned}
& \delta_{\mathrm{h}}=-0.0050 \times \operatorname{Ex}(\mathrm{t} / \mathrm{L})^{2}-0.0069 \times \text { Preload }+2.2413 \\
& \mathrm{~d}=-0.0030 \times \text { Half-wall Height }-0.0080 \times \mathrm{P} / \mathrm{BL}+1.0364
\end{aligned}
$$

Table 13. Multivariable regression analysis for determining thrust position factor for Cellular (Aerated) Cement Block 2.

\section{SUMMARY OUTPUT - d}

\begin{tabular}{lr}
\hline \multicolumn{2}{c}{ Regression Statistics } \\
\hline Multiple R & 1 \\
R Square & 1 \\
Adjusted R Squar & 1 \\
Standard Error & $3.25 \mathrm{E}-17$ \\
Observations & 10 \\
\hline
\end{tabular}

ANOVA

\begin{tabular}{lrrrrr}
\hline & $d f$ & \multicolumn{1}{c}{$S S$} & \multicolumn{1}{c}{$M S$} & $F$ & ignificance $F$ \\
\hline Regression & 2 & 0.00556 & 0.00278 & $2.64 \mathrm{E}+30$ & $2.7 \mathrm{E}-105$ \\
Residual & 7 & $7.38 \mathrm{E}-33$ & $1.05 \mathrm{E}-33$ & & \\
Total & 9 & 0.00556 & & & \\
\hline
\end{tabular}

Coefficients'andard Errı $t$ Stat $\quad P$-value Lower 95\%Upper 95\% ower 95.0\%/pper 95.0\%

\begin{tabular}{lllllllll}
\hline Intercept & 1.036372 & $1.11 \mathrm{E}-16$ & $9.34 \mathrm{E}+15$ & $4.2 \mathrm{E}-110$ & 1.036372 & 1.036372 & 1.036372 & 1.036372
\end{tabular}

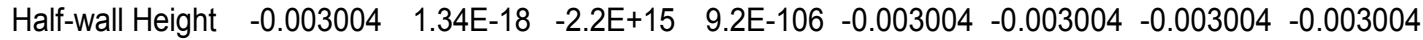

\begin{tabular}{lllllllll} 
Thrust & -0.007994 & $5.79 \mathrm{E}-18$ & $-1.4 \mathrm{E}+15$ & $2.8 \mathrm{E}-104$ & -0.007994 & -0.007994 & -0.007994 & -0.007994 \\
\hline
\end{tabular}

Table 14. Multivariable regression analysis for determining lateral displacement for Cellular (Aerated) Cement Block 2.

SUMMARY OUTPUT - Lateral Displacement

\begin{tabular}{lr}
\hline \multicolumn{2}{c}{ Regression Statistics } \\
\hline Multiple R & 0.804942 \\
R Square & 0.647931 \\
Adjusted R Squar & 0.54734 \\
Standard Error & 0.211373 \\
Observations & 10 \\
\hline
\end{tabular}

ANOVA

\begin{tabular}{lccccc}
\hline & $d f$ & $S S$ & $M S$ & $F$ & ignificance $F$ \\
\hline Regression & 2 & 0.575569 & 0.287785 & 6.441235 & 0.025894 \\
Residual & 7 & 0.312749 & 0.044678 & & \\
Total & 9 & 0.888318 & & & \\
\hline
\end{tabular}

\begin{tabular}{lrrrrrrrr}
\hline & Coefficients'andard Errı & \multicolumn{1}{c}{$t$ Stat } & \multicolumn{1}{l}{ P-value } & Lower 95\% Upper 95\% ower 95.0\%/pper 95.0\% \\
\hline Intercept & 2.241349 & 0.496853 & 4.511086 & 0.002761 & 1.066477 & 3.416221 & 1.066477 & 3.416221 \\
$\mathrm{E}^{*}(\mathrm{t} / \mathrm{L})^{2}$ & -0.004984 & 0.001451 & -3.43497 & 0.010911 & -0.008415 & -0.001553 & -0.008415 & -0.001553 \\
Preload (psi) & -0.006885 & 0.005766 & -1.19394 & 0.271388 & -0.02052 & 0.006751 & -0.02052 & 0.006751 \\
\hline
\end{tabular}




\section{Cellular (Aerated) Cement - Block 3}

$$
\begin{aligned}
& \delta_{\mathrm{h}}=-0.0007 \times \operatorname{Ex}(\mathrm{t} / \mathrm{L})^{2}-0.0038 \times \text { Preload }+1.1562 \\
& \mathrm{~d}=-0.0030 \times \text { Half-wall Height }-0.0080 \times \mathrm{P} / \mathrm{BL}+1.0364
\end{aligned}
$$

Table 15. Multivariable regression analysis for determining thrust position factor for Cellular (Aerated) Cement Block 3.

\section{SUMMARY OUTPUT - $d$}

\begin{tabular}{lr}
\hline \multicolumn{2}{c}{ Regression Statistics } \\
\hline Multiple R & 1 \\
R Square & 1 \\
Adjusted R Squar & 1 \\
Standard Error & $4.89 \mathrm{E}-17$ \\
Observations & 16 \\
\hline
\end{tabular}

ANOVA

\begin{tabular}{lrrrrr}
\hline & $d f$ & \multicolumn{1}{c}{$S S$} & MS & $F$ & ignificance $F$ \\
\hline Regression & 2 & 0.054006 & 0.027003 & $1.13 \mathrm{E}+31$ & $2.8 \mathrm{E}-197$ \\
Residual & 13 & $3.11 \mathrm{E}-32$ & $2.39 \mathrm{E}-33$ & & \\
Total & 15 & 0.054006 & & & \\
\hline
\end{tabular}

Coefficients'andard Errı $t$ Stat $\quad P$-value $\quad$ Lower 95\%Upper 95\% ower 95.0\%/pper 95.0\%

\begin{tabular}{lllllllll}
\hline Intercept & 1.036372 & $1.03 \mathrm{E}-16$ & $1 \mathrm{E}+16$ & $3.6 \mathrm{E}-202$ & 1.036372 & 1.036372 & 1.036372 & 1.036372
\end{tabular}

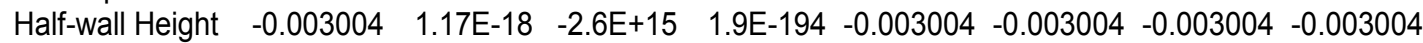

\begin{tabular}{llllllllll} 
Thrust & -0.007994 & $1.69 \mathrm{E}-18$ & $-4.7 \mathrm{E}+15$ & $6.6 \mathrm{E}-198$ & -0.007994 & -0.007994 & -0.007994 & -0.007994 \\
\hline
\end{tabular}

Table 16. Multivariable regression analysis for determining lateral displacement for Cellular (Aerated) Cement Block 3.

SUMMARY OUTPUT - Lateral Displacement

\begin{tabular}{lr}
\hline \multicolumn{2}{c}{ Regression Statistics } \\
\hline Multiple R & 0.855778 \\
R Square & 0.732355 \\
Adjusted R Squar & 0.691179 \\
Standard Error & 0.152894 \\
Observations & 16 \\
\hline
\end{tabular}

ANOVA

\begin{tabular}{lrrrrr}
\hline & $d f$ & \multicolumn{1}{c}{ SS } & MS & $F$ & ignificance $F$ \\
\hline Regression & 2 & 0.831543 & 0.415772 & 17.78593 & 0.00019 \\
Residual & 13 & 0.303894 & 0.023376 & & \\
Total & 15 & 1.135437 & & & \\
\hline
\end{tabular}

\begin{tabular}{lrrrrrrrr}
\hline & \multicolumn{1}{c}{ Coefficients'andard Errı } & \multicolumn{1}{c}{$t$ Stat } & \multicolumn{1}{r}{ P-value } & Lower 95\% Upper 95\% ower 95.0\%/pper 95.0\% \\
\hline Intercept & 1.561195 & 0.101945 & 15.31406 & $1.07 \mathrm{E}-09$ & 1.340956 & 1.781435 & 1.340956 & 1.781435 \\
$\mathrm{E}^{*}(\mathrm{t} / \mathrm{L})^{2}$ & -0.000733 & 0.000182 & -4.0301 & 0.001429 & -0.001126 & -0.00034 & -0.001126 & -0.00034 \\
Preload (psi) & -0.00378 & 0.00081 & -4.66731 & 0.00044 & -0.005529 & -0.00203 & -0.005529 & -0.00203 \\
\hline
\end{tabular}




\section{Cellular (Aerated) Cement - Block Category}

$$
\begin{aligned}
& \delta_{\mathrm{h}}=-0.0002 \times \operatorname{Ex}(\mathrm{t} / \mathrm{L})^{2}-0.0026 \times \text { Preload }+1.1896 \\
& \mathrm{~d}=-0.0030 \times \text { Half-wall Height }-0.0080 \times \mathrm{P} / \mathrm{BL}+1.0364
\end{aligned}
$$

Table 17. Multivariable regression analysis for determining thrust position factor for Cellular (Aerated) Cement Block Category.

\begin{tabular}{|c|c|c|c|c|}
\hline \multicolumn{2}{|c|}{ Regression Statistics } & & & \\
\hline Multiple R & 0.751584 & & & \\
\hline R Square & 0.564879 & & & \\
\hline Adjusted R Squar & 0.549339 & & & \\
\hline Standard Error & 0.104594 & & & \\
\hline Observations & 59 & & & \\
\hline \multicolumn{5}{|l|}{ ANOVA } \\
\hline & $d f$ & $M S$ & ignificance & \\
\hline Regression & 2 & $0.795326 \quad 0.397663$ & 36.34988 & \\
\hline Residual & 56 & $0.612632 \quad 0.01094$ & & \\
\hline \multirow[t]{2}{*}{ Total } & 58 & 1.407958 & & \\
\hline & Coefficients! & andard Errı $t$ Stat & P-value Lower 95\% & Upper 95\% ower 95.0\%/pper 95.0\% \\
\hline Intercept & 1.036372 & 0.07580213 .67202 & $1.72 \mathrm{E}-19 \quad 0.884522$ & $1.188223 \quad 0.884522 \quad 1.188223$ \\
\hline Half-wall Height & -0.003004 & 0.001402 & $0.036523-0.005812$ & $-0.000195-0.005812-0.000195$ \\
\hline Thrust & -0.007994 & $0.000944 \quad-8.46971$ & $1.31 \mathrm{E}-11-0.009885$ & $-0.006103-0.009885-0.006103$ \\
\hline
\end{tabular}
SUMMARY OUTPUT - d

Table 18. Multivariable regression analysis for determining lateral displacement for Cellular (Aerated) Cement Block Category. SUMMARY OUTPUT - Lateral Displacement

\begin{tabular}{lr}
\hline \multicolumn{2}{c}{ Regression Statistics } \\
\hline Multiple R & 0.565639 \\
R Square & 0.319947 \\
Adjusted R Squar & 0.29566 \\
Standard Error & 0.359078 \\
Observations & 59 \\
\hline
\end{tabular}

\begin{tabular}{lrrrrr} 
ANOVA & \multicolumn{1}{c}{ SS } & MS & $F$ & ignificance $F$ \\
\hline \multicolumn{1}{l}{ Regression } & 2 & 3.397042 & 1.698521 & 13.17328 & $2.05 \mathrm{E}-05$ \\
Residual & 56 & 7.220465 & 0.128937 & & \\
Total & 58 & 10.61751 & & & \\
\hline
\end{tabular}

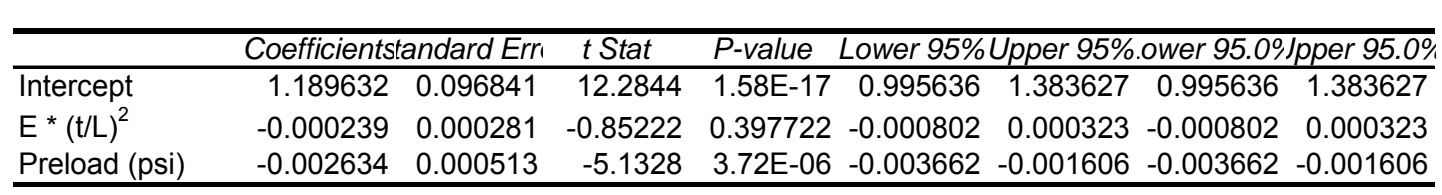




\title{
Hollow Block - Block 1 and Block Category
}

\author{
$\delta_{\mathrm{h}}=-0.0149 \times \operatorname{Ex}(\mathrm{t} / \mathrm{L})^{2}-0.0078 \times$ Preload +6.3100 \\ $\mathrm{d}=-0.0005 \times$ Half-wall Height $-0.0040 \times \mathrm{P} / \mathrm{BL}+.9973$
}

Table 19. Multivariable regression analysis for determining thrust position factor for Hollow Block 1 and Hollow Block Category. SUMMARY OUTPUT - d

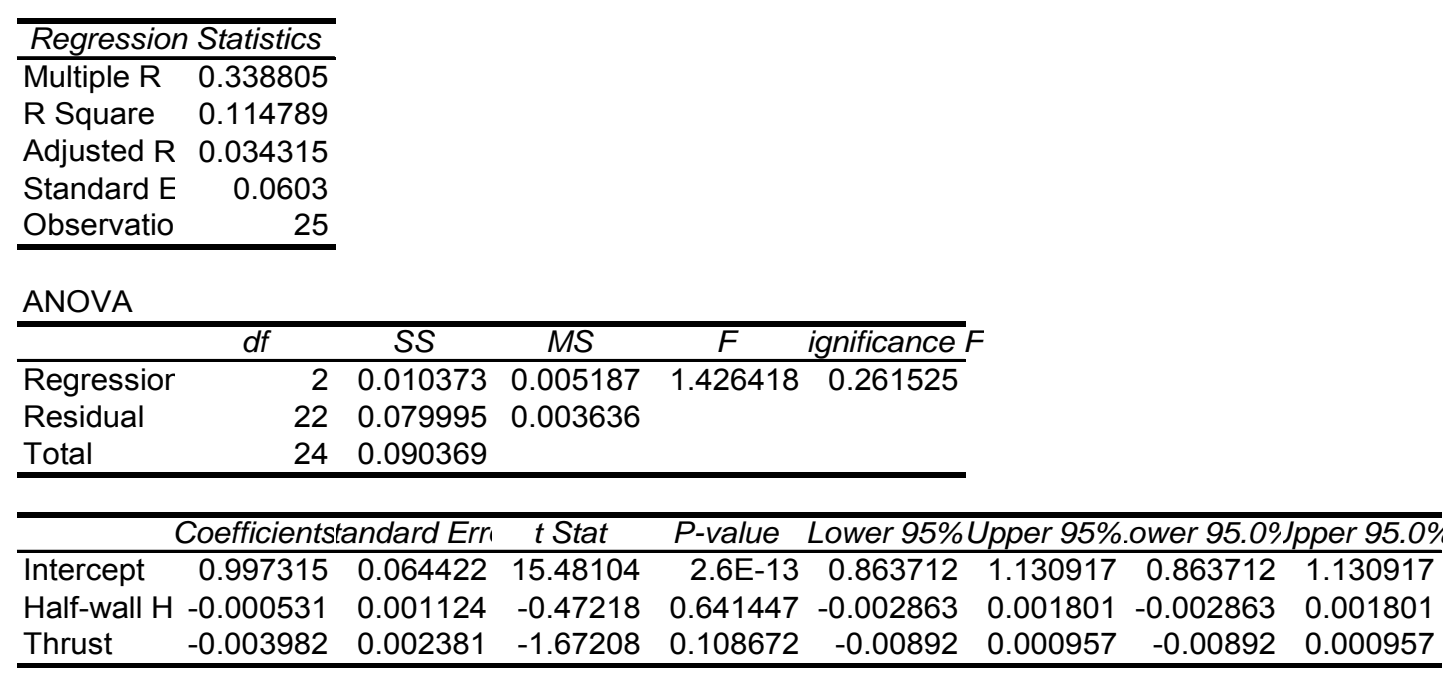

Table 20. Multivariable regression analysis for determining lateral displacement for Hollow Block 1 and Hollow Block Category.

SUMMARY OUTPUT - Lateral Displacement

\begin{tabular}{lr}
\hline Regression Statistics \\
\hline Multiple R & 0.886145 \\
R Square & 0.785252 \\
Adjusted R & 0.76573 \\
Standard E & 0.358112 \\
Observatio & 25 \\
\hline
\end{tabular}

\begin{tabular}{|c|c|c|c|c|c|}
\hline & $d f$ & SS & $\overline{M S}$ & $F$ & ignificance $F$ \\
\hline$\overline{\text { Regressior }}$ & 2 & 10.31671 & 5.158355 & 40.22286 & $4.48 E-08$ \\
\hline Residual & 22 & 2.821376 & 0.128244 & & \\
\hline Total & 24 & 13.13809 & & & \\
\hline
\end{tabular}

\begin{tabular}{lrrrrrrrr}
\hline & Coefficientstandard Err & \multicolumn{1}{c}{$t$ Stat } & \multicolumn{1}{c}{ P-value } & \multicolumn{1}{c}{ Lower 95\% Upper 95\% ower 95.0\%/pper 95.0\%/ } \\
\hline Intercept & 6.310035 & 0.580526 & 10.86951 & $2.59 \mathrm{E}-10$ & 5.106098 & 7.513972 & 5.106098 & 7.513972 \\
$\mathrm{E}^{*}(\mathrm{t} / \mathrm{L})^{2}$ & -0.014864 & 0.002116 & -7.02463 & $4.76 \mathrm{E}-07$ & -0.019252 & -0.010475 & -0.019252 & -0.010475 \\
Preload $(p \leqslant-0.007844$ & 0.001275 & -6.15209 & $3.42 \mathrm{E}-06$ & -0.010488 & -0.0052 & -0.010488 & -0.0052 \\
\hline
\end{tabular}




\section{Extruded Block - Block 1 and Block Category}

$$
\begin{aligned}
& \delta_{\mathrm{h}}=-0.0023 \times \operatorname{Ex}(\mathrm{t} / \mathrm{L})^{2}-0.0026 \times \text { Preload }+2.3448 \\
& \mathrm{~d}=-0.0028 \times \text { Half-wall Height }-0.0032 \times \mathrm{P} / \mathrm{BL}+0.9707
\end{aligned}
$$

Table 21. Multivariable regression analysis for determining thrust position factor for Extruded Block 1 and Extruded Block Category. SUMMARY OUTPUT - $d$

\begin{tabular}{lr}
\hline \multicolumn{2}{c}{ Regression Statistics } \\
\hline Multiple R & 0.959291 \\
R Square & 0.920239 \\
Adjusted R Sqı & 0.914738 \\
Standard Error & 0.008843 \\
Observations & 32 \\
\hline
\end{tabular}

ANOVA

\begin{tabular}{|c|c|c|c|c|c|c|c|c|}
\hline & Coefficien & andard Errı & $t$ Stat & $P$-value & Lower 95\% & Upper 95\%. & ower 95.0\% & Jpper 95.0\% \\
\hline Inter & 0.970696 & 0.011519 & 84.26656 & $3.18 \mathrm{E}-36$ & 0.947137 & 0.994256 & 0.947137 & $\overline{4256}$ \\
\hline $\mathrm{Ha}$ & $h-0.0$ & 66 & -1 & 1.3 & 151 & 2473 & 151 & 473 \\
\hline Thru & -0.003155 & 0.000203 & -15.5582 & $1.3 \mathrm{E}-15$ & .00357 & .00274 & -0.00357 & -0.0 \\
\hline
\end{tabular}

\begin{tabular}{lrcccc}
\hline & $d f$ & $S S$ & $M S$ & $F$ & ignificance $F$ \\
\hline Regression & 2 & 0.026166 & 0.013083 & 167.2925 & $1.19 \mathrm{E}-16$ \\
Residual & 29 & 0.002268 & $7.82 \mathrm{E}-05$ & & \\
Total & 31 & 0.028434 & & & \\
\hline
\end{tabular}

Table 22. Multivariable regression analysis for determining lateral displacement for Extruded Block 1 and Extruded Block Category.

SUMMARY OUTPUT - Lateral Displacement

\begin{tabular}{lr}
\hline \multicolumn{2}{c}{ Regression Statistics } \\
\hline Multiple R & 0.718663 \\
R Square & 0.516476 \\
Adjusted R Sq & 0.48313 \\
Standard Error & 0.332078 \\
Observations & 32 \\
\hline
\end{tabular}

ANOVA

\begin{tabular}{lrrrrr}
\hline & $d f$ & \multicolumn{1}{c}{ SS } & MS & $F$ & ignificance $F$ \\
\hline Regression & 2 & 3.415946 & 1.707973 & 15.48818 & $2.65 \mathrm{E}-05$ \\
Residual & 29 & 3.198001 & 0.110276 & & \\
Total & 31 & 6.613948 & & & \\
\hline
\end{tabular}

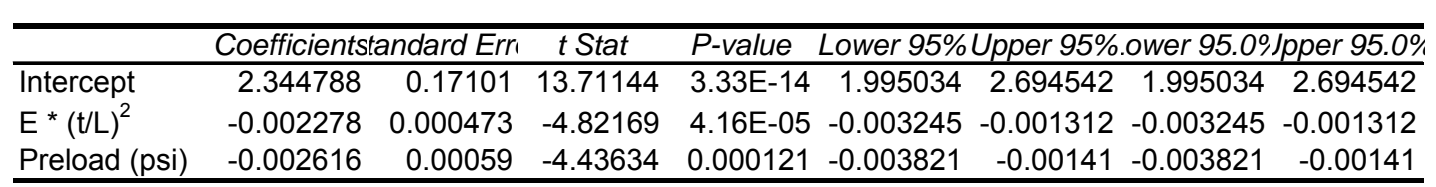


Foam Block - Block 1 and Block Category

$\delta_{\mathrm{h}}=0.0332 \times \operatorname{Ex}(\mathrm{t} / \mathrm{L})^{2}-0.0293 \times$ Preload +1.6465

$\mathrm{d}=-0.0076 \times$ Half-wall Height $-0.0507 \times \mathrm{P} / \mathrm{BL}+1.3455$

Table 23. Multivariable regression analysis for determining thrust position factor for Foam Block 1 and Foam Block Category.

SUMMARY OUTPUT - d

\begin{tabular}{lr}
\hline Regression Statistics \\
\hline Multiple R & 0.739879 \\
R Square & 0.547421 \\
Adjusted R & 0.502163 \\
Standard E & 0.0869 \\
Observatio & 23 \\
\hline
\end{tabular}

ANOVA

\begin{tabular}{lrrrrr}
\hline & $d f$ & \multicolumn{1}{c}{$S$ SS } & \multicolumn{1}{c}{ MS } & $F$ & ignificance $F$ \\
\hline Regressior & 2 & 0.182681 & 0.09134 & 12.09557 & 0.000361 \\
Residual & 20 & 0.151031 & 0.007552 & & \\
Total & 22 & 0.333712 & & & \\
\hline
\end{tabular}

\begin{tabular}{lrrrrrrrr}
\hline & Coefficientstandard Err & \multicolumn{1}{c}{$t$ Stat } & \multicolumn{2}{c}{ P-value } & Lower 95\% Upper 95\%.ower 95.0\%/pper 95.0\% \\
\hline Intercept & 1.34553 & 0.107881 & 12.47239 & $6.85 \mathrm{E}-11$ & 1.120495 & 1.570566 & 1.120495 & 1.570566 \\
Half Wall - & -0.007586 & 0.001566 & -4.84349 & $9.86 \mathrm{E}-05$ & -0.010854 & -0.004319 & -0.010854 & -0.004319 \\
thrust & -0.050669 & 0.016055 & -3.15601 & 0.00497 & -0.084159 & -0.017179 & -0.084159 & -0.017179 \\
\hline
\end{tabular}

Table 24. Multivariable regression analysis for determining lateral displacement for Foam Block 1 and Foam Block Category.

SUMMARY OUTPUT - Lateral Displacement

\begin{tabular}{lr}
\hline \multicolumn{2}{c}{ Regression Statistics } \\
\hline Multiple R & 0.40062 \\
R Square & 0.160497 \\
Adjusted R & 0.076546 \\
Standard E & 0.617647 \\
Observatio & 23 \\
\hline
\end{tabular}

\begin{tabular}{lrrrrr} 
ANOVA & \multicolumn{1}{c}{ SS } & \multicolumn{1}{c}{ MS } & \multicolumn{1}{c}{$F$} & ignificance $F$ \\
\hline Regressior & 2 & 1.458659 & 0.72933 & 1.911805 & 0.17387 \\
Residual & 20 & 7.62975 & 0.381487 & & \\
Total & 22 & 9.088409 & & & \\
\hline
\end{tabular}

\begin{tabular}{lrrrrrrrr}
\hline \multicolumn{1}{c}{ Coefficientstandard Errt } & \multicolumn{1}{c}{$t$ Stat } & \multicolumn{1}{r}{ P-value } & Lower 95\%Upper 95\%.ower 95.0\%/pper 95.0\% \\
\hline Intercept & 1.64646 & 0.488142 & 3.372913 & 0.003024 & 0.628214 & 2.664705 & 0.628214 & 2.664705 \\
$\mathrm{E}^{*}(\mathrm{t} / \mathrm{L})^{2}$ & 0.033177 & 0.0351 & 0.945213 & 0.35583 & -0.040041 & 0.106395 & -0.040041 & 0.106395 \\
Preload $(p s$ & -0.02932 & 0.016125 & -1.81832 & 0.084026 & -0.062955 & 0.004316 & -0.062955 & 0.004316 \\
\hline
\end{tabular}




\section{Other Block - Other Block Category}

$$
\begin{aligned}
& \delta_{\mathrm{h}}=-0.0002 \times \operatorname{Ex}(\mathrm{t} / \mathrm{L})^{2}-0.0017 \times \text { Preload }+1.4152 \\
& \mathrm{~d}=-0.0039 \times \text { Half-wall Height }-0.0021 \times \mathrm{P} / \mathrm{BL}+0.9591
\end{aligned}
$$

Table 25. Multivariable regression analysis for determining thrust position factor for Other Block Category.

\begin{tabular}{|c|c|}
\hline \multicolumn{2}{|c|}{ Regression Statistics } \\
\hline Multiple R & 0.32398 \\
\hline R & 0.1 \\
\hline Adju & 38 \\
\hline Standard E & 0.153 \\
\hline Observatio & \\
\hline
\end{tabular}
SUMMARY OUTPUT - $d$

\begin{tabular}{lrrccr} 
ANOVA & \multicolumn{1}{c}{ SS } & MS & $F$ & ignificance $F$ \\
\hline Regressior & 2 & 0.802822 & 0.401411 & 17.12173 & $9.31 \mathrm{E}-08$ \\
Residual & 292 & 6.845805 & 0.023445 & & \\
Total & 294 & 7.648627 & & & \\
\hline
\end{tabular}

\begin{tabular}{lrrrlllll}
\hline & Coefficientstandard Err & \multicolumn{1}{c}{$t$ Stat } & \multicolumn{1}{l}{$P$-value } & \multicolumn{2}{l}{ Lower 95\% Upper 95\%.ower 95.0\%/pper 95.0\% } \\
\hline Intercept & 0.959056 & 0.042978 & 22.31504 & $4.61 \mathrm{E}-65$ & 0.87447 & 1.043642 & 0.87447 & 1.043642 \\
Half-Wall $\mathrm{-}-0.003901$ & 0.000814 & -4.7941 & $2.61 \mathrm{E}-06$ & -0.005502 & -0.002299 & -0.005502 & -0.002299 \\
Thrust & -0.002079 & 0.000449 & -4.63367 & $5.42 \mathrm{E}-06$ & -0.002962 & -0.001196 & -0.002962 & -0.001196 \\
\hline
\end{tabular}

Table 26. Multivariable regression analysis for determining lateral displacement for Other Block Category.

SUMMARY OUTPUT - Lateral Displacement

\begin{tabular}{|c|c|c|c|c|c|}
\hline & $d f$ & SS & $\overline{M S}$ & $F$ & ignificance \\
\hline$\overline{\text { Regressior }}$ & 2 & 29.93322 & 14.96661 & 52.26783 & $3.95 \mathrm{E}-20$ \\
\hline Residual & 292 & 83.6126 & 0.286345 & & \\
\hline Total & 294 & 113.5458 & & & \\
\hline
\end{tabular}

\begin{tabular}{lr}
\hline \multicolumn{2}{l}{ Regression Statistics } \\
\hline Multiple R & 0.513442 \\
R Square & 0.263622 \\
Adjusted R & 0.258579 \\
Standard E & 0.535112 \\
Observatio & 295 \\
\hline
\end{tabular}

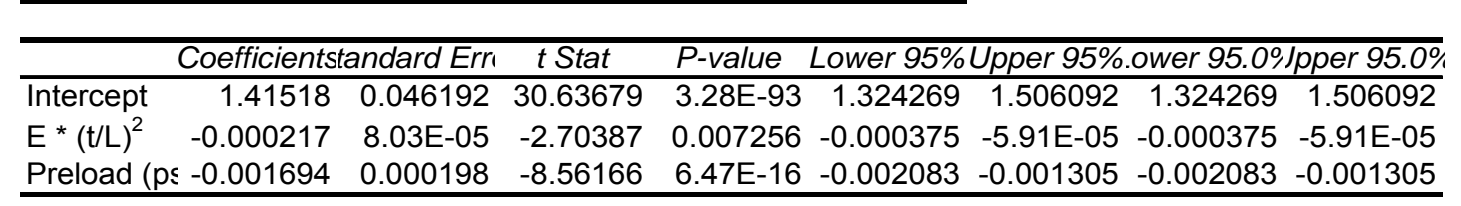




\section{Appendix B}

Once a set of stopping designs have been created, the comparison table can be used to show a side-by-side comparison of each alternative, with respect to design evaluation, block material properties, and construction details. Activate the drop-down box to select which properties will be compared with the selected blocks. Below is a list of each comparison category and type.

- Design Evaluation

o Preload Required to achieve design pressure, psi

o Est. lateral displacement at design pressure, in

o Est. thrust force at design pressure, $1 \mathrm{bs} / \mathrm{in}$

o Est. convergence based on wall stiffness, in

o Transverse pressure at 0 psi preload, psi

o Max. transverse pressure, psi

o Preload required for design convergence, psi

o Est. lateral displacement at design convergence, in

0 Est. thrust force at design convergence, $1 \mathrm{bs} / \mathrm{in}$

o Transverse pressure at design convergence, psi

o Convergence at peak transverse pressure, in

- Block Material Properties

o Block compressive strength, psi

o Block effective modulus, psi

o Block weight, lbs

o Block density, lbs / cu. ft 
o Strain-softening compressive strength, psi

o Strain-softening effective modulus, psi

- Construction Details

o Unit block cost, \$

o Estimated wall material cost, \$

o Number of blocks per wall

o Construction time, $\min$

o Labor cost, $\$$

o Total Cost per wall, $\$$

o Work, ft-lbs 


\section{Appendix C}

A half-wall is constructed with the strain-softening material placed on top of the wall (Klondike wall 46-inches tall, 5.625-inches thick; ACCOA wall 48 inches tall, 8-inches thick). In order to simulate the arching mechanism, a half-wall section of a stopping is placed in the Mine Roof Simulator (MRS). The half-wall is then hydraulically clamped to a fixed vertical height. The upper platen remains fixed in place as the lower platen moves horizontally at a constant rate of 0.5 inches per minute, causing the wall to rotate. As the base of the wall is forced to move horizontally, hinge points and deformation zones are created at the ends of the wall on opposite sides, consistent with the arch loading mechanism. The horizontal force applied to the ends of the half-wall is measured and is equated to the transverse pressure acting on the wall. 

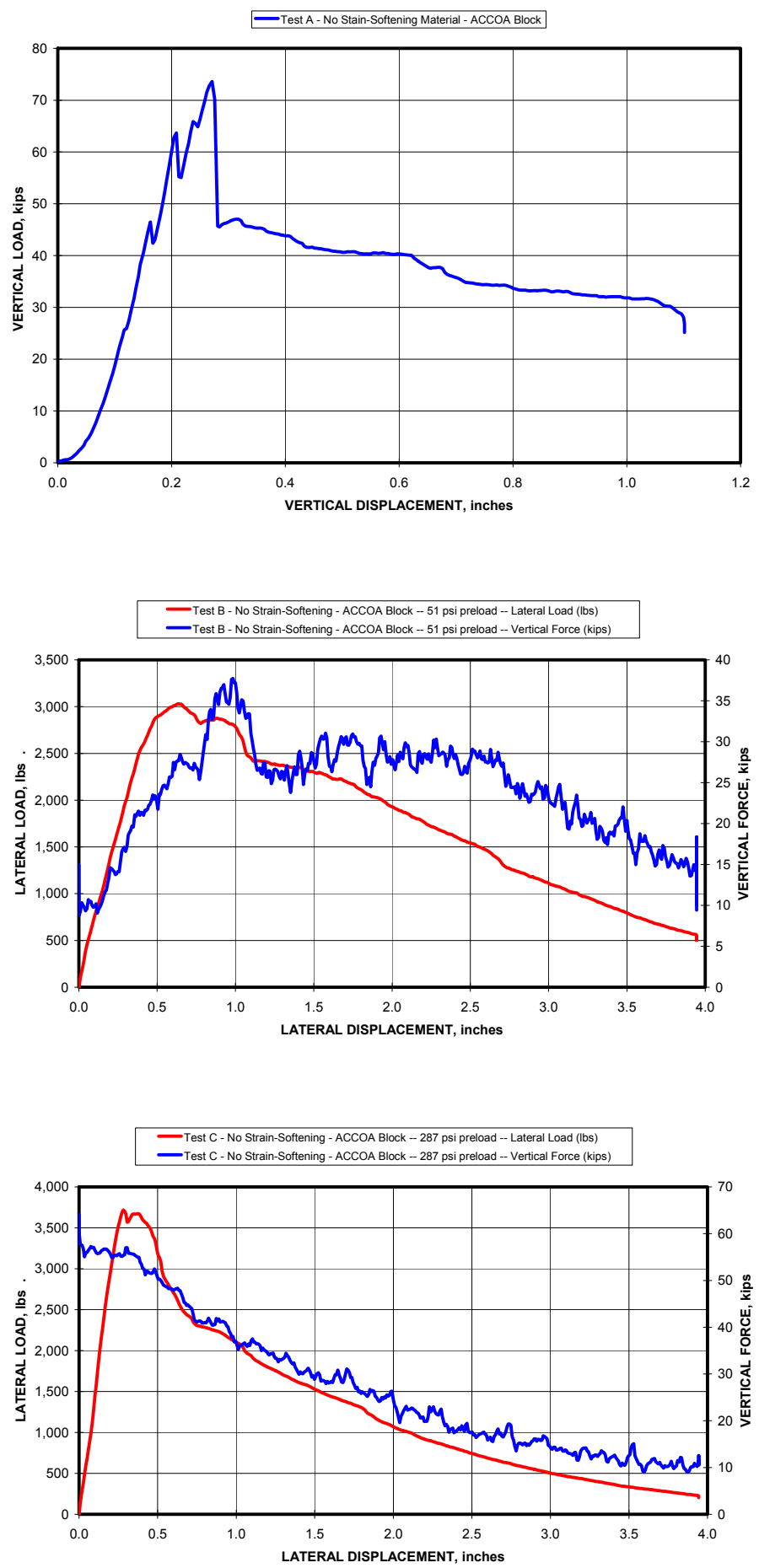

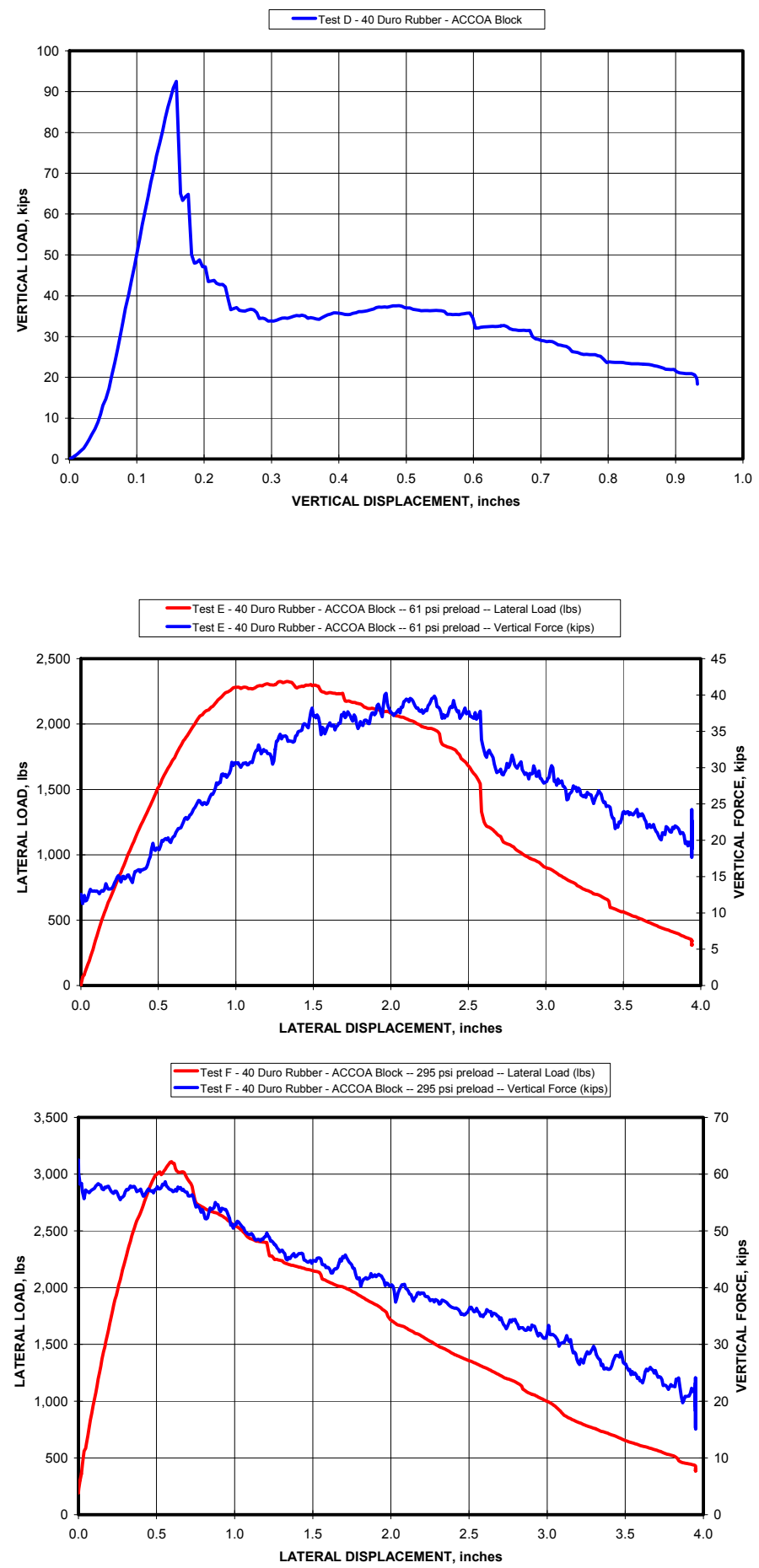

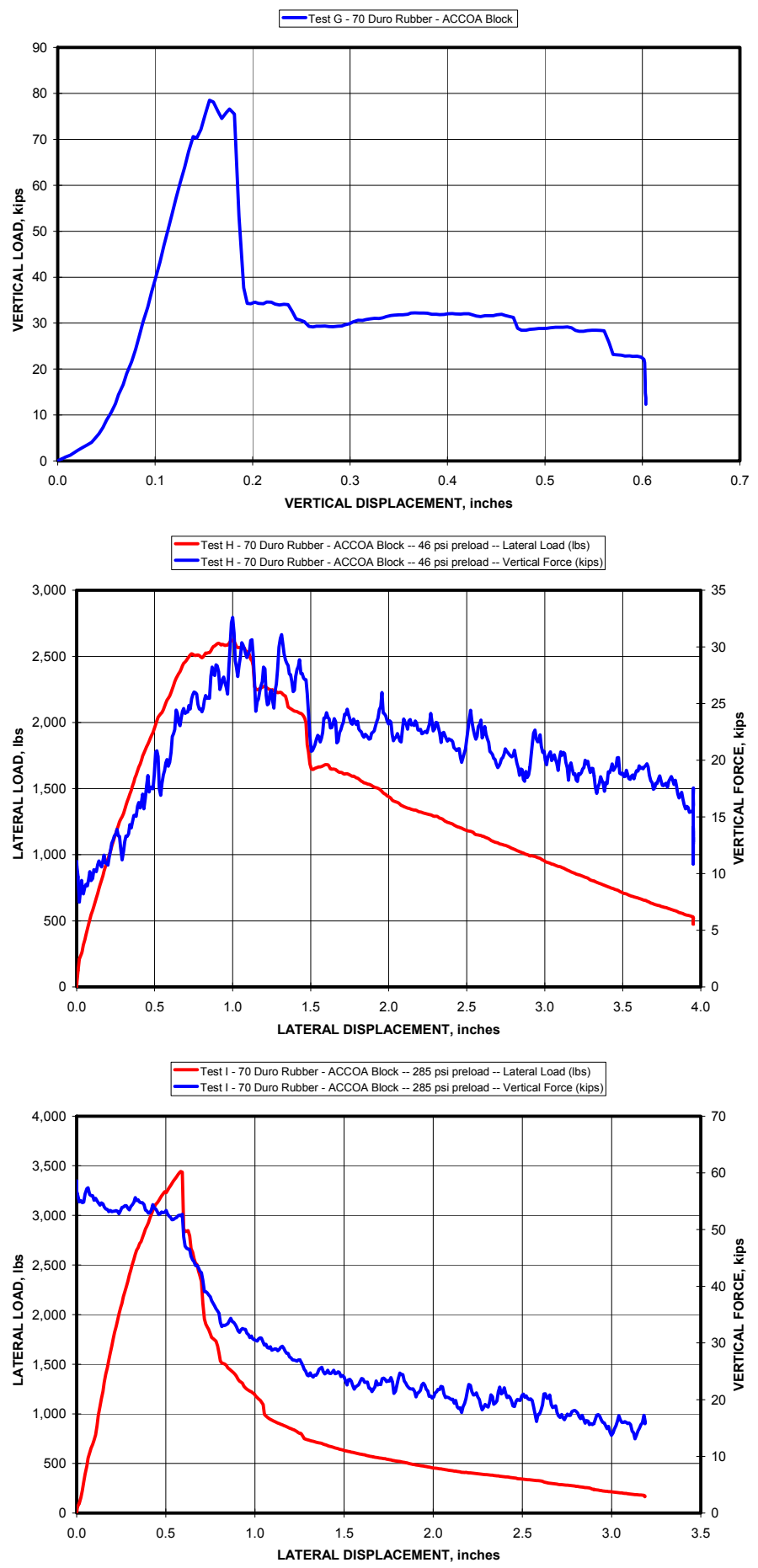

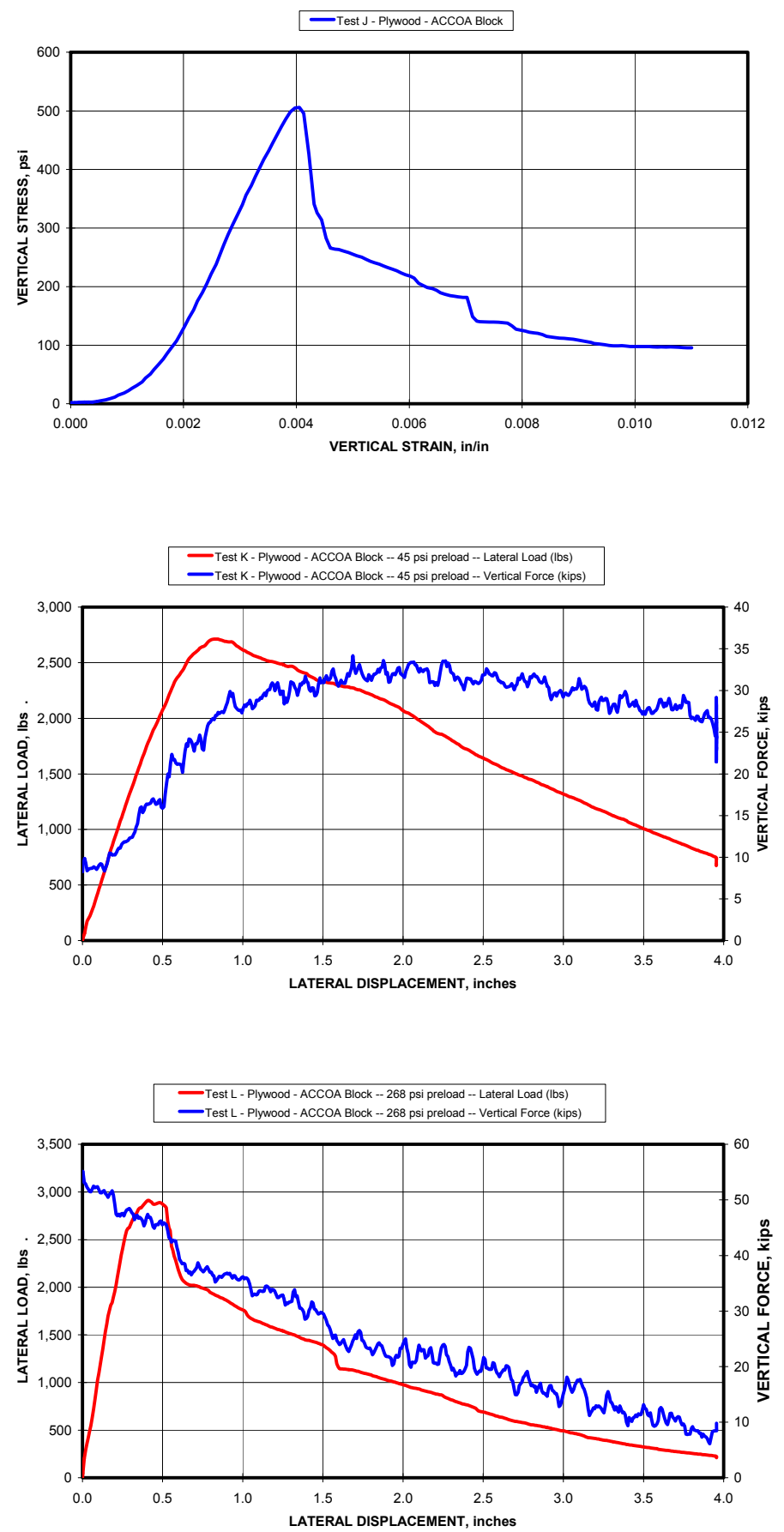

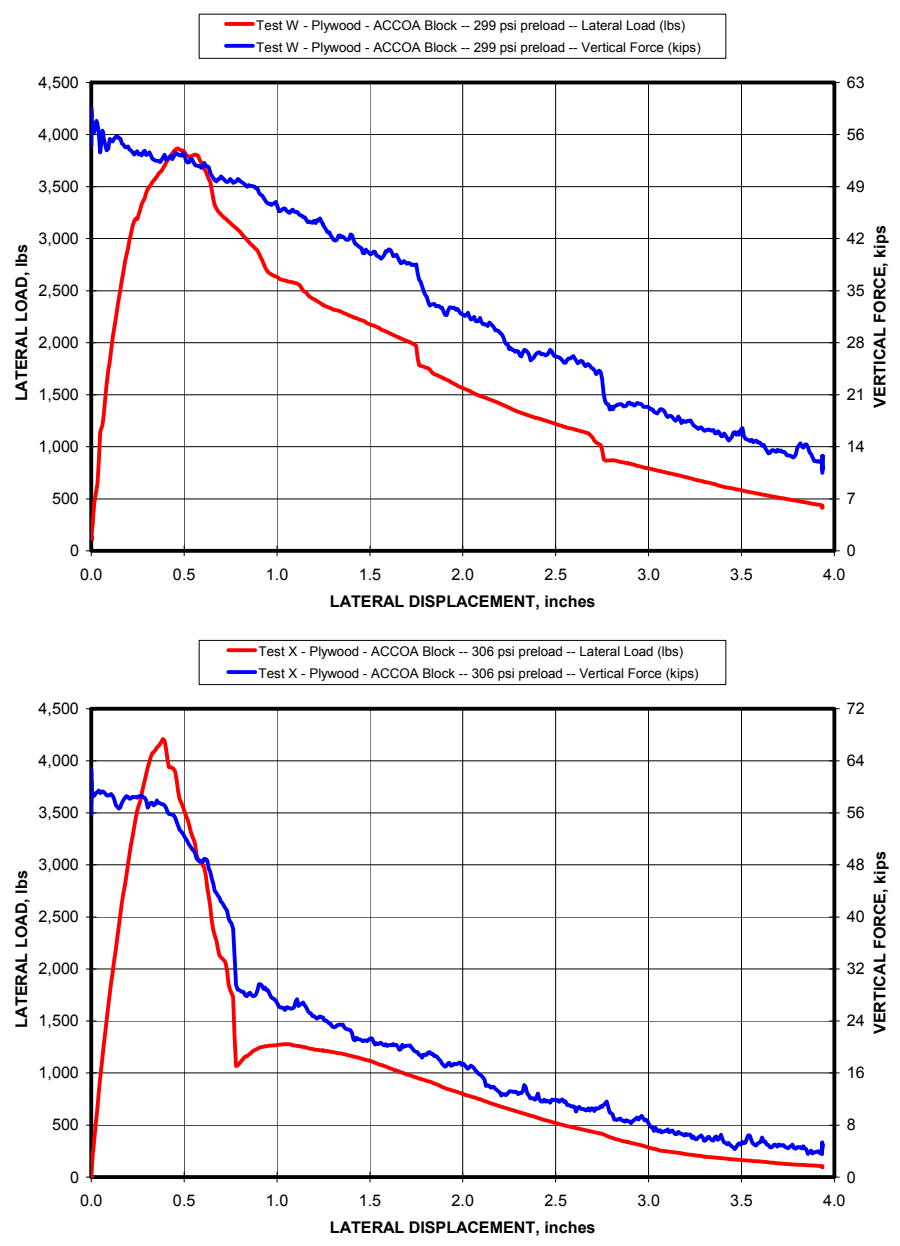

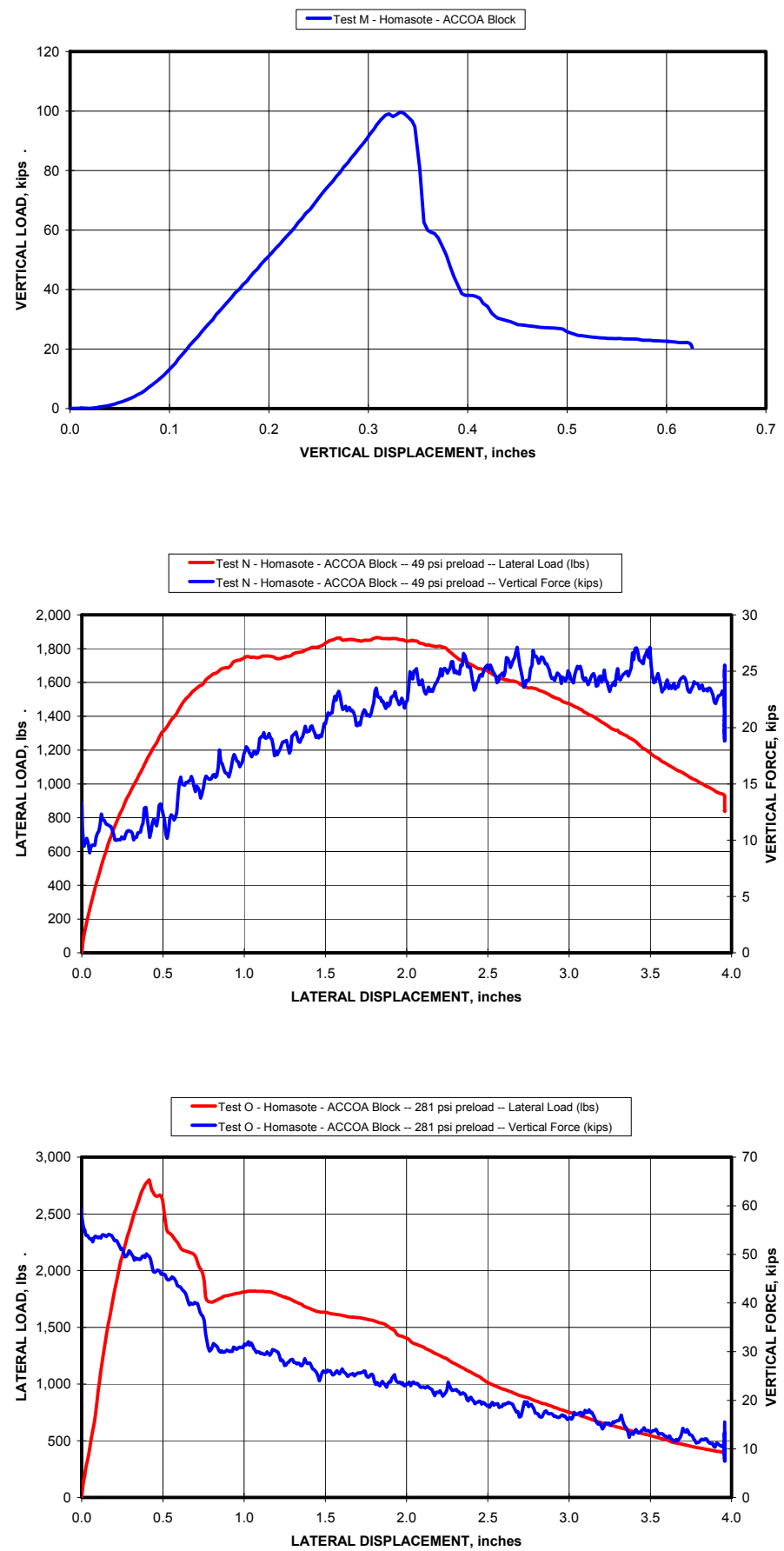

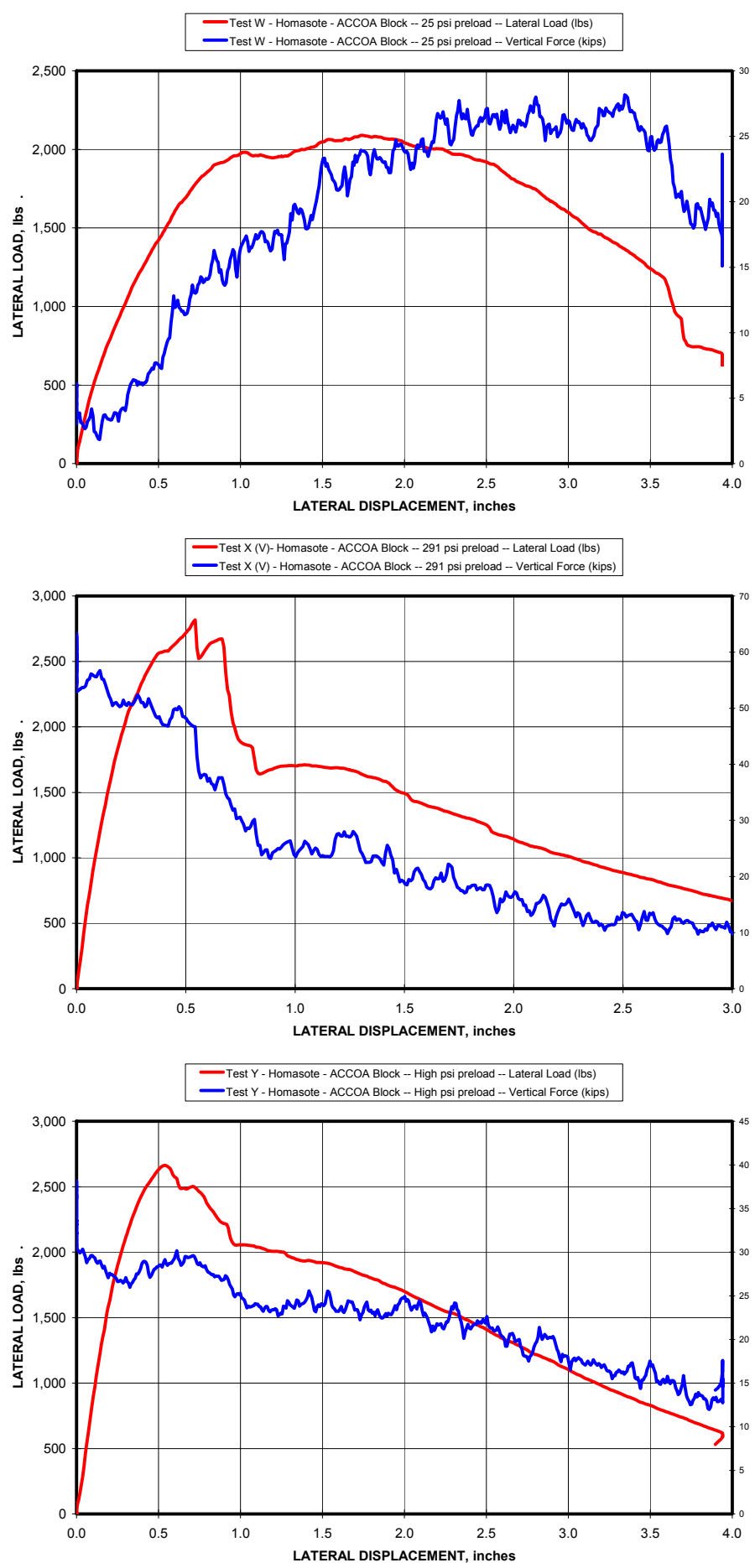

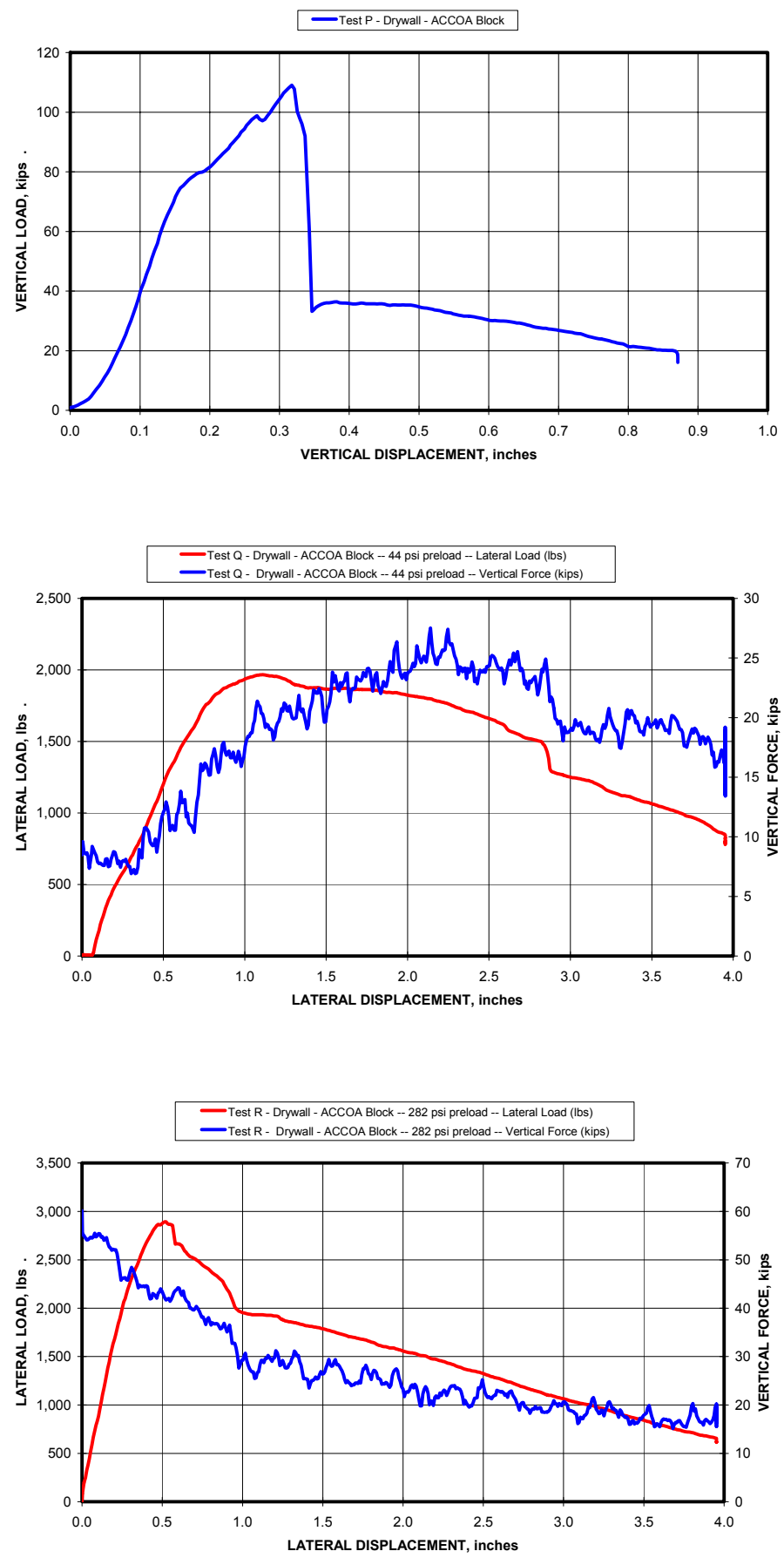

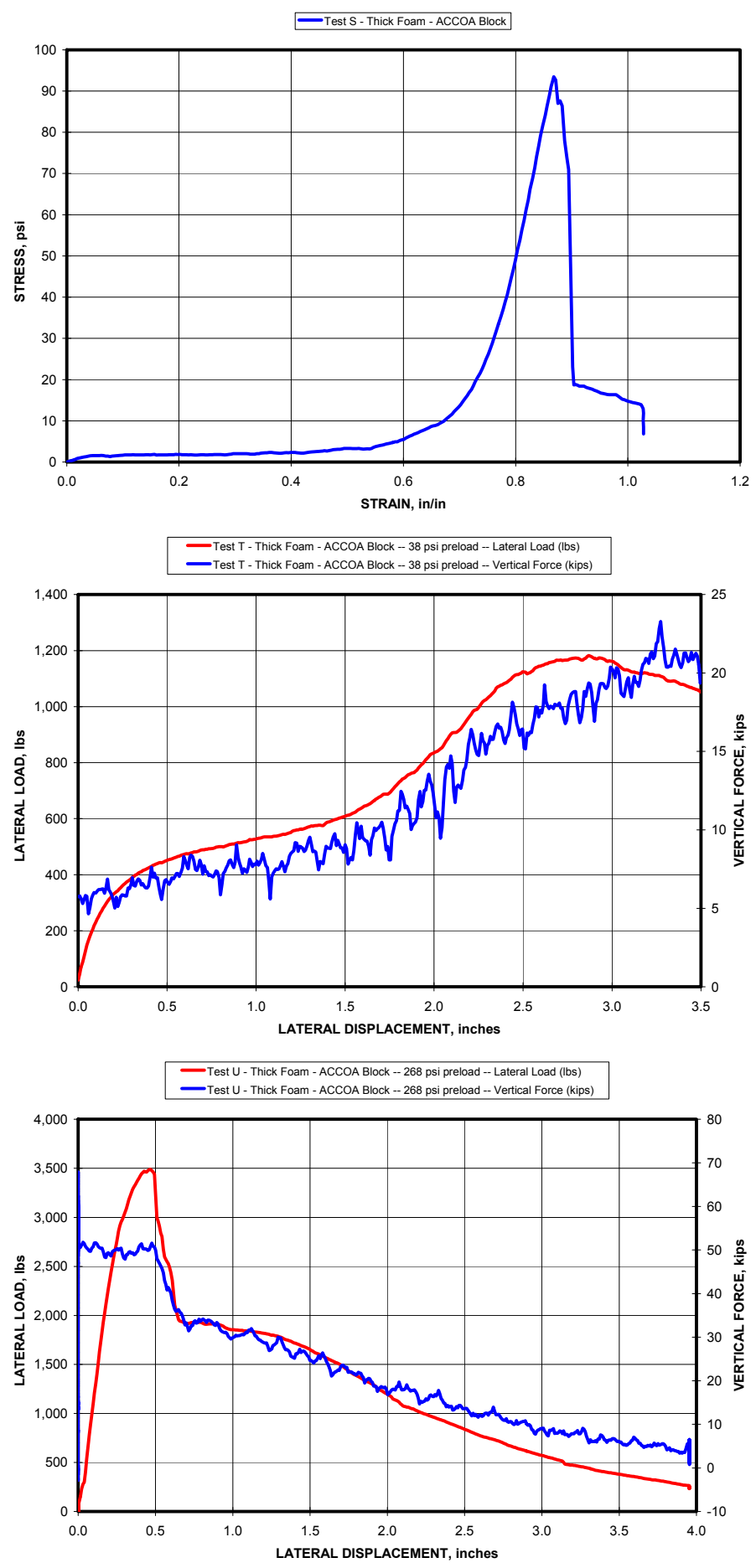

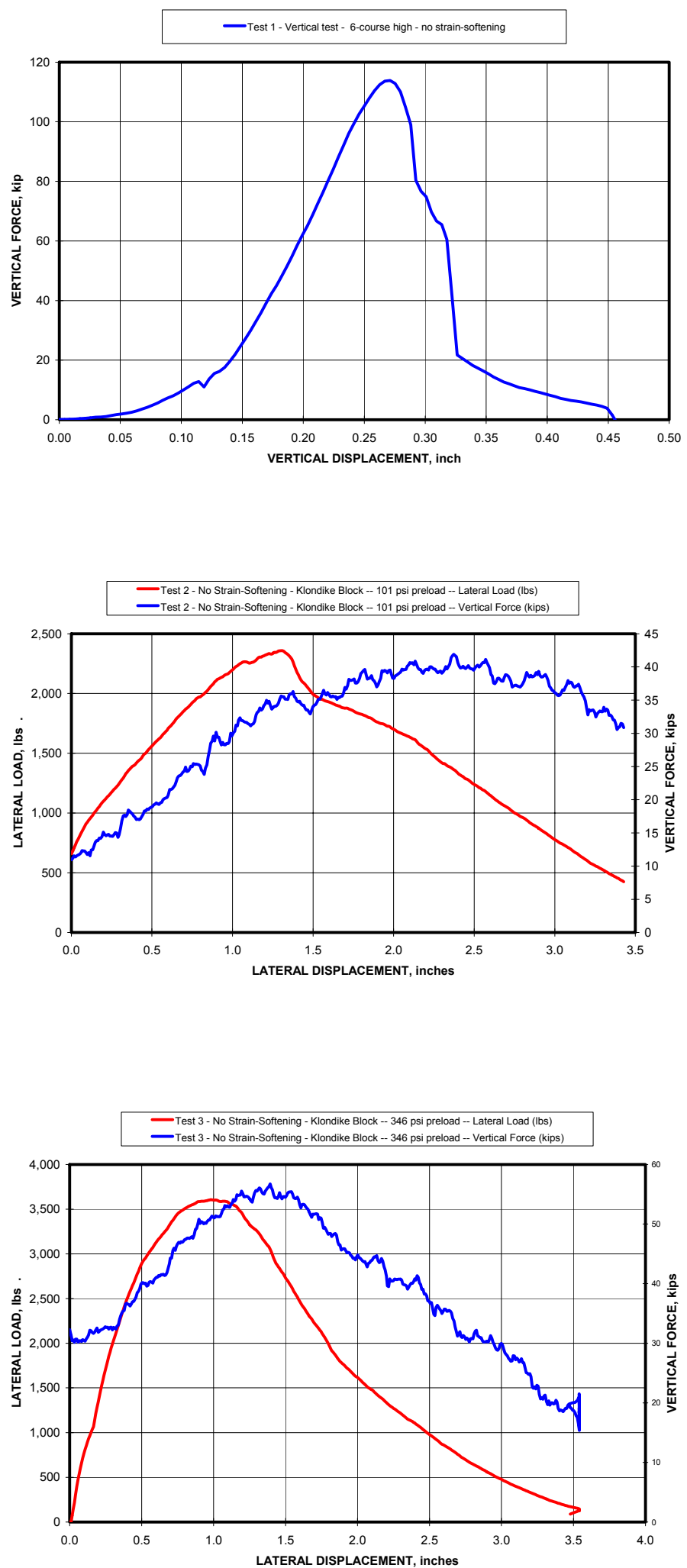

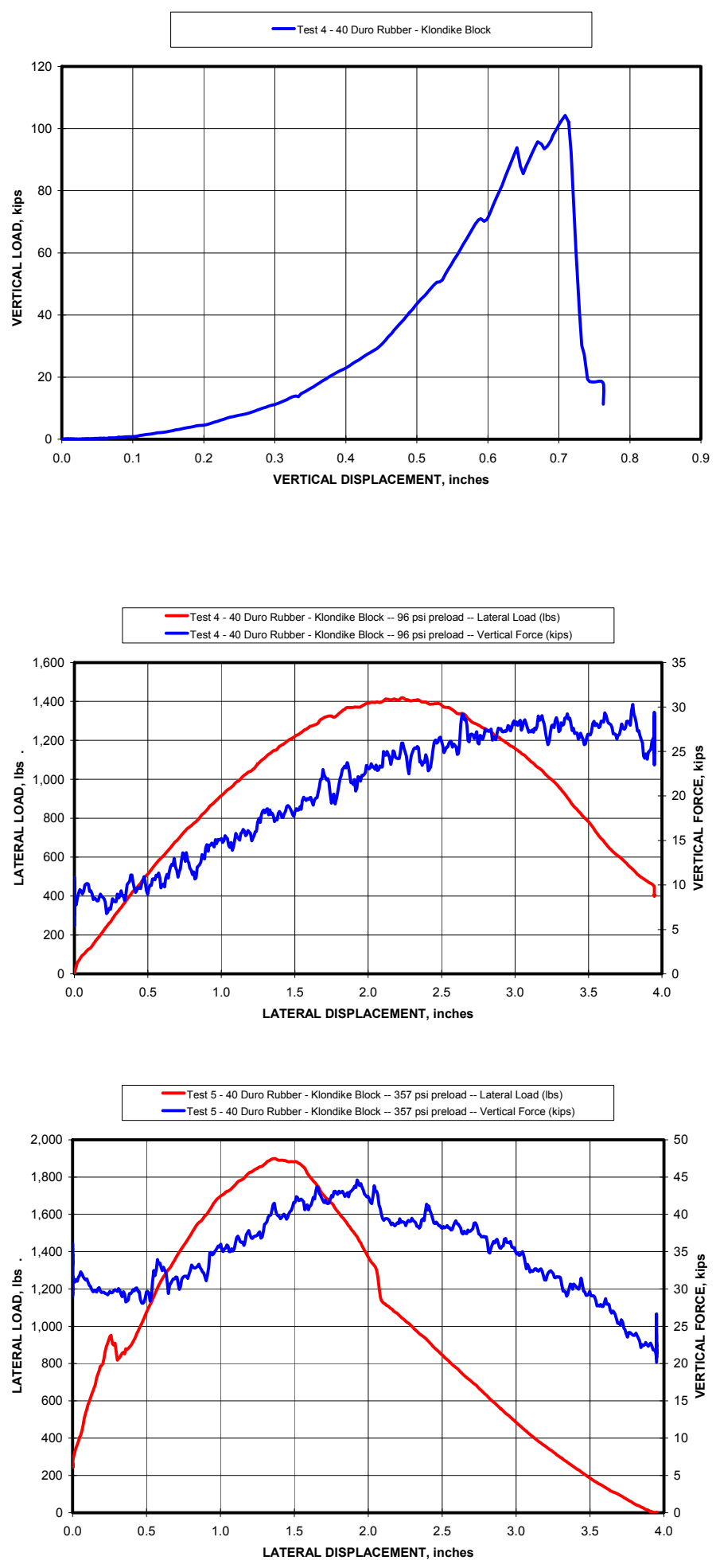

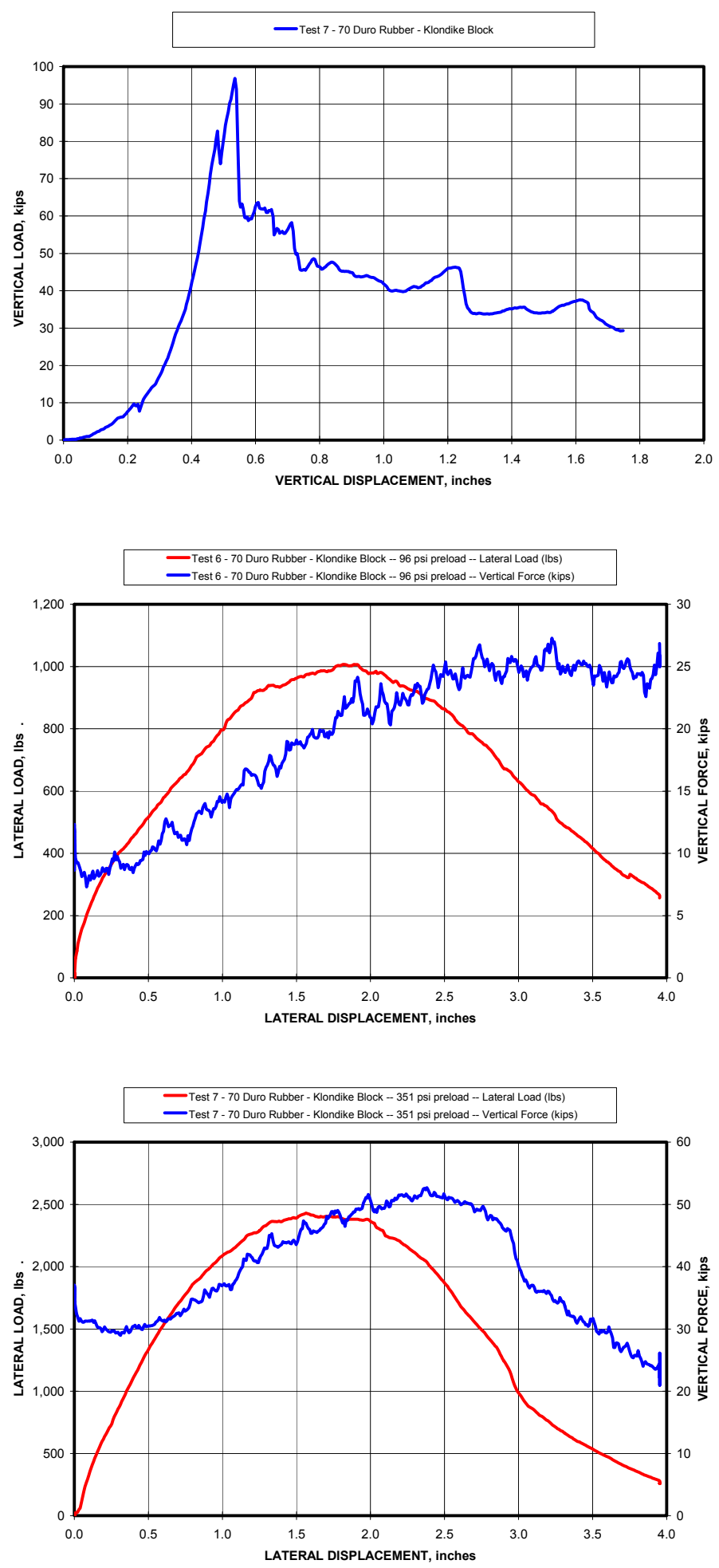

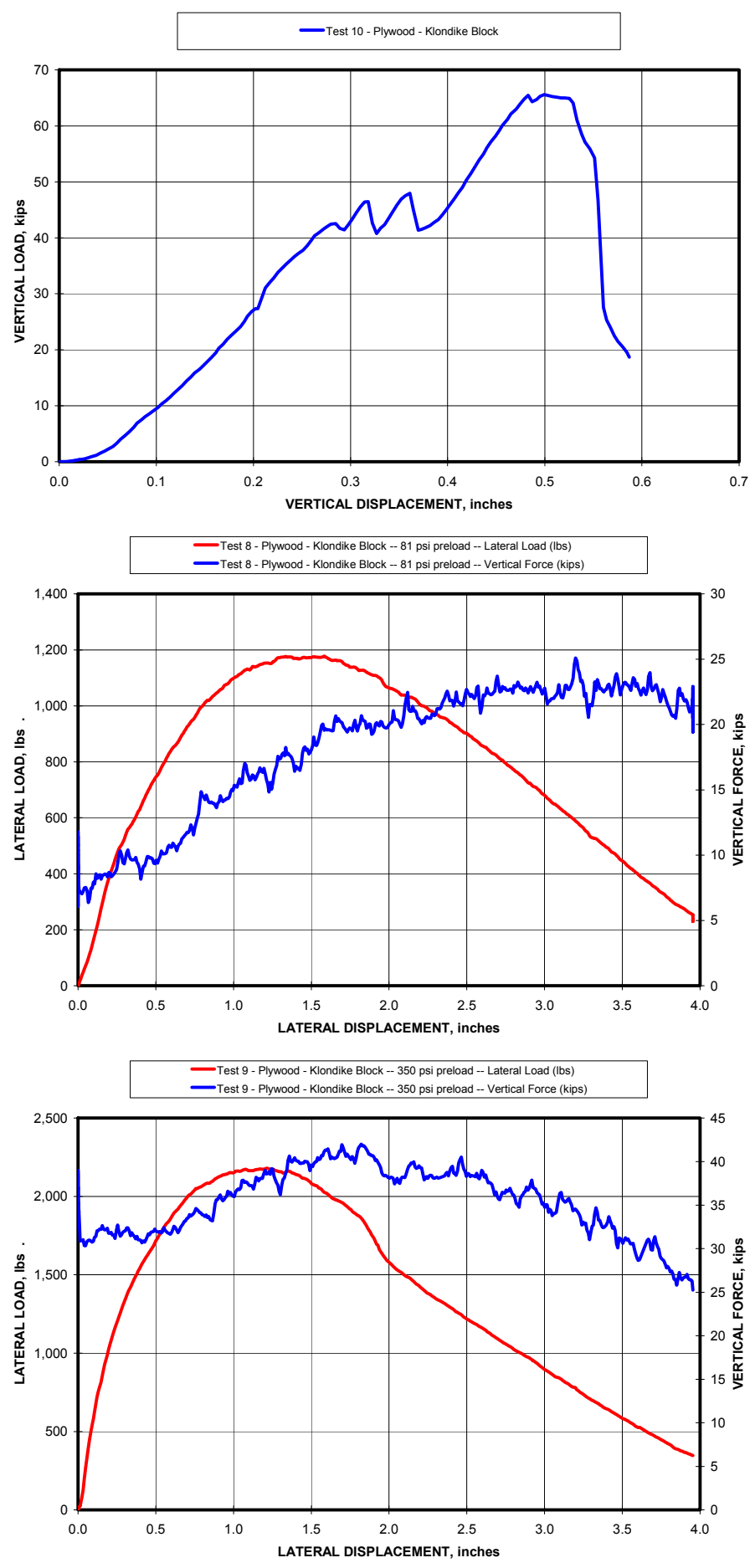

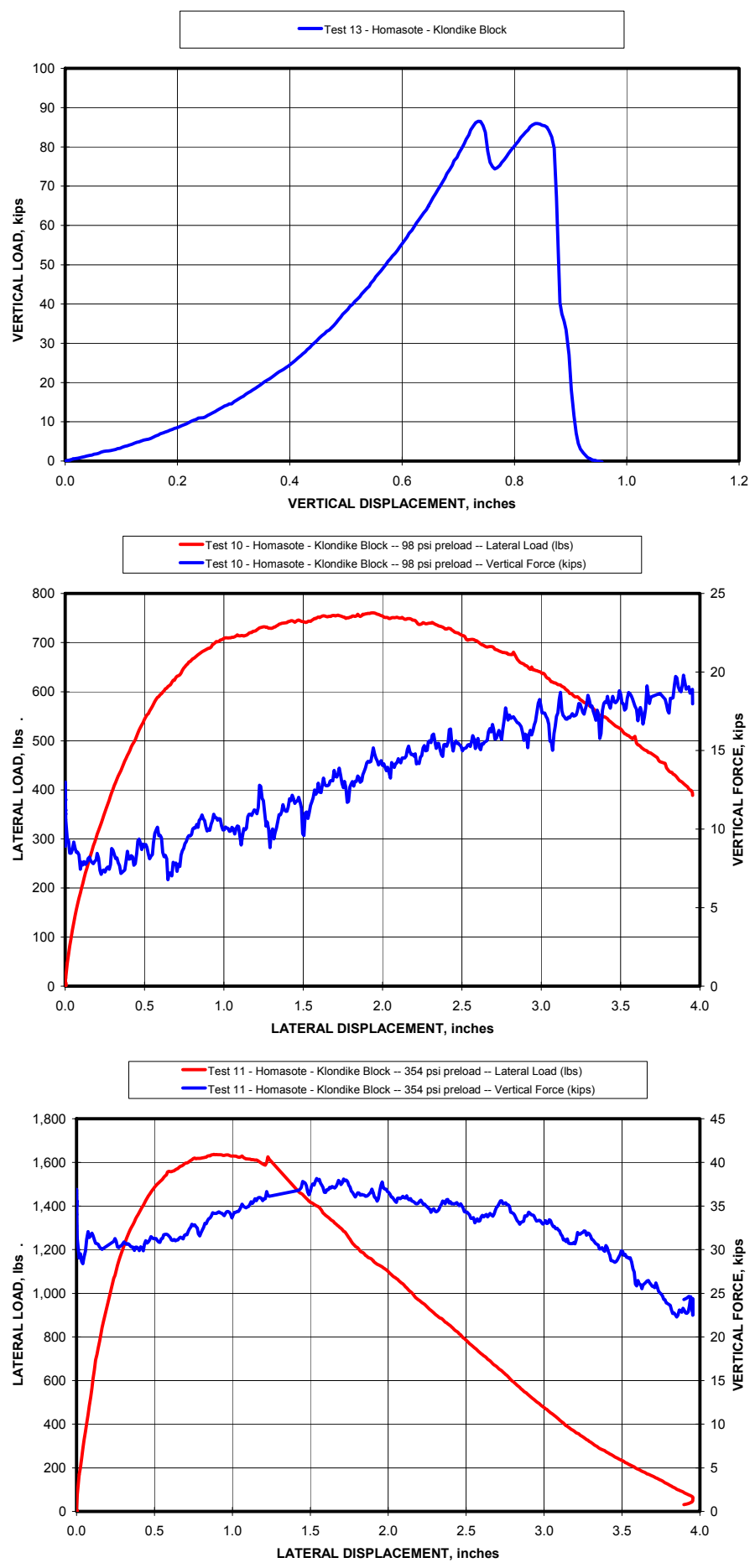

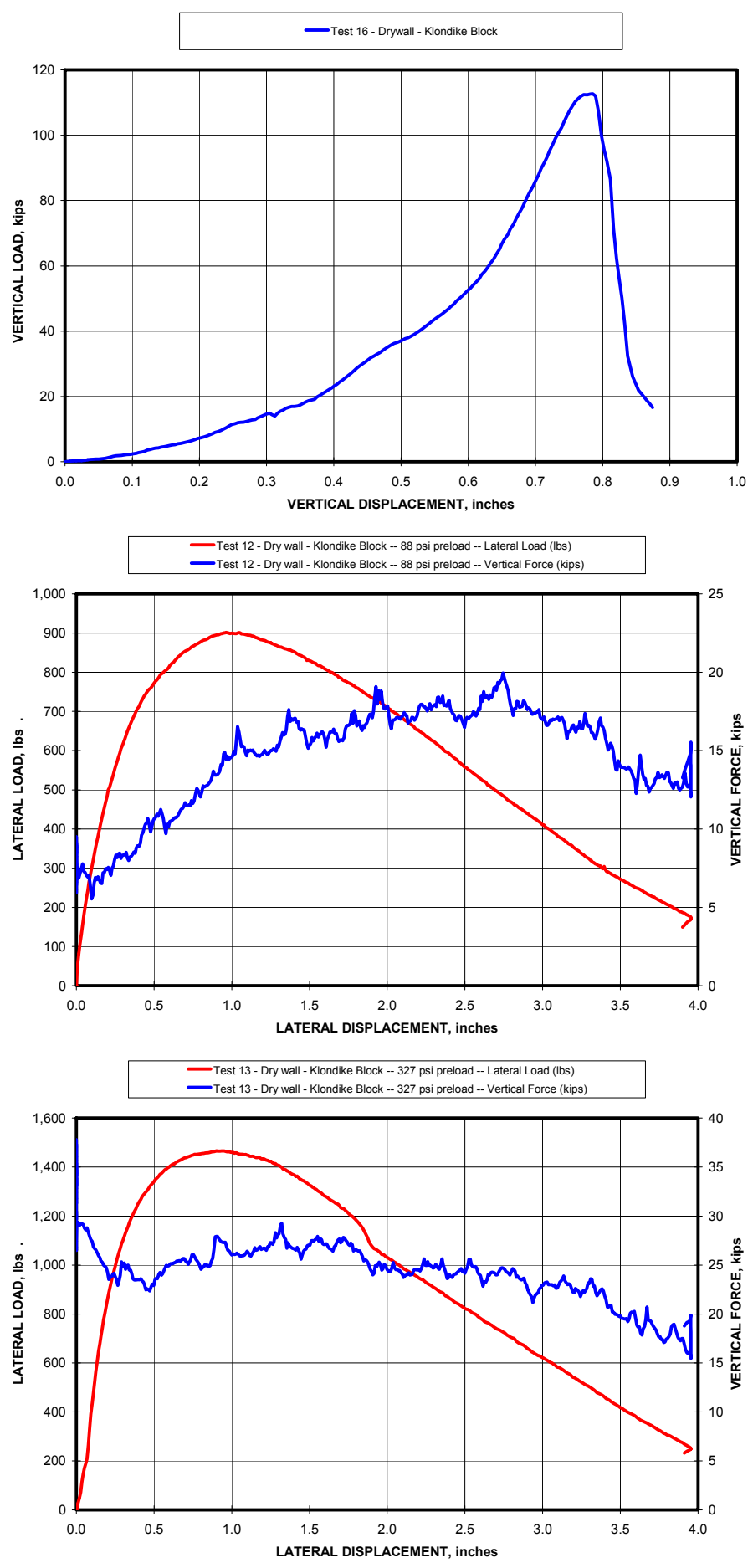

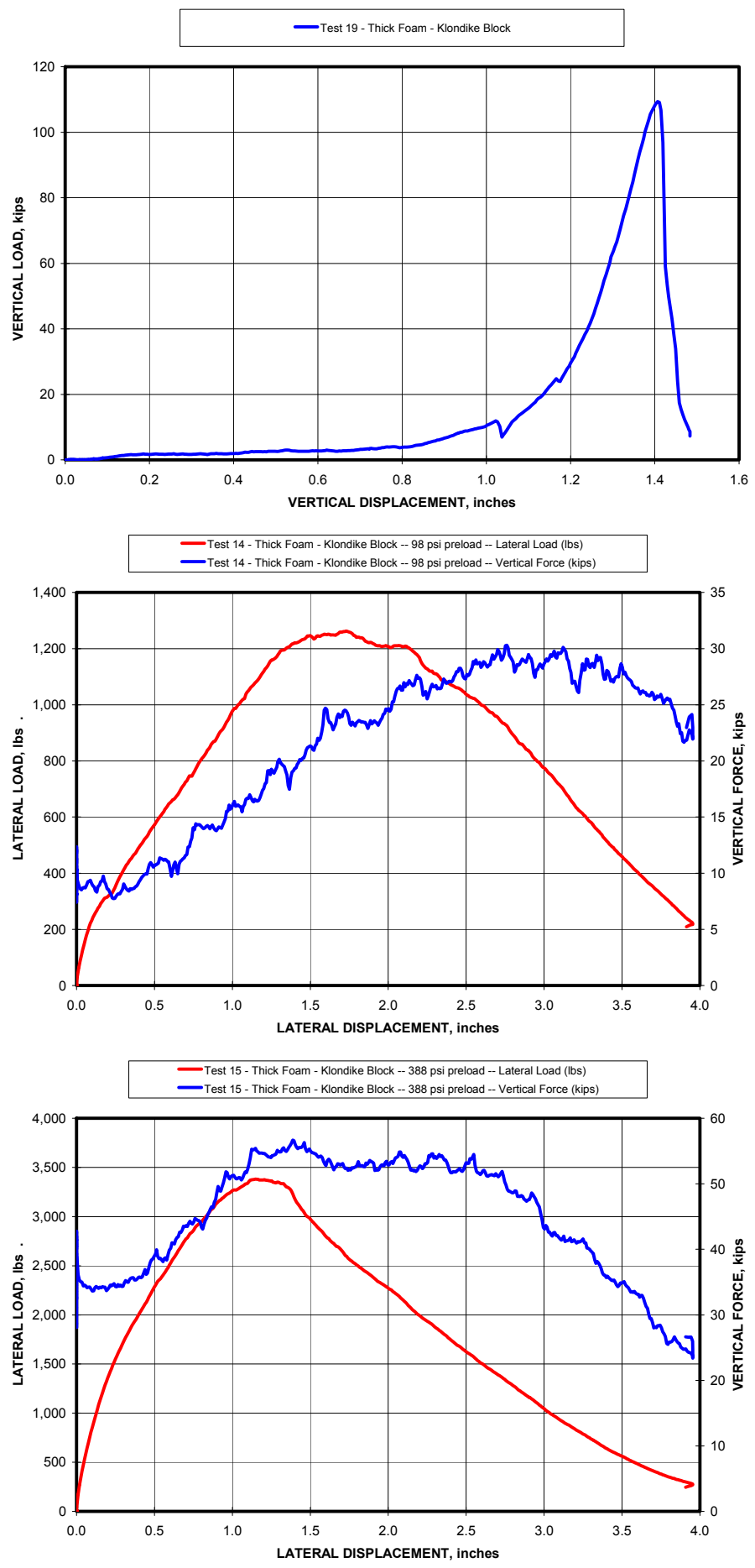

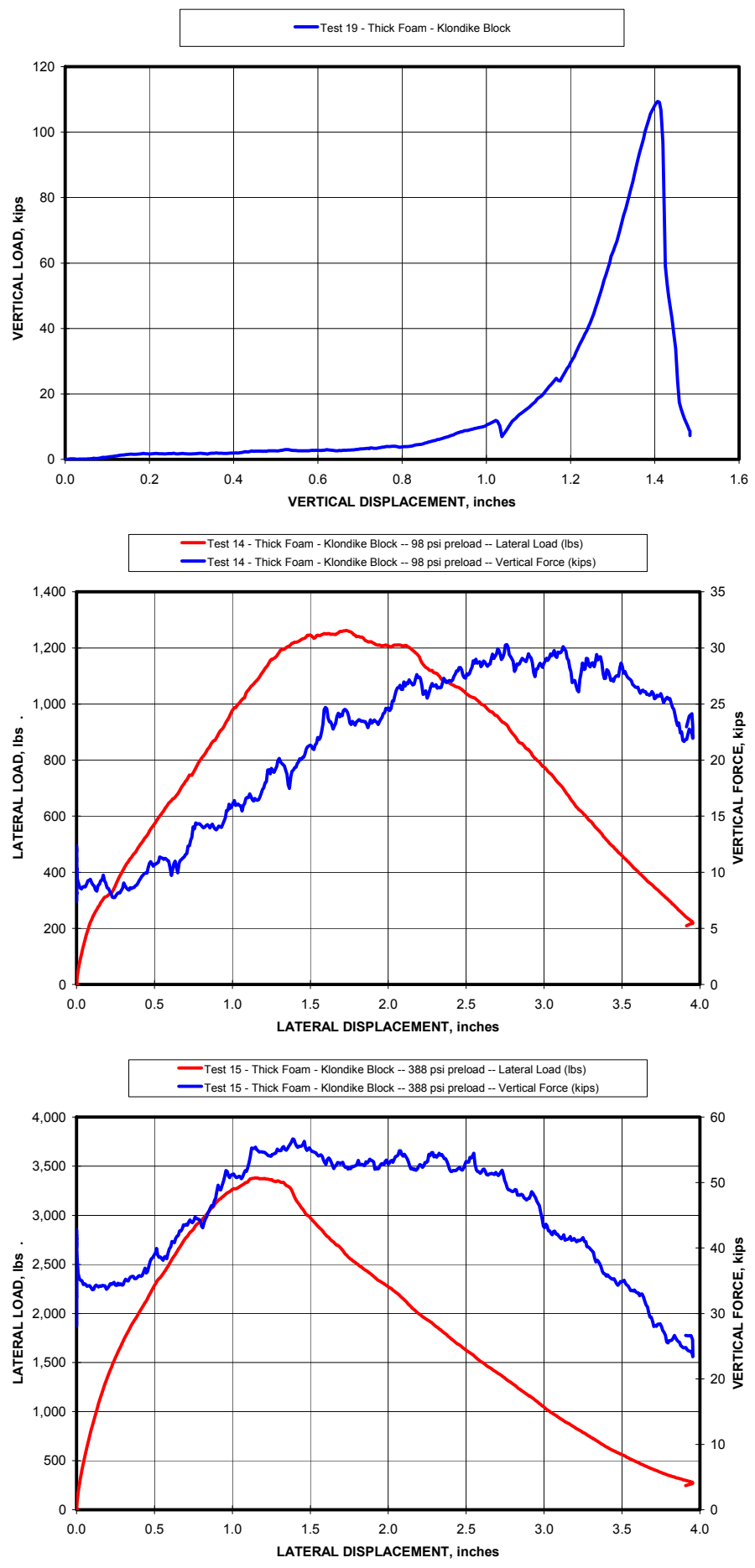
Samples of deformable materials were tested in the 1-million pound capacity MTS Rock Mechanics load frame (shown in Figure 50). The upper platen remains fixed in place as the lower platen moves vertically at an approximate rate of $0.004 \mathrm{in} / \mathrm{min}$. Each sample was 1 inch in diameter and each specimen's thickness is listed in Table 3.

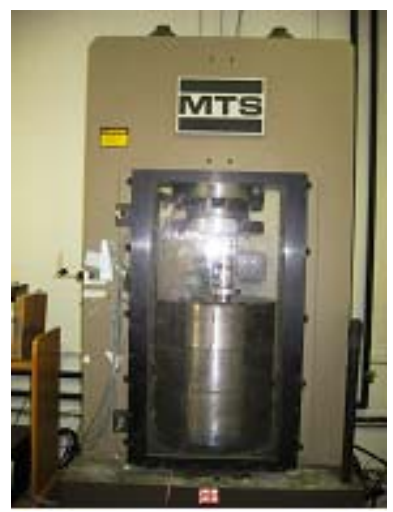

Figure 50. MTS Rock Mechanics load frame

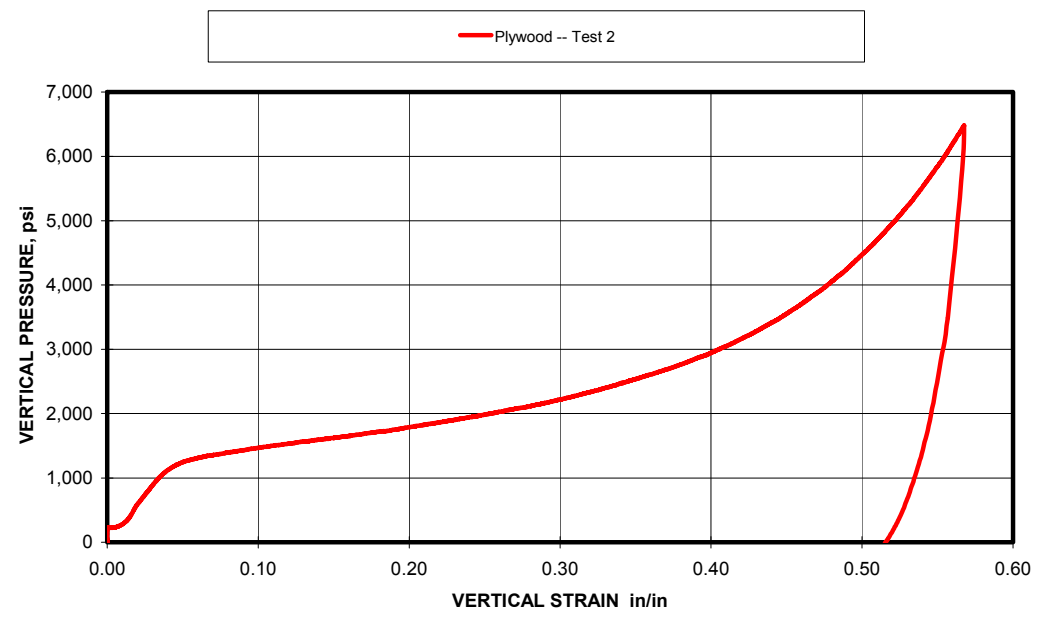



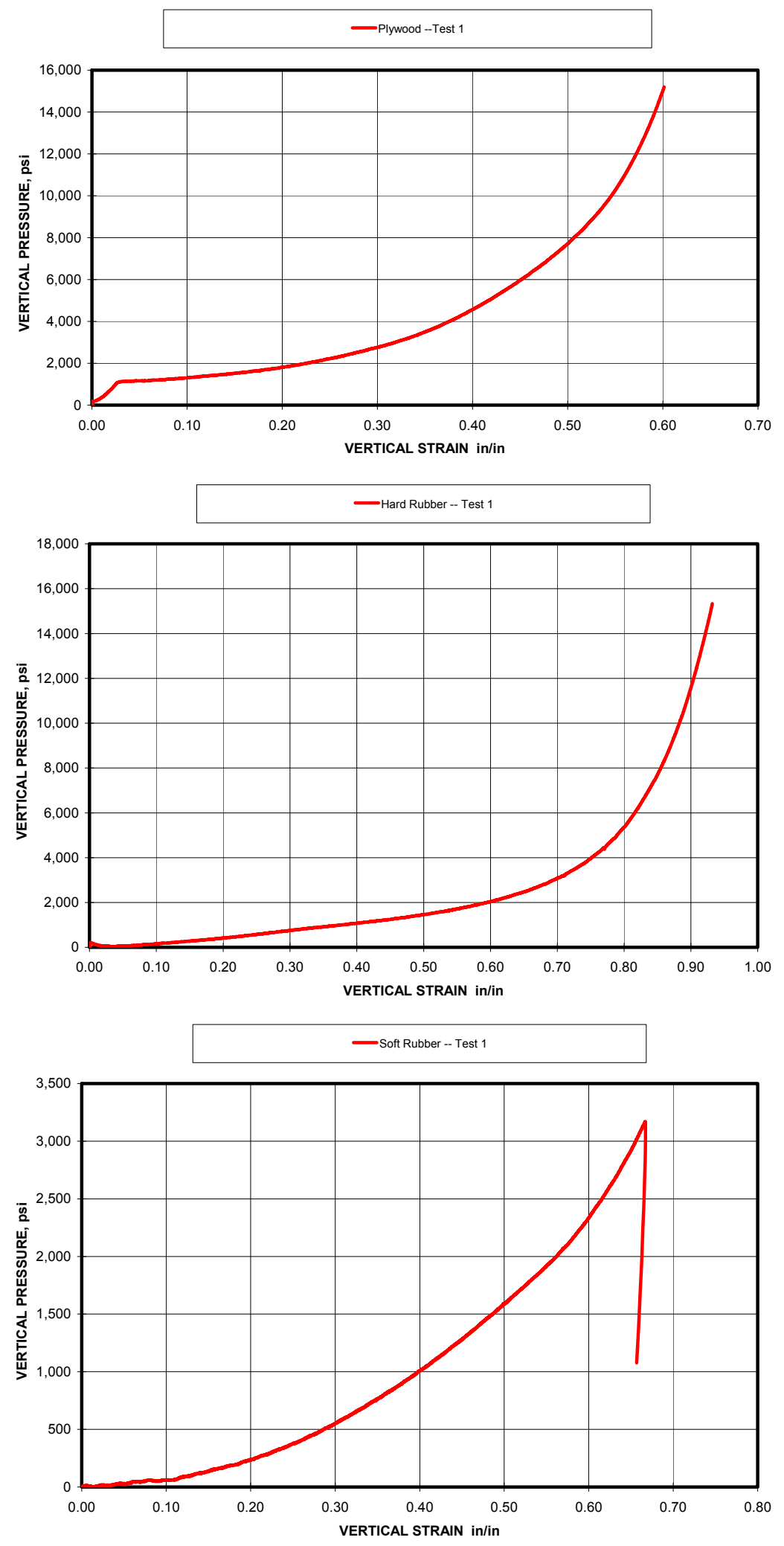

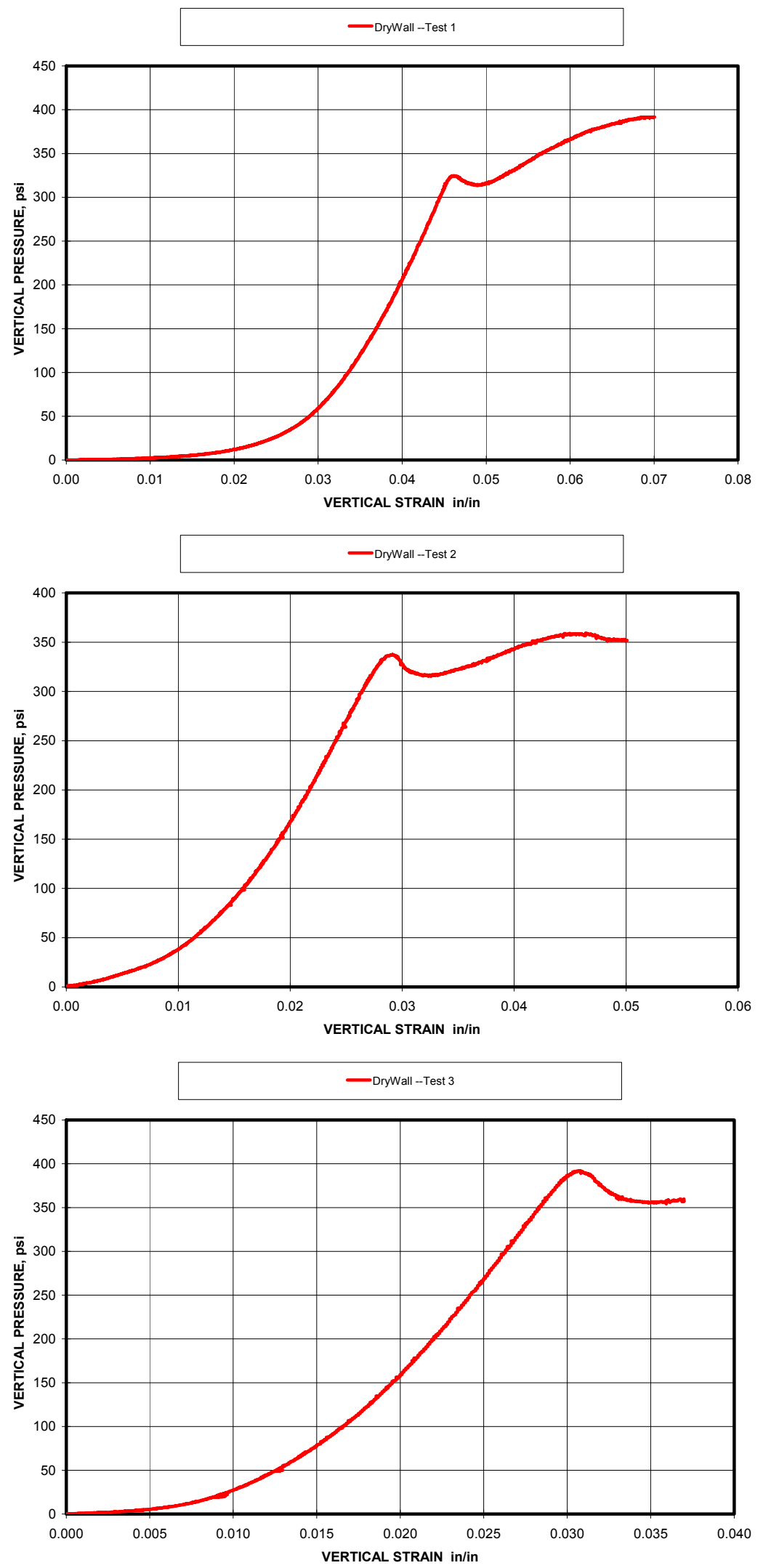

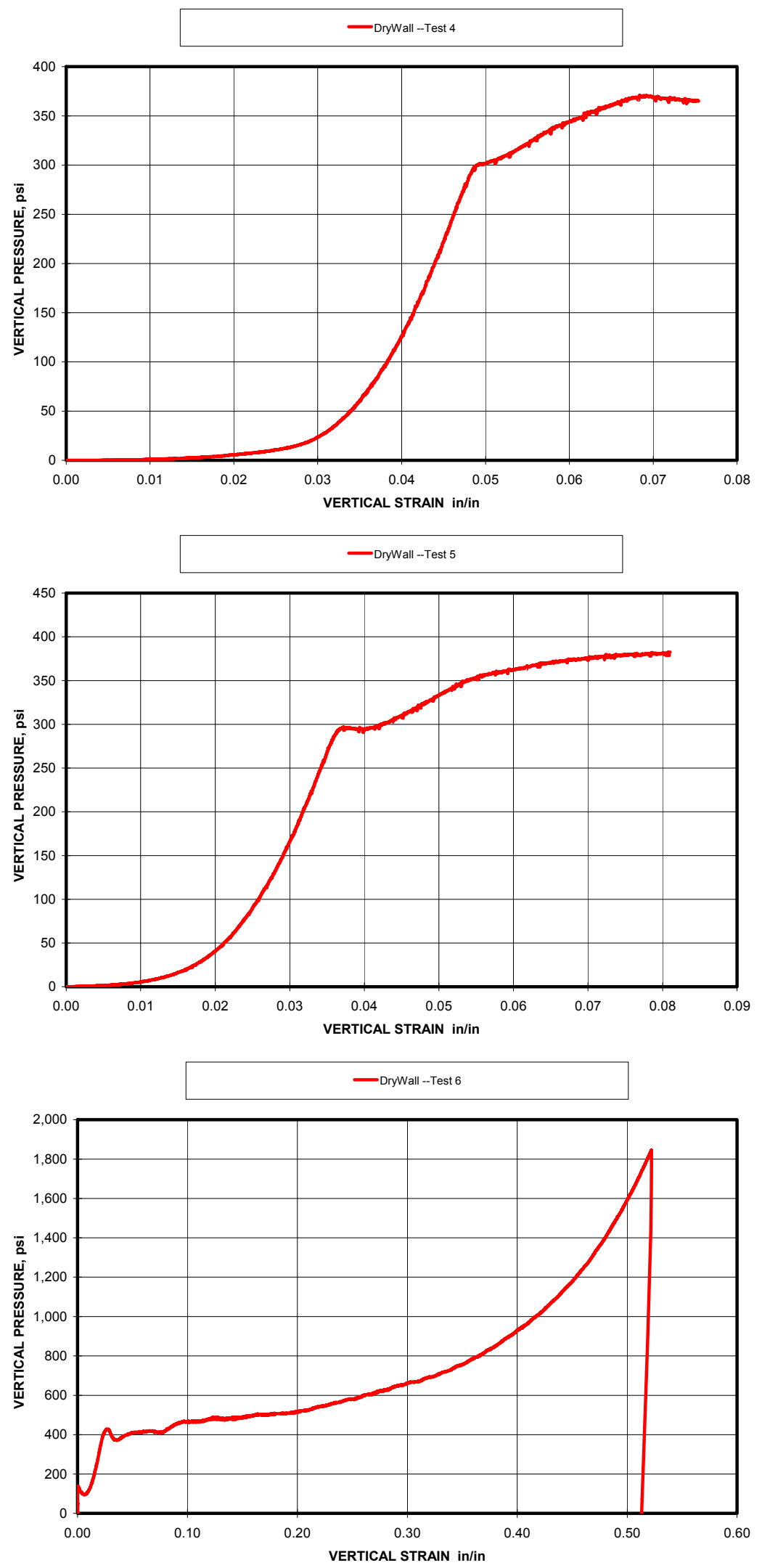

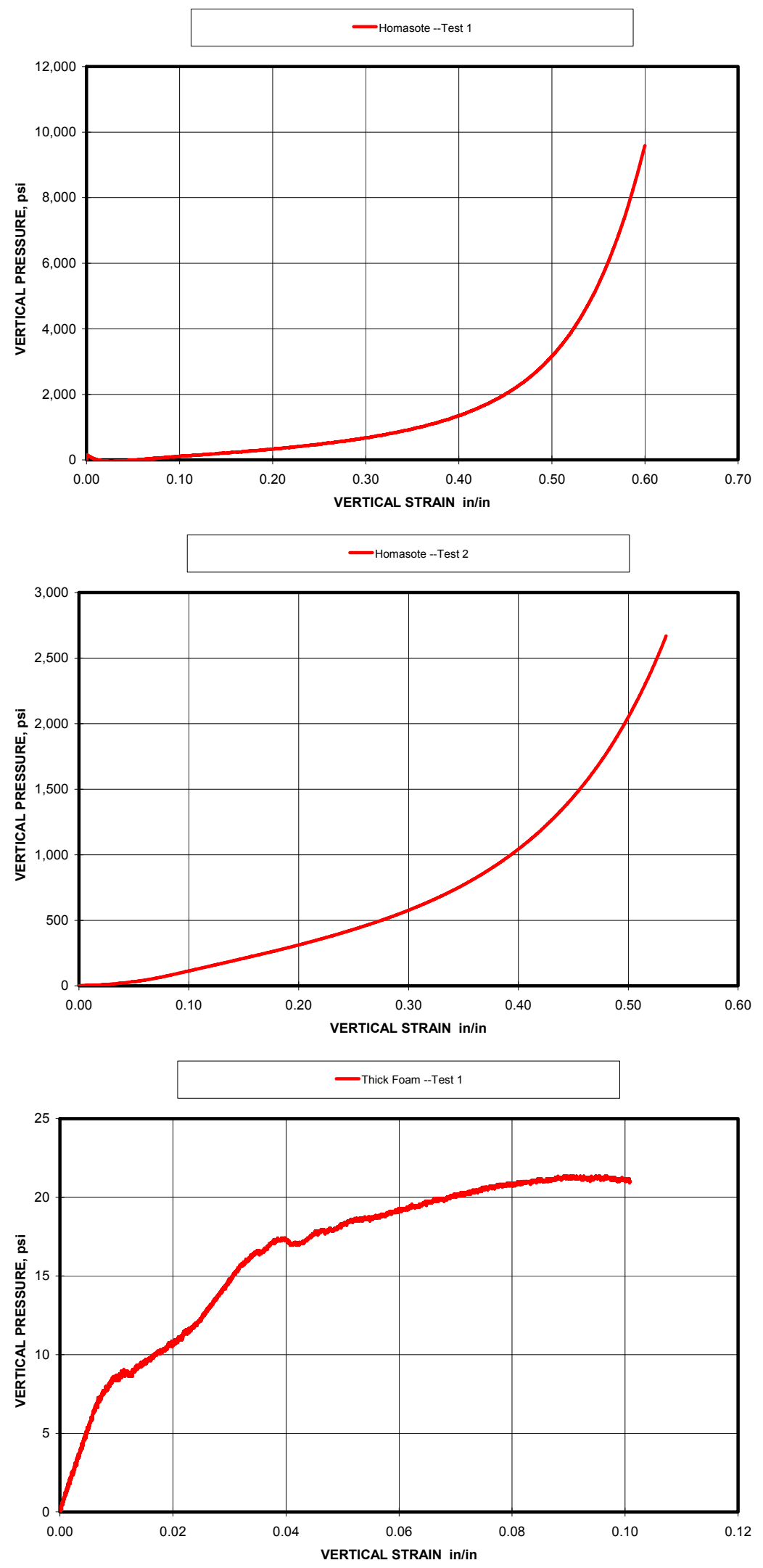

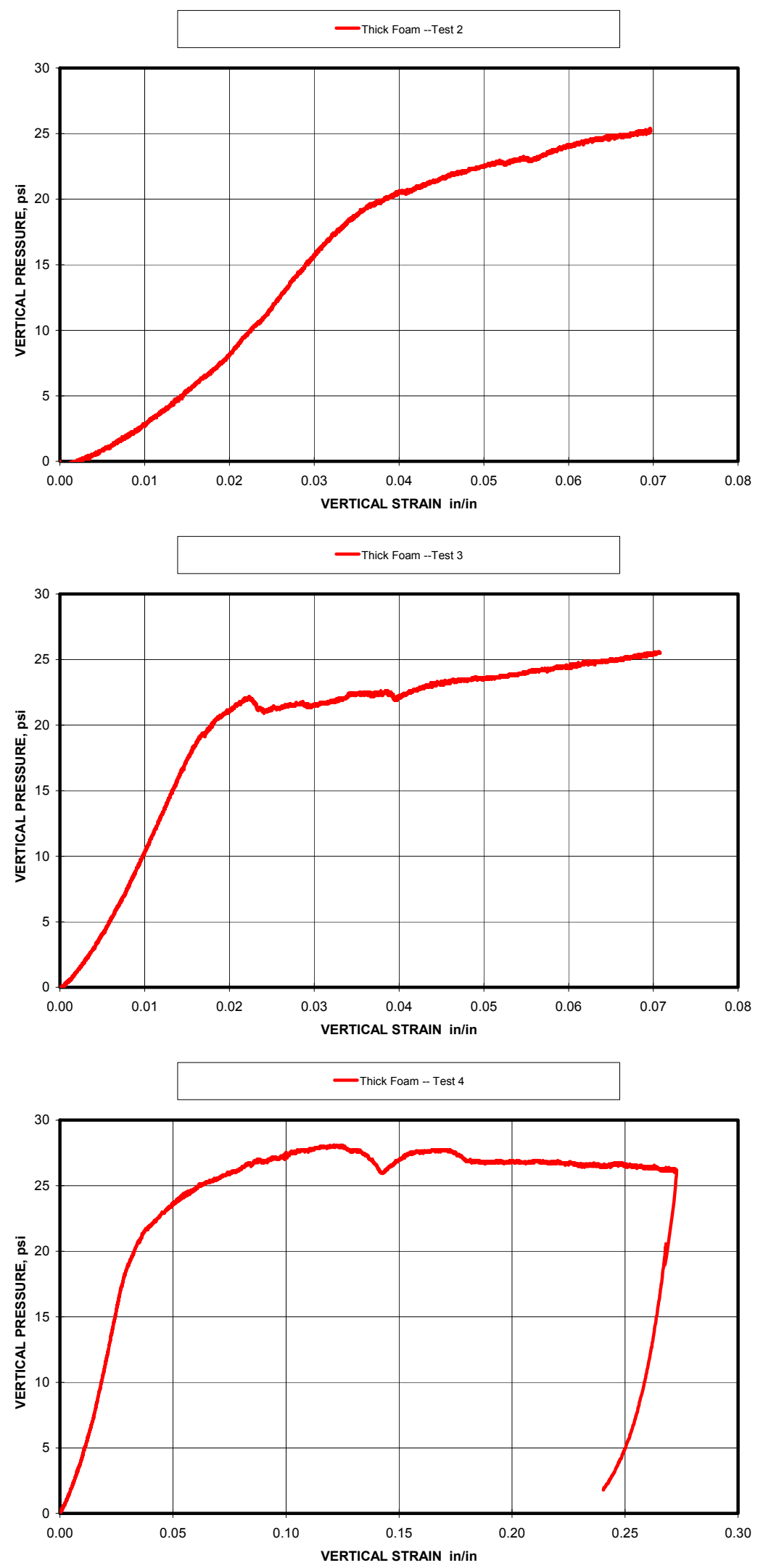

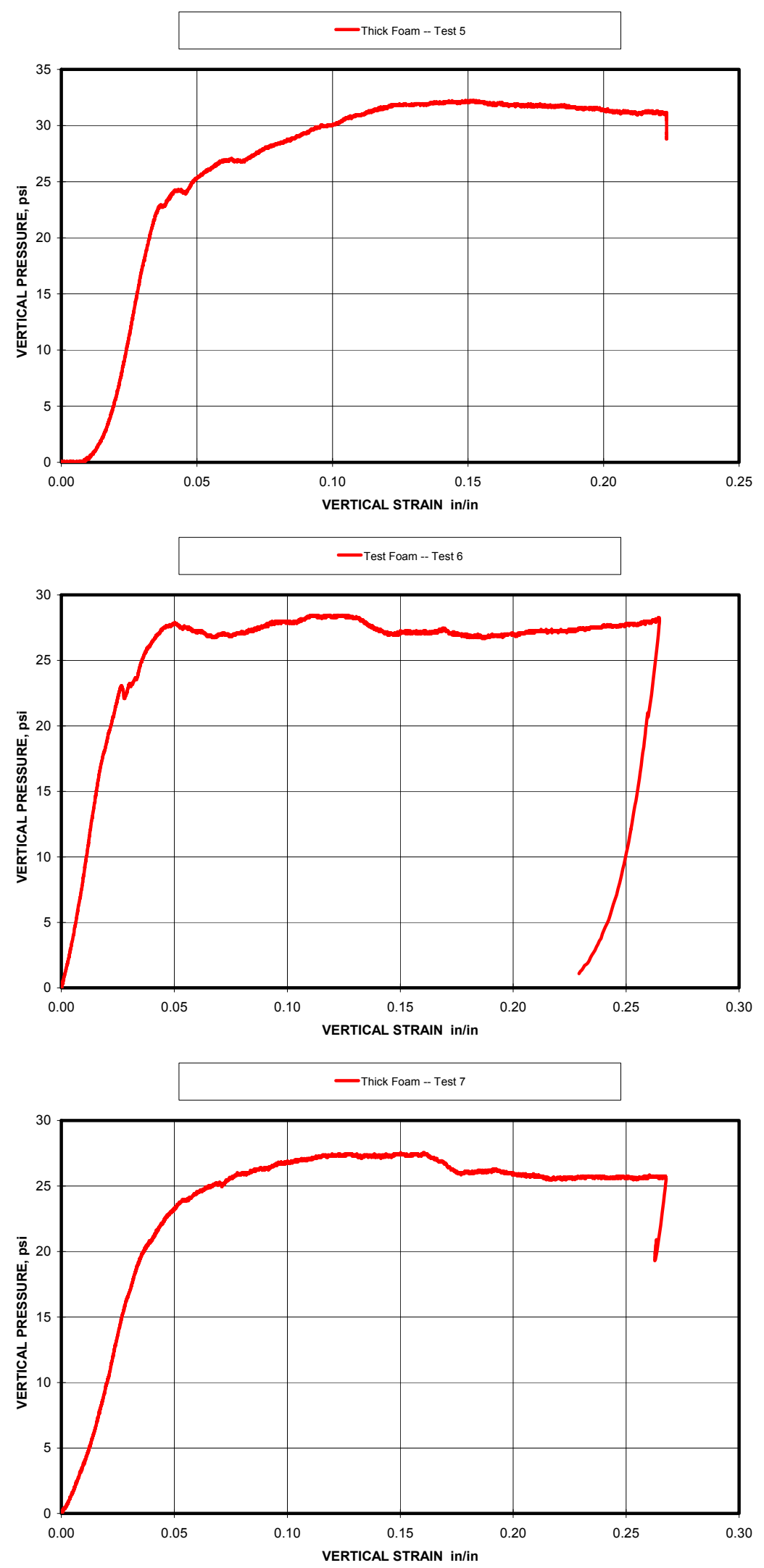


\section{INDEX}

arch, 7, 9, 10, 12, 27, 32, 62, 64

arching, 5, 6, 7, 10, 11, 12, 13, 18, 21,

$27,28,29,76$

arching thrust, 11, 13, 20, 21

block categories, 44

boundary conditions, $23,29,31,34,76$

compressive strength, 11, 12, 14, 17, 44 convergence, $19,22,30,31,35,36,55$,

76,77

deformable materials, 22, 24, 28, 30, 34,

$35,45,54,76$

effective system modulus, 31, 41, 45, 76

height, 7, 8, 16, 51
Hybrid Theoretical Lateral Displacement Model, 9, 46, 50, 77

lateral displacement, 7, 9, 13, 17, 18, 19, 21,32

Mine Roof Simulator, 26, 27

modulus of elasticity, 23

stopping, 1, 7, 25, 32, 45, 76

thickness, 7, 15

three-hinged arch, 10

transverse load, 1, 7, 9, 12, 15, 16, 18,

$19,22,25,29,32,76$

ventilation, $1,57,58,76$

V-STOP, 38, 40, 41, 42, 43, 46, 49, 51, $53,59,62,64$ 